\title{
Endometrial injury in women undergoing assisted reproductive techniques (Review)
}

Nastri CO, Lensen SF, Gibreel A, Raine-Fenning N, Ferriani RA, Bhattacharya S, Martins WP

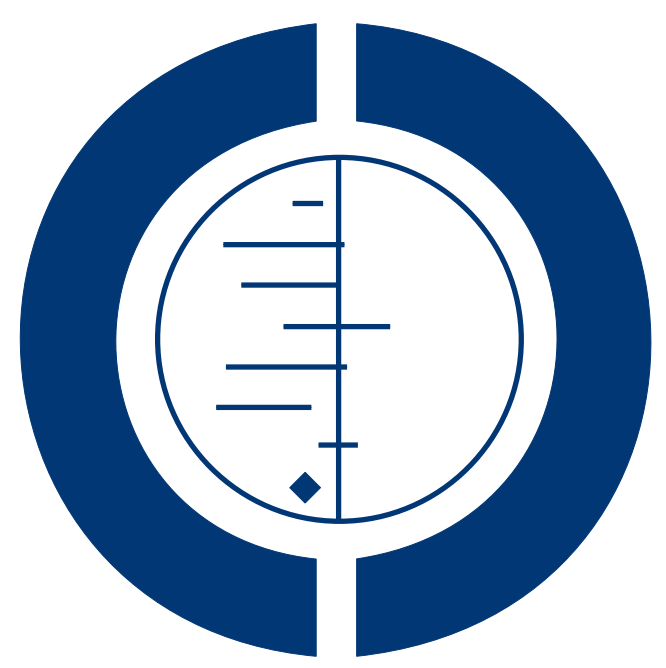

\section{THE COCHRANE COLLABORATION $^{\circledR}$}

This is a reprint of a Cochrane review, prepared and maintained by The Cochrane Collaboration and published in The Cochrane Library 2015, Issue 3

http://www.thecochranelibrary.com

\section{WILEY}

Endometrial injury in women undergoing assisted reproductive techniques (Review)

Copyright @ 2015 The Cochrane Collaboration. Published by John Wiley \& Sons, Ltd. 
TABLE OF CONTENTS

HEADER . . . . . . . . . . . . . . . . . . . . . . . . . . . . . . . . . . . . . . . . . . . . .

ABSTRACT . . . . . . . . . . . . . . . . . . . . . . . . . . . . . . . . . . . . . . . . . . . . . .

PLAIN LANGUAGE SUMMARY . . . . . . . . . . . . . . . . . . . . . . . . . . . . . . . . . . . . . . . . . . . .

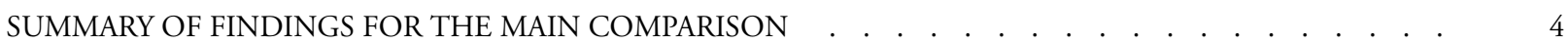

BACKGROUND . . . . . . . . . . . . . . . . . . . . . . . . . . . . . . . . . . . . . . . . . . . .

OBJECTIVES . . . . . . . . . . . . . . . . . . . . . . . . . . . . . . . . . . . . . . . . . . . . .

METHODS . . . . . . . . . . . . . . . . . . . . . . . . . . . . . . . . . . . . . . .

RESULTS . . . . . . . . . . . . . . . . . . . . . . . . . . . . . . . . . . . . . . . . . . . . .

Figure 1. . . . . . . . . . . . . . . . . . . . . . . . . . . . . . . . . . . . . . . .

Figure 2. . . . . . . . . . . . . . . . . . . . . . . . . . . . . . . . . . . . . .

Figure 3. . . . . . . . . . . . . . . . . . . . . . . . . . . . . . . . . . . . . .

Figure $4 . \quad$. . . . . . . . . . . . . . . . . . . . . . . . . . . . . . . . . . . . . . . . . . 14

Figure 5. . . . . . . . . . . . . . . . . . . . . . . . . . . . . . . . . . . . 15

Figure 6. . . . . . . . . . . . . . . . . . . . . . . . . . . . . . . . . . . . . . 16

Figure $7 . \quad$. . . . . . . . . . . . . . . . . . . . . . . . . . . . . . . . . . . . .

Figure 8.

ADDITIONAL SUMMARY OF FINDINGS . . . . . . . . . . . . . . . . . . . . . . . . . . . . . . . . . .

DISCUSSION . . . . . . . . . . . . . . . . . . . . . . . . . . . . . . . . . . . . . . 21

AUTHORS' CONCLUSIONS . . . . . . . . . . . . . . . . . . . . . . . . . . . . . . . . . . . . . . . . .

ACKNOWLEDGEMENTS . . . . . . . . . . . . . . . . . . . . . . . . . . . . . . . . . . . 23

REFERENCES . . . . . . . . . . . . . . . . . . . . . . . . . . . . . . . . . . . . . . . . . . . .

CHARACTERISTICS OF STUDIES . . . . . . . . . . . . . . . . . . . . . . . . . . . . . . . . . . . . . . 26

DATA AND ANALYSES . . . . . . . . . . . . . . . . . . . . . . . . . . . . . . . . . . . . . . . . . . . . . . . . . . .

Analysis 1.1. Comparison 1 Endometrial injury between day 7 of the previous cycle and day 7 of the ET cycle vs control,

Outcome 1 Live birth or ongoing pregnancy per randomly assigned woman (by manipulation/no manipulation in control group).

Analysis 1.2. Comparison 1 Endometrial injury between day 7 of the previous cycle and day 7 of the ET cycle vs control, Outcome 2 Live birth or ongoing pregnancy per randomly assigned woman (by embryo transfer history). . .

Analysis 1.3. Comparison 1 Endometrial injury between day 7 of the previous cycle and day 7 of the ET cycle vs control, Outcome 3 Miscarriage per clinical pregnancy.

Analysis 1.4. Comparison 1 Endometrial injury between day 7 of the previous cycle and day 7 of the ET cycle vs control, Outcome 4 Clinical pregnancy per randomly assigned woman (by manipulation/no manipulation in control group).

Analysis 1.5. Comparison 1 Endometrial injury between day 7 of the previous cycle and day 7 of the ET cycle vs control, Outcome 5 Clinical pregnancy per randomly assigned woman (by embryo transfer history).

Analysis 1.6. Comparison 1 Endometrial injury between day 7 of the previous cycle and day 7 of the ET cycle vs control, Outcome 6 Multiple pregnancy per clinical pregnancy. . . . . . . . . . . . . . . . . . . . . . . .

Analysis 1.7. Comparison 1 Endometrial injury between day 7 of the previous cycle and day 7 of the ET cycle vs control, Outcome 7 Pain (visual analogue scale).

Analysis 1.8. Comparison 1 Endometrial injury between day 7 of the previous cycle and day 7 of the ET cycle vs control, Outcome 8 Pain (complaint).

Analysis 1.9. Comparison 1 Endometrial injury between day 7 of the previous cycle and day 7 of the ET cycle vs control, Outcome 9 Bleeding.

Analysis 2.1. Comparison 2 Endometrial injury on the day of oocyte retrieval vs control, Outcome 1 Live birth or ongoing pregnancy per randomly assigned woman.

Analysis 2.3. Comparison 2 Endometrial injury on the day of oocyte retrieval vs control, Outcome 3 Clinical pregnancy per randomly assigned woman. 
DIFFERENCES BETWEEN PROTOCOL AND REVIEW . . . . . . . . . . . . . . . . . . . . . . . . . . . 77

INDEX TERMS . . . . . . . . . . . . . . . . . . . . . . . . . . . . . . . . . . . . . . . . . . . . 77 


\title{
[Intervention Review] \\ Endometrial injury in women undergoing assisted reproductive techniques
}

\author{
Carolina O Nastri ${ }^{1}$, Sarah F Lensen ${ }^{2}$, Ahmed Gibreel ${ }^{3}$, Nick Raine-Fenning ${ }^{4}$, Rui A Ferriani ${ }^{1}$, Siladitya Bhattacharya ${ }^{5}$, Wellington P \\ Martins $^{1}$ \\ ${ }^{1}$ Department of Obstetrics and Gynecology, Medical School of Ribeirao Preto, University of Sao Paulo, Ribeirao Preto, Brazil. \\ ${ }^{2}$ Department of Obstetrics and Gynaecology, University of Auckland, Auckland, New Zealand. ${ }^{3}$ Obstetrics \& Gynaecology, Faculty \\ of Medicine, Mansoura University, Mansoura, Egypt. ${ }^{4}$ Division of Child Health, Obstetrics and Gynaecology, School of Medicine, \\ University of Nottingham, Nottingham, UK. ${ }^{5}$ Obstetrics and Gynaecology, Aberdeen Maternity Hospital, Aberdeen, UK \\ Contact address: Wellington P Martins, Department of Obstetrics and Gynecology, Medical School of Ribeirao Preto, University of \\ Sao Paulo, Hospital das Clinicas da FMRP-USP, 8 andar, Campus Universitario da USP, Ribeirao Preto, Sao Paulo, 14048-900, Brazil. \\ wpmartins@gmail.com.
}

Editorial group: Cochrane Menstrual Disorders and Subfertility Group.

Publication status and date: New search for studies and content updated (conclusions changed), published in Issue 3, 2015.

Review content assessed as up-to-date: 19 January 2015.

Citation: Nastri CO, Lensen SF, Gibreel A, Raine-Fenning N, Ferriani RA, Bhattacharya S, Martins WP. Endometrial injury in women undergoing assisted reproductive techniques. Cochrane Database of Systematic Reviews 2015, Issue 3. Art. No.: CD009517. DOI: $10.1002 / 14651858 . C D 009517 . p u b 3$.

Copyright (C) 2015 The Cochrane Collaboration. Published by John Wiley \& Sons, Ltd.

\begin{abstract}
A B S T R A C T
Background

Implantation of an embryo within the endometrial cavity is a critical step in assisted reproductive techniques (ART). Previous research has suggested that endometrial injury - intentional damage to the endometrium - can increase the probability of pregnancy in women undergoing ART.
\end{abstract}

Objectives

To assess the effectiveness and safety of endometrial injury performed before embryo transfer in women undergoing ART.

Search methods

We searched the Cochrane Menstrual Disorders and Subfertility Group (MDSG) Specialised Register, the Cochrane Central Register of Controlled Trials (CENTRAL), the Database of Abstracts of Reviews of Effects (DARE), MEDLINE, EMBASE, the Cumulative Index to Nursing and Allied Health Literature (CINAHL), Latin American Caribbean Health Sciences Literature (LILACS) and ClinicalTrials.gov. The original search was performed in November 2011, and further searches were done in March 2014 and January 2015.

\section{Selection criteria}

Randomised controlled trials comparing intentional endometrial injury before embryo transfer in women undergoing ART, versus no intervention or a sham procedure.

\section{Data collection and analysis}

Two independent review authors screened studies and extracted data which were checked by a third review author. Two review authors independently assessed risk of bias. We contacted and corresponded with study investigators as required and analysed data using risk ratio (RR) and a random-effects model. We assessed the quality of the evidence by using GRADE (Grades of Recommendation, Assessment, Development and Evaluation) criteria.

Endometrial injury in women undergoing assisted reproductive techniques (Review)

Copyright $\Subset 2015$ The Cochrane Collaboration. Published by John Wiley \& Sons, Ltd. 


\section{Main results}

We included 14 trials that included 1063 women in the intervention groups and 1065 women in the control groups. Thirteen studies compared endometrial injury performed between day 7 of the previous cycle and day 7 of the embryo transfer (ET) cycle versus no injury, and one study compared endometrial injury on the day of oocyte retrieval versus no injury. Overall, eight of the 14 included studies were deemed to be at high risk of bias in at least one domain.

In studies comparing endometrial injury performed between day 7 of the previous cycle and day 7 of the ET cycle versus no intervention or a sham procedure, endometrial injury was associated with an increase in live birth or ongoing pregnancy rate: RR $1.42,95 \%$ confidence interval (CI) 1.08 to 1.85 ; P value 0.01 ; nine RCTs; 1496 women; $\mathrm{I}^{2}=53 \%$; moderate-quality evidence. In other words, moderate-quality evidence suggests that if $26 \%$ of women achieve live birth without endometrial injury, between $28 \%$ and $48 \%$ will achieve live birth with endometrial injury. A sensitivity analysis removing the studies at high risk of bias showed no difference in effect.

There was no evidence of an effect on miscarriage, however the evidence is of low-quality: RR 0.99, 95\% CI 0.63 to 1.53 ; P value 0.06; eight RCTs; 500 clinical pregnancies; $\mathrm{I}^{2}=10 \%$; low-quality evidence.

Endometrial injury was also associated with an increased clinical pregnancy rate: RR $1.34,95 \%$ CI 1.21 to $1.61 ; \mathrm{P}$ value $0.002 ; 13$ RCTs; 1972 women; $I^{2}=45 \%$; moderate-quality evidence. This suggests that if $30 \%$ of women achieve clinical pregnancy without endometrial injury, between $33 \%$ and $48 \%$ will achieve clinical pregnancy with this intervention.

Endometrial injury was associated with increased pain, however the evidence was of very low quality. One study reported pain on a VAS scale: MD 4.60, 95\% CI 3.98 to 5.22; P value < 0.00001; one RCT; 158 women. Two studies reported the number of pain complaints after the procedure; one recorded no events in either group, and the other reported that endometrial injury increased pain complaints: OR 8.65, 95\% CI 2.49 to 30.10; P value 0.0007; one RCT; 101 women.

Results from the only randomised controlled trial (RCT) comparing endometrial injury on the day of oocyte retrieval versus no injury, reported that this endometrial injury markedly decreased live birth (RR 0.31, 95\% CI 0.14 to 0.69; P value $0.004 ; 156$ women; lowquality evidence) and clinical pregnancy (RR $0.36,95 \%$ CI 0.18 to 0.71 ; P value 0.003 ; one RCT; 156 women; low-quality evidence).

\section{Authors' conclusions}

Moderate-quality evidence indicates that endometrial injury performed between day 7 of the previous cycle and day 7 of the embryo transfer (ET) cycle is associated with an improvement in live birth and clinical pregnancy rates in women with more than two previous embryo transfers. There is no evidence of an effect on miscarriage, multiple pregnancy or bleeding. The procedure is mildly painful. Endometrial injury on the day of oocyte retrieval is associated with a reduction of clinical and ongoing pregnancy rates.

Although current evidence suggests some benefit of endometrial injury, we need evidence from well-designed trials that avoid instrumentation of the uterus in the preceding three months, do not cause endometrial damage in the control group, stratify the results for women with and without recurrent implantation failure (RIF) and report live birth.

\section{PLAIN LANGUAGE SUMMARY}

\section{Endometrial injury in women undergoing assisted reproductive techniques}

\section{Review question}

To assess the safety and efficacy of performing an endometrial injury (such as endometrial biopsy) on reproductive outcomes in women undergoing ART.

\section{Background}

Couples who have trouble getting pregnant may seek fertility treatments to help them conceive. These treatments are known as assisted reproductive techniques (ART), such as in vitro fertilisation (IVF). In ART, eggs are collected from the woman and are combined with semen in the laboratory to create embryos. Embryos are transferred back into the womb in the hope that they will establish a pregnancy. Implantation is the process by which an embryo is embedded in the lining of the womb; it is the first step toward establishing a successful pregnancy. It has been suggested that the chances of implantation are increased by intentional endometrial scratching, such as by endometrial biopsy or curettage, before replacement of the embryo.

\section{Study characteristics}

Endometrial injury in women undergoing assisted reproductive techniques (Review)

Copyright ( 2015 The Cochrane Collaboration. Published by John Wiley \& Sons, Ltd. 
Cochrane authors included 14 clinical trials (2128 women) evaluating the effects of endometrial injury on outcomes of ART. Thirteen of these trials studied endometrial injury during the menstrual cycle before embryo transfer. One trial studied endometrial injury on the day of oocyte retrieval, which is just a few days before the day the embryo is transferred into the womb. Whether participants had undergone previous embryo transfers varied among the included studies. The evidence is current to January 2015.

\section{Key results}

The included studies suggest that endometrial injury performed sometime during the month before the start of ovarian stimulation as part of ART improves the chances that a woman will achieve live birth and clinical pregnancy. Moderate-quality evidence suggests that if $26 \%$ of women achieve live birth without endometrial injury, between $28 \%$ and $48 \%$ will achieve live birth with this intervention. Contrary to this, endometrial injury performed on the day the eggs are picked up reduces the chances of pregnancy.

We are still uncertain about the effect of endometrial injury on adverse events such as miscarriage, multiple pregnancy or vaginal bleeding. However, the endometrial injury procedure does appear to cause some pain, although this is short lived.

\section{Quality of the evidence}

Evidence that endometrial injury performed in the cycle before ART increases the probability of live birth and clinical pregnancy is of moderate quality. For all other outcomes the evidence is of low or very low quality. The quality of the evidence is reduced because insufficient participants were included in the studies, and because a large proportion of the included studies have important limitations in the methods that they used. 
SUMMARY OF FINDINGS FOR THE MAIN COMPARISON [Explanation]

Patient or population: subfertile women undergoing IVF/ICSI

Settings: private and academic clinics

Intervention: endometrial injury performed between day 7 of the previous cycle and day 7 of the ET cycle vs no control

\begin{tabular}{|c|c|c|c|c|c|c|c|}
\hline \multirow[t]{2}{*}{ Outcomes } & \multicolumn{2}{|c|}{ Illustrative comparative risks* $(95 \% \mathrm{Cl})$} & \multirow{2}{*}{$\begin{array}{l}\text { Relative effect } \\
(95 \% \text { Cl) }\end{array}$} & \multirow{2}{*}{$\begin{array}{l}\text { Number of partici- } \\
\text { pants } \\
\text { (studies) }\end{array}$} & \multirow{2}{*}{$\begin{array}{l}\text { NNTB } \\
(95 \% \text { CI) }\end{array}$} & \multirow{2}{*}{$\begin{array}{l}\text { Quality of the evidence } \\
\text { (GRADE) }\end{array}$} & \multirow{2}{*}{$\begin{array}{l}\text { Comments } \\
\text { (study authors' interpre- } \\
\text { tation) }\end{array}$} \\
\hline & Control & Endometrial injury & & & & & \\
\hline $\begin{array}{l}\text { Live } \\
\text { birth/Ongoing preg- } \\
\text { nancy per randomly } \\
\text { assigned woman }\end{array}$ & 26.0 per 100 & $\begin{array}{l}34.2 \text { per } 100 \\
(28.1-48.1)\end{array}$ & $\begin{array}{l}\text { RR } 1.42 \\
(1.08-1.85)\end{array}$ & $\begin{array}{l}1496 \\
\text { (9 studies) }\end{array}$ & $\begin{array}{l}12 \\
(5-48)\end{array}$ & $\begin{array}{l}\oplus \oplus \oplus \bigcirc \\
\text { Moderate }^{a}\end{array}$ & Benefit \\
\hline $\begin{array}{l}\text { Clinical pregnancy } \\
\text { per randomly as- } \\
\text { signed woman }\end{array}$ & 29.8 per 100 & $\begin{array}{l}38.6 \text { per } 100 \\
(33.4-48.0)\end{array}$ & $\begin{array}{l}\text { RR 1.34 } \\
(1.12-1.61)\end{array}$ & $\begin{array}{l}1972 \\
\text { (13 studies) }\end{array}$ & $\begin{array}{l}11 \\
(5-28)\end{array}$ & $\begin{array}{l}\oplus \oplus \oplus \bigcirc \\
\text { Moderate }^{b}\end{array}$ & Benefit \\
\hline $\begin{array}{l}\text { Miscarriage per clin- } \\
\text { ical pregnancy }\end{array}$ & 15.8 per 100 & $\begin{array}{l}14.7 \text { per } 100 \\
(10.0-24.2)\end{array}$ & $\begin{array}{l}\text { RR } 0.99 \\
(0.63-1.53)\end{array}$ & $\begin{array}{l}500 \\
\text { (8 studies) }\end{array}$ & - & $\begin{array}{l}\oplus \oplus \bigcirc \bigcirc \\
\mathbf{L o w}^{c, d}\end{array}$ & - \\
\hline
\end{tabular}

*The assumed risk in the control group was determined as the median value across studies. The assumed risk in the endometrial injury group (and its $95 \% \mathrm{Cl}$ ) is based on the assumed risk in the comparison group and the relative effect of the intervention (and its $95 \% \mathrm{Cl}$ ).

CI: Confidence interval; RR: Risk ratio; NNTB: Number needed to treat for an additional beneficial outcome

GRADE Working Group grades of evidence.

High quality: Further research is very unlikely to change our confidence in the estimate of effect.

Moderate quality: Further research is likely to have an important impact on our confidence in the estimate of effect and may change the estimate.

Low quality: Further research is very likely to have an important impact on our confidence in the estimate of effect and is likely to change the estimate.

Very low quality: We are very uncertain about the estimate.

${ }^{a}$ This outcome was downgraded by 1 level because of serious imprecision: The $95 \% \mathrm{Cl}$ is wide and includes from no clinically relevant effect to large benefit.

${ }^{b}$ This outcome was downgraded by 1 level because of serious imprecision: The $95 \% \mathrm{Cl}$ is wide and included from small to large benefit.

${ }^{c}$ This outcome was downgraded by 2 levels because of very serious imprecision: The $95 \% \mathrm{Cl}$ is too large and relatively few events were reported in the included studies. 


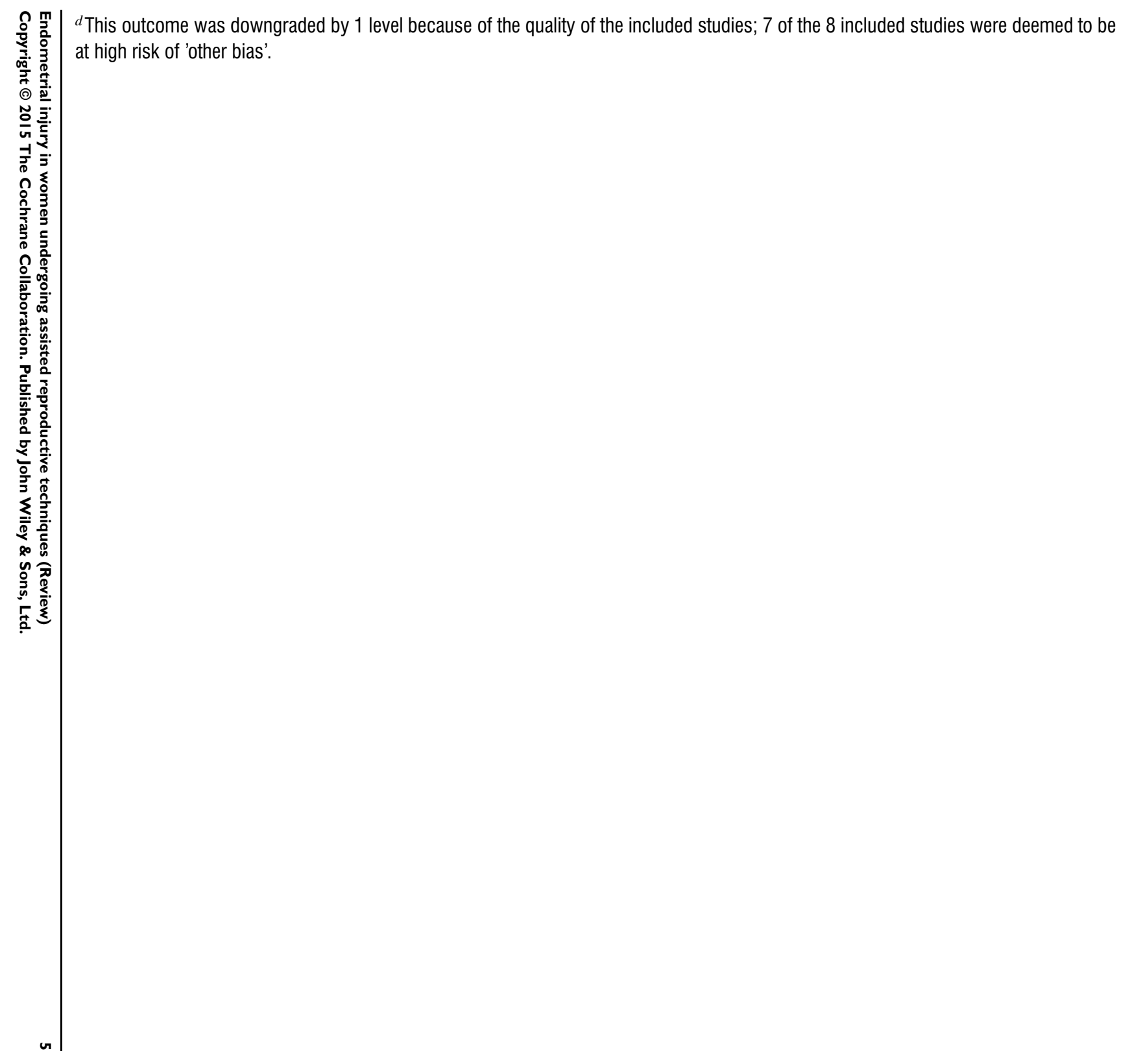




\section{B A C K G R O U N D}

\section{Description of the condition}

Assisted reproductive techniques (ART) include treatments and procedures requiring in vitro handling of human oocytes and sperm, or of embryos, with the objective of achieving pregnancy and live birth (Zegers-Hochschild 2009). The most common forms of ART include in vitro fertilisation (IVF) and intracytoplasmic sperm injection (ICSI). ART are widely used for the treatment of infertility, but success rates remain relatively low, with less than $30 \%$ of treatment cycles resulting in a live birth (Gunby 2010). A key determinant of treatment success is implantation of the embryo, which depends on two factors: the quality of the embryo and the receptivity of the endometrium. Even when goodquality embryos are transferred, implantation may not occur. The cumulative chance of achieving a pregnancy improves with second and third attempts, but thereafter improvement is reduced (Luke 2012). Recurrent implantation failure (RIF) is a clinical situation with many definitions; most published articles define RIF as failure of two to six previous treatment cycles (Polanski 2014). Lack of implantation may be attributed in part to the endometrium, and one of the interventions suggested to improve endometrial receptivity is physical injury to the endometrium: Results from the first published study examining this intervention suggest that it could improve implantation $(27.7 \%$ vs $14.2 \%$; P value $<0.001)$, clinical pregnancy $(66.7 \%$ vs $30.3 \%$; P value $<0.001)$ and live birth rates (48.9\% vs 23.6\%; P value 0.016) (Barash 2003).

\section{Description of the intervention}

Endometrial injury is defined as intentional damage to the endometrium performed with the objective of improving the reproductive outcomes of women or couples desiring pregnancy. The most common intervention is endometrial scratching performed using a pipelle. In the context of an ART cycle, endometrial injury is performed some time prior to embryo transfer and can be performed as an office procedure with or without ultrasound guidance. To perform endometrial injury, a speculum is inserted into the vagina and the external cervical os is located. A pipelle or similar device is then introduced through the external os and advanced until it reaches the uterine fundus and a sample of the endometrium is retrieved by suction and rotation within the uterine cavity. The movements made to obtain the sample are believed to result in some disturbance or "injury" to the endometrium.

\section{How the intervention might work}

The underlying mechanism of how endometrial injury may improve endometrial receptivity remains unclear; however several pathways have been hypothesised. The first hypothesis suggests that the mechanical effect of local injury to the proliferative endometrium induces endometrial decidualisation, a process that naturally occurs in preparation for pregnancy and therefore favours implantation (Li 2009; Zhou 2008). A second hypothesis is that the injury induces a wound healing response, which involves recruitment of immune system cells to the site of healing (Siristatidis 2014), as it is associated with a significant increase in the secretion of cytokines, interleukins, growth factors, macrophages and dendritic cells - all of which are beneficial for embryo implantation (Gnainsky 2010; Li 2009). Recruited immune cells are capable of living for months and are able to differentiate into tissueresident macrophages or dendritic cells, thus playing a direct role in decidual development and embryo implantation (Siristatidis 2014). Uterine natural killer (NK) cells are a major source of immunoregulatory cytokines in the endometrium and are thought to be reduced in numbers during controlled ovarian stimulation (Siristatidis 2014). Endometrial injury may increase the quantity of NK cells within the endometrium, restoring these to sufficient numbers (Junovich 2011). Cytokines, growth factors and NK cells are also responsible for increased angiogenesis, thereby providing adequate blood flow to the tissue and preventing embryo rejection (Siristatidis 2014). A third hypothesis is related to the observation that ovarian stimulation during ART leads to abnormal maturation of the endometrium, such that it is advanced at the time of embryo transfer and may be less receptive to an implanting embryo (Lass 1998; Ubaldi 1997). This hypothesis suggests that endometrial injury retards endometrial maturation, leading to better synchronicity between the endometrium and the transferred embryo (Li 2009).

\section{Why it is important to do this review}

Several studies have indicated that endometrial injury may induce changes in the endometrium that improve reproductive outcomes in women undergoing ART cycles. It is necessary to identify, evaluate and summarise the evidence for endometrial injury as a fertility treatment in women undergoing ART cycles, and to present it in a way that supports clinical practice.If endometrial injury is found to be beneficial it will help many women and couples to conceive from ART, which currently has a limited success rate of approximately 30\% per cycle (Gunby 2010).

\section{O B JE C T IVES}

To assess the effectiveness and safety of endometrial injury performed before embryo transfer in women undergoing ART. 


\section{Criteria for considering studies for this review}

\section{Types of studies}

Only randomised controlled trials (RCTs) were considered eligible; quasi- and pseudo-randomised trials were not included. Crossover trials were to be included for completeness, but only data from the first phase would be pooled in the meta-analysis because this design is not valid in the context of subfertility trials (Vail 2003); however, no cross-over trials were identified.

\section{Types of participants}

Women undergoing ART.

\section{Types of interventions}

The studied intervention is intentional endometrial injury performed within six months before ART. We planned to include studies evaluating the following comparisons: (1) Endometrial injury versus No intervention or a Sham procedure; (2) Higher versus Lower degree of endometrial injury (e.g. Pipelle vs Hysteroscopy); and (3) different numbers of interventions (e.g. Only one procedure vs Multiple procedures).

\section{Types of outcome measures}

\section{Primary outcomes}

\section{Effectiveness}

1. Live birth or ongoing pregnancy per randomly assigned woman.

i) Ongoing pregnancy, defined as a clinical pregnancy of 12 or more weeks' gestation, was used as a surrogate for live birth in cases where studies did not report live birth but reported ongoing pregnancy.

\section{Adverse events}

1. Miscarriage per clinical pregnancy.

\section{Adverse events}

1. Multiple gestation per clinical pregnancy.

2. Pain reported during the intervention and any mock intervention, as measured by any validated qualitative or quantitative scale.

3. Abnormal bleeding during or after the intervention or the mock intervention.

\section{Additional data}

Implantation rate is defined as the number of gestational sacs evident on ultrasound divided by the number of transferred embryos (Zegers-Hochschild 2009). Although implantation rate is relevant information for this review, it was not included as an outcome because differences in the denominators make these data statistically inappropriate for pooling. Implantation rates in the individual studies are described in the Characteristics of included studies table.

\section{Search methods for identification of studies}

We searched for RCTs in accordance with a search strategy developed in consultation with the Trials Search Co-ordinator for the Cochrane Menstrual Disorders and Subfertility Group (MDSG). We applied no language restrictions.

\section{Electronic searches}

We performed the original search in November 2011 and new searches in March 2014 and January 2015. We designed search strategies for the following databases: the MDSG Specialised Register (Appendix 1); the Cochrane Central Register of Controlled Trials (CENTRAL) (Appendix 2); the Database of Abstracts of Reviews of Effects (DARE) (Appendix 3); MEDLINE (Appendix 4); EMBASE (Appendix 5); PsycINFO (Appendix 6); the Cumulative Index to Nursing and Allied Health Literature (CINAHL) (Appendix 7); and Latin American Caribbean Health Sciences Literature (LILACS) (Appendix 8).

We searched for ongoing trials on clinicaltrials.gov, Current Controlled Trials and the World Health Organization International Clinical Trials Registry Platform (WHO ICTRP). We searched for conference abstracts on the Web of Science and for grey literature on OpenGrey.

\section{Searching other resources}

We searched the reference lists of included and excluded trials.

\section{Secondary outcomes}

\section{Data collection and analysis}

\section{Effectiveness}

1. Clinical pregnancy per randomly assigned woman.

\section{Selection of studies}

Endometrial injury in women undergoing assisted reproductive techniques (Review) 
Two review authors (SFL and AG) assessed eligibility independently and in a standardised manner. These review authors resolved disagreements by discussion and consulting with a third review author $(\mathrm{CON})$.

\section{Data extraction and management}

We extracted data from eligible trials by using a data extraction form that had been designed and pilot-tested by the review authors. When studies had multiple publications, we used the main trial report as the reference and obtained additional details from secondary papers. We tried to correspond with study investigators to resolve data queries as required. Two review authors (SFL and AG) extracted data from the included studies and resolved disagreements by discussion or by consultation with a third review author $(\mathrm{CON})$.

\section{Assessment of risk of bias in included studies}

Two review authors (SFL and AG) independently assessed methodological quality and data collection by using the Cochrane 'Risk of bias' assessment tool (Higgins 2011). We assessed selection bias (random sequence generation and allocation concealment), attrition bias (incomplete outcome data), reporting bias (selective reporting), performance bias (blinding of participants and personnel), detection bias (blinding of outcome assessors) and other biases (other problems that could put a trial at high risk of bias). We presented and described all judgements in the conclusions portion of the Risk of bias in included studies tables.

\section{Measures of treatment effect}

We summarised the effects of the intervention as risk ratios (RRs) for binary outcomes (live birth, clinical pregnancy, miscarriage) and as mean differences (MDs) for continuous outcomes (pain). We evaluated the precision of the estimates by using the $95 \%$ confidence interval (CI). We considered the clinical relevance of all comparisons while taking into account the precision of the estimates. We planned to determine the number needed to treat for an additional beneficial outcome (NNTB) or for an additional harmful outcome (NNTH) when a significant difference was observed.

\section{Unit of analysis issues}

We used the number of randomly assigned women as the denominator for live birth, clinical pregnancy, pain and bleeding. We used the number of clinical pregnancies as the denominator for miscarriage and multiple pregnancy, as these outcomes can occur only in pregnant women. No 'per cycle' data were included.

\section{Dealing with missing data}

We analysed the data on an intention-to-treat (ITT) basis as far as possible and attempted to obtain missing data from the trial researchers. We assumed that participants who dropped out after randomisation because of cycle cancellation did not achieve clinical pregnancy or live birth; no other assumptions were made.

\section{Assessment of heterogeneity}

We pooled data in a meta-analysis only when clinical and methodological characteristics of the included studies were considered to be sufficiently similar for meta-analysis to provide a clinically meaningful summary. We assessed heterogeneity using $\mathrm{I}^{2}$; when we observed substantial heterogeneity, we explored this by conducting planned subgroup analyses.

\section{Assessment of reporting biases}

We tried to minimise the potential impact of reporting biases by performing a comprehensive search for eligible studies and by looking for duplication of data. We planned to perform funnel plot analysis if more than 10 studies were included in a comparison. When possible, we used published protocols for included studies to investigate selective reporting (i.e. comparisons of outcomes listed in the study protocol vs outcomes reported in papers).

\section{Data synthesis}

We carried out statistical analysis of the data by using Review Manager (RevMan 5). When we considered studies to be sufficiently similar, we combined data using a random-effects model, as we considered that the method used to promote endometrial injury and its effect size were likely to differ across the trials in each analysis.

For this update of the review, we planned the following comparisons.

1. 'Endometrial injury between day 7 of the previous cycle and day 7 of the ET cycle' versus 'No injury'.

2. 'Endometrial injury on the day of oocyte retrieval' versus 'No injury'.

3. 'Higher' versus 'Lower' degree of endometrial injury.

We made a post hoc decision to merge comparisons 1 and 3 to enable subgroup analyses as described below.

\section{Subgroup analysis and investigation of heterogeneity}

When data were available, we undertook subgroup analyses to assess treatment effects within different subgroups. We planned to conduct subgroup analyses based on the presence of RIF because women who have impaired implantation ability are, at least theoretically, a group with better potential to benefit from the intervention. Using a broadly accepted classification of RIF (Polanski 2014), we divided subgroups according to previous ART demographics: ' $\leq 1$ previous embryo transfers', ' $\geq 2$ previous embryo 
transfers' and 'Unselected women or unclear number of previous embryo transfers'.

After inclusion of the studies, we observed that in several RCTs, some degree of intrauterine manipulation was also performed in the control groups. Such manipulation occurred by insertion of an instrument - such as a hysteroscope or a sound - into the uterine cavity as part of the standard treatment or as a sham procedure. As such intrauterine manipulation probably causes some degree of endometrial injury, it may reduce the observed differences in reproductive outcomes caused by the intervention. To assess this, a second subgroup analysis was performed according to the type of control intervention provided: 'No intrauterine manipulation in the control group' or 'Intrauterine manipulation in the control group'.

We took into account all statistical heterogeneity when interpreting the results, especially if we noted any variation in the direction of effect.

\section{Sensitivity analysis}

We conducted sensitivity analyses for the primary outcomes to determine whether review conclusions were robust to arbitrary decisions made regarding eligibility and analysis. These analyses included consideration of whether review conclusions would have been different if eligibility had been restricted to studies without high risk of bias in any domain.

\section{Overall quality of the body of evidence: 'Summary of findings' table}

We prepared a 'Summary of findings' table to evaluate the overall quality of the body of evidence for the main review outcomes (live birth, clinical pregnancy, miscarriage) using GRADE (Grades of Recommendation, Assessment, Development and Evaluation) criteria (study limitations (i.e. risk of bias), consistency of effect, imprecision, indirectness, publication bias). We justified and documented judgements about evidence quality (high, moderate, low) and incorporated this into reporting of results for each outcome.

\section{R E S U L T S}

\section{Description of studies}

\section{Results of the search}

We ran the first electronic search on 14 December 2011, and new searches on 11 March 2014 and 19 January 2015. From the first search, we retrieved 288 references, of which five studies were included. From the updating search, we retrieved a total of 535 references: CENTRAL $=17$; CINAHL $=26$; EMBASE $=83$; LILACS = 34; MEDLINE $=35$; PsycINFO $=7$; Scopus $=181$; Web of Knowledge $=63$; ClinicalTrials $=51$; Current Controlled Trials = 8; WHO ICTRP $=70$ and Australian New Zealand Clinical Trials Register (ANZCTR) $=2$; we retrieved two additional references through a manual search. From 535 records screened on the basis of title and abstract, we identified 52 potentially eligible records; two review authors (SFL and AG) independently assessed these trials completely for eligibility. From those, we excluded 23 records and identified 14 as ongoing trials and 14 as eligible; the trial flow diagram is shown in Figure 1. 
Figure I. Study flow diagram.

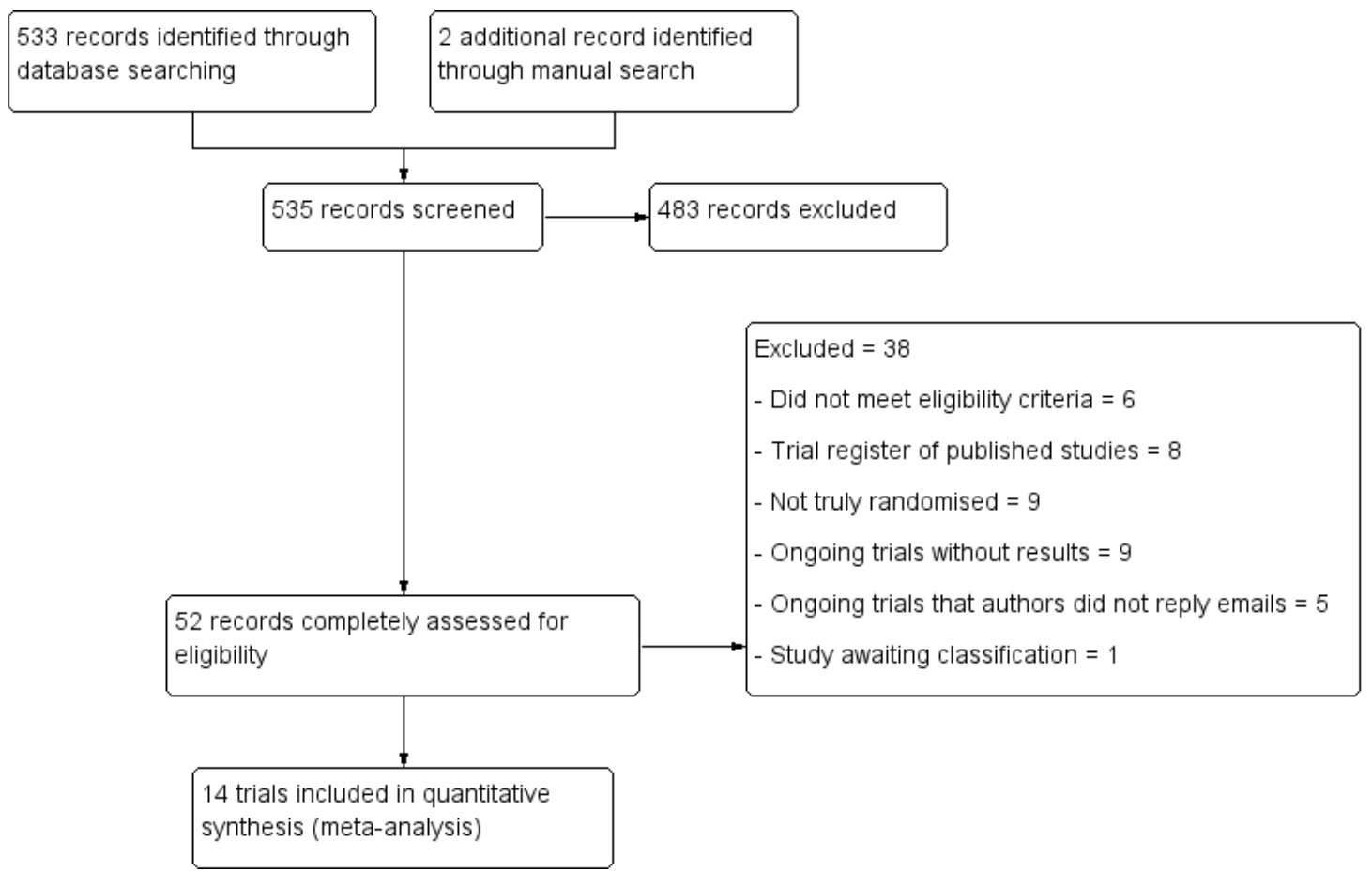

\section{Included studies}

\section{Study design and setting}

We included in this review 14 parallel-design randomised controlled trials (RCTs). Twelve were completed and published trials, 11 as full articles (Baum 2012; Gibreel 2015; Guven 2014; Inal 2012; Karimzadeh 2009; Karimzade 2010; Narvekar 2010; Nastri 2013; Safdarian 2011; Shohayeb 2012; Yeung 2014) and one only as a conference abstract (Karim Zadeh 2008). Two are ongoing trials from which preliminary results were included (Aleyamma 2013; Polanski 2014). Twelve studies were single-centre trials conducted in Brazil (Nastri 2013), Hong Kong (Yeung 2014), India (Aleyamma 2013; Narvekar 2010), Iran (Karim Zadeh 2008; Karimzadeh 2009; Karimzade 2010; Safdarian 2011), Israel (Baum 2012), Turkey (Guven 2014; Inal 2012) and the United Kingdom (Polanski 2014). Two studies were conducted at more than one centre - one in Egypt and Saudi Arabia (Shohayeb 2012) and the other across three centres in Egypt (Gibreel 2015).

\section{Participants}

The studies included 1063 women in the intervention groups and 1065 women in the control groups. Seven studies included only women who had undergone previous unsuccessful IVF attempts (Aleyamma 2013; Baum 2012; Gibreel 2015; Karim Zadeh 2008; Karimzadeh 2009; Narvekar 2010; Shohayeb 2012), five included women regardless of the number of previous attempts (Guven 2014; Nastri 2013; Polanski 2014; Safdarian 2011; Yeung 2014) and one study included only women submitted for their first IVF/ ICSI cycle (Karimzade 2010).

\section{Interventions}

Eleven studies compared endometrial injury performed between day 7 of the previous cycle and day 7 of the ET cycle using a Pipelle de Cornier - once in nine studies (Aleyamma 2013; Guven 2014; Karim Zadeh 2008; Karimzadeh 2009; Nastri 2013; Polanski 2014; Safdarian 2011; Yeung 2014; Gibreel 2015) and twice in two studies (Inal 2012; Yeung 2014). We included these studies under the comparison 'Endometrial injury between day 7 of the previous cycle and day 7 of the ET cycle versus No injury'. In one study (Karimzade 2010), researchers caused a more severe endometrial disturbance by using a Novak curette on the day of oocyte retrieval relatively close to the moment of embryo implantation. This study was included in the second comparison, 'Endometrial injury on the day of oocyte retrieval versus No injury'. Two studies compared endometrial injury versus an active control that might also cause 
endometrial injury: One compared hysteroscopy and endometrial scraping using a Novak curette versus only hysteroscopy between days 4 and 7 of the cycle before the ET cycle (Shohayeb 2012); the other compared hysteroscopy and Pipelle on days 7 to 10 plus an additional Pipelle on days 24 to 25 of the cycle before the ET cycle versus only hysteroscopy on days 7 to 10 (Narvekar 2010). These studies were included in the first post hoc comparison.

\section{Outcomes}

10/14 trials reported live birth; one trial (Karimzade 2010) reported only ongoing pregnancy, and that was used as a surrogate for live birth.

$14 / 14$ trials reported clinical pregnancy.

8/14 trials reported miscarriage.

$4 / 14$ trials reported multiple pregnancy.

$3 / 14$ trials reported pain.

$3 / 14$ trials reported bleeding.

\section{Excluded studies}

We excluded three studies because they were not truly randomised (Matsumoto 2014; Yoldemir 2011; Zhou 2008).

\section{Ongoing studies}

We have identified 14 ongoing studies from trial registries; see Characteristics of ongoing studies for details.

\section{Studies awaiting classification}

A new search on 19 January 2015 identified one further study (Hur 2012), which has been placed under Studies awaiting classification. This study was published only as a conference abstract, and we have not been able to ascertain whether it was an RCT or a pseudorandomised trial.

\section{Risk of bias in included studies}

We summarised all risk of bias judgements in Figure 2 and Figure 3. See the Characteristics of included studies table for detailed information. 
Figure 2. Risk of bias summary: review authors' judgements about each risk of bias item for each included study.

\begin{tabular}{|c|c|c|c|c|c|c|c|}
\hline & 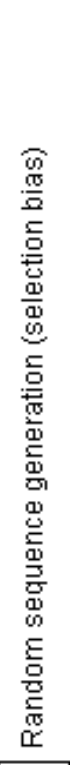 & 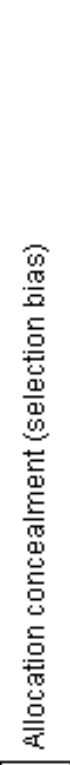 & 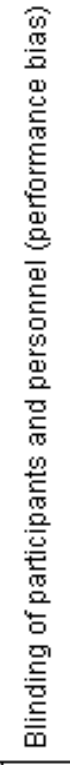 & 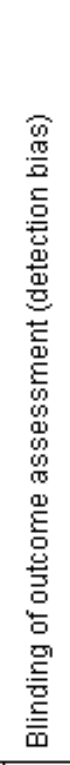 & 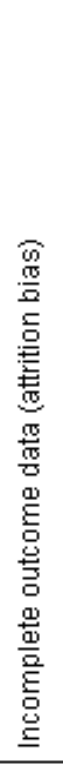 & 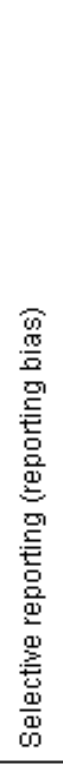 & 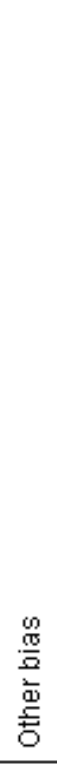 \\
\hline Aleyamma 2013 & + & + & + & + & $?$ & + & - \\
\hline Baum 2012 & + & $?$ & $\odot$ & $\odot$ & $\odot$ & $\odot$ & $\odot$ \\
\hline Gibreel 2015 & + & + & + & + & + & + & - \\
\hline Guven 2014 & + & + & + & $\odot$ & + & + & $\oplus$ \\
\hline Inal 2012 & + & $?$ & + & + & + & + & + \\
\hline Karimzade 2010 & $?$ & $?$ & $\odot$ & + & $\odot$ & $\odot$ & + \\
\hline Karim Zadeh 2008 & $?$ & $?$ & $\odot$ & + & + & $?$ & \\
\hline Karimzadeh 2009 & + & + & + & 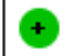 & $\odot$ & $?$ & $\oplus$ \\
\hline Narvekar 2010 & + & + & $\odot$ & + & + & + & \\
\hline Nastri 2013 & + & + & + & + & $\odot$ & $\odot$ & $\oplus$ \\
\hline Polanski 2014 & + & + & + & $\odot$ & + & + & \\
\hline Safdarian 2011 & $?$ & $?$ & + & + & + & $?$ & $?$ \\
\hline Shohayeb 2012 & + & + & $\odot$ & + & + & + & \\
\hline Yeung 2014 & + & + & $\odot$ & + & $\odot$ & + & \\
\hline
\end{tabular}


Figure 3. Risk of bias graph: review authors' judgements about each risk of bias item presented as percentages across all included studies.

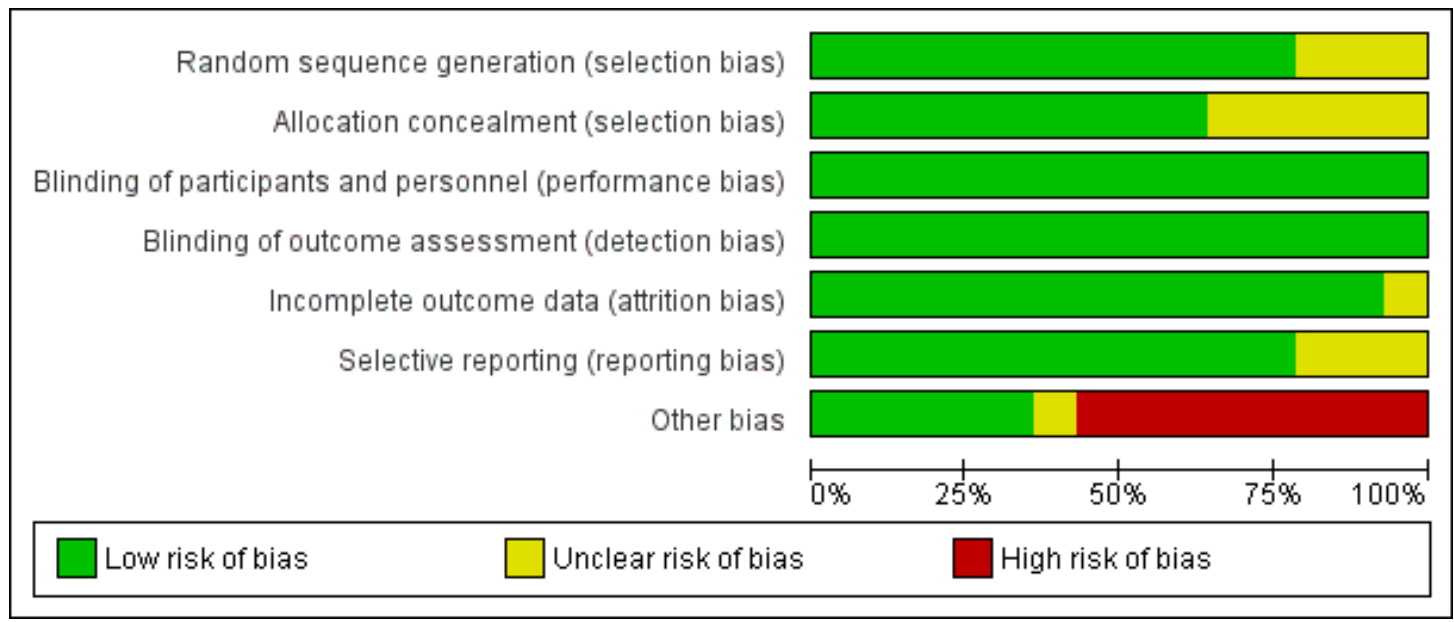

\section{Allocation}

\section{Random sequence generation}

Eleven studies used adequate methods for random sequence generation and were deemed to be at low risk of selection bias. Three studies claimed to be randomised but did not report the method used for randomisation (Karim Zadeh 2008; Karimzade 2010; Safdarian 2011); they were judged to be at unclear risk of bias.

\section{Allocation concealment}

Nine studies used adequate methods for concealment of the random sequence and were deemed to be at low risk of selection bias. Five studies did not report an attempt to conceal the allocation (Baum 2012; Inal 2012; Karim Zadeh 2008; Karimzade 2010; Safdarian 2011); they were judged to be at unclear risk of bias.

\section{Blinding}

For the purposes of this review, we did not consider lack of blinding to be a source of performance or detection bias.

\section{Incomplete outcome data}

Thirteen studies were considered to be at low risk of attrition bias, as all randomly assigned women were included in the analysis. In one study, the number of participants lost to follow-up was unclear, and the study was considered to be at unclear risk of attrition bias (Aleyamma 2013).

\section{Selective reporting}

Three trials were considered to be at unclear risk because they report only clinical pregnancy, without reporting miscarriage or live birth (Karim Zadeh 2008; Karimzadeh 2009; Safdarian 2011). The other 11 studies reported miscarriage or live birth rates (or both) and were deemed to be at low risk of reporting bias.

\section{Other potential sources of bias}

Seven studies were at high risk of other sources of bias. Two studies are described in the preliminary reports of ongoing trials (Aleyamma 2013; Polanski 2014). One study (Karim Zadeh 2008) was published only as a conference abstract, and we could retrieve no further information from trial authors.

In five studies, both intervention and control groups may have received some degree of unintentional endometrial injury, thus introducing a systematic error and potentially altering the degree to which the intervention was observed to affect outcomes. In Baum 2012, the sham procedure used to conceal allocation consisted of insertion of a Pipelle into the cervix while trying not to pass the internal os; in Gibreel 2015, the sham procedure included the introduction of a sound into the cervix to the internal os. In this 
same study (Gibreel 2015), 15 of 193 women in the intervention group and 12 of 194 in the control group underwent hysteroscopy because of difficulties associated with insertion of the device. In one study, all women underwent hysteroscopy or saline sonography between one and three months before randomisation (Yeung 2014); in two studies, all women underwent hysteroscopy after randomisation (Narvekar 2010; Shohayeb 2012).

One study was considered at unclear risk of other bias because it was under-reported, and we could not obtain all of the information needed for a complete risk of bias assessment (Safdarian 2011).

\section{Effects of interventions}

See: Summary of findings for the main comparison Effect of endometrial injury performed between day 7 of the previous cycle and day 7 of the ET cycle vs no injury; Summary of findings 2 Effect of endometrial injury on the day of oocyte retrieval vs no injury

\section{Endometrial injury between day 7 of the previous cycle and day 7 of the ET cycle versus control}

\section{Primary outcomes}

1.1 and 1.2 Live birth or ongoing pregnancy per randomly assigned woman

Endometrial injury was associated with an increase in live birth/ ongoing pregnancy rate: RR $1.42,95 \%$ CI 1.08 to 1.85 ; P value 0.01 ; nine RCTs; 1496 women; $\mathrm{I}^{2}=53 \%$; moderate-quality evidence (Analysis 1.1; Figure 4). Sensitivity analysis excluding the six studies at high risk of bias showed similar estimates: RR 1.81, 95\% CI 1.31 to 2.50; P value 0.0003 ; three RCTs; 382 women; $\mathrm{I}^{2}=0 \%$.

Figure 4. Forest plot of comparison: I Endometrial injury vs no injury, outcome: I.2 Live birth/Ongoing pregnancy per randomly assigned woman.

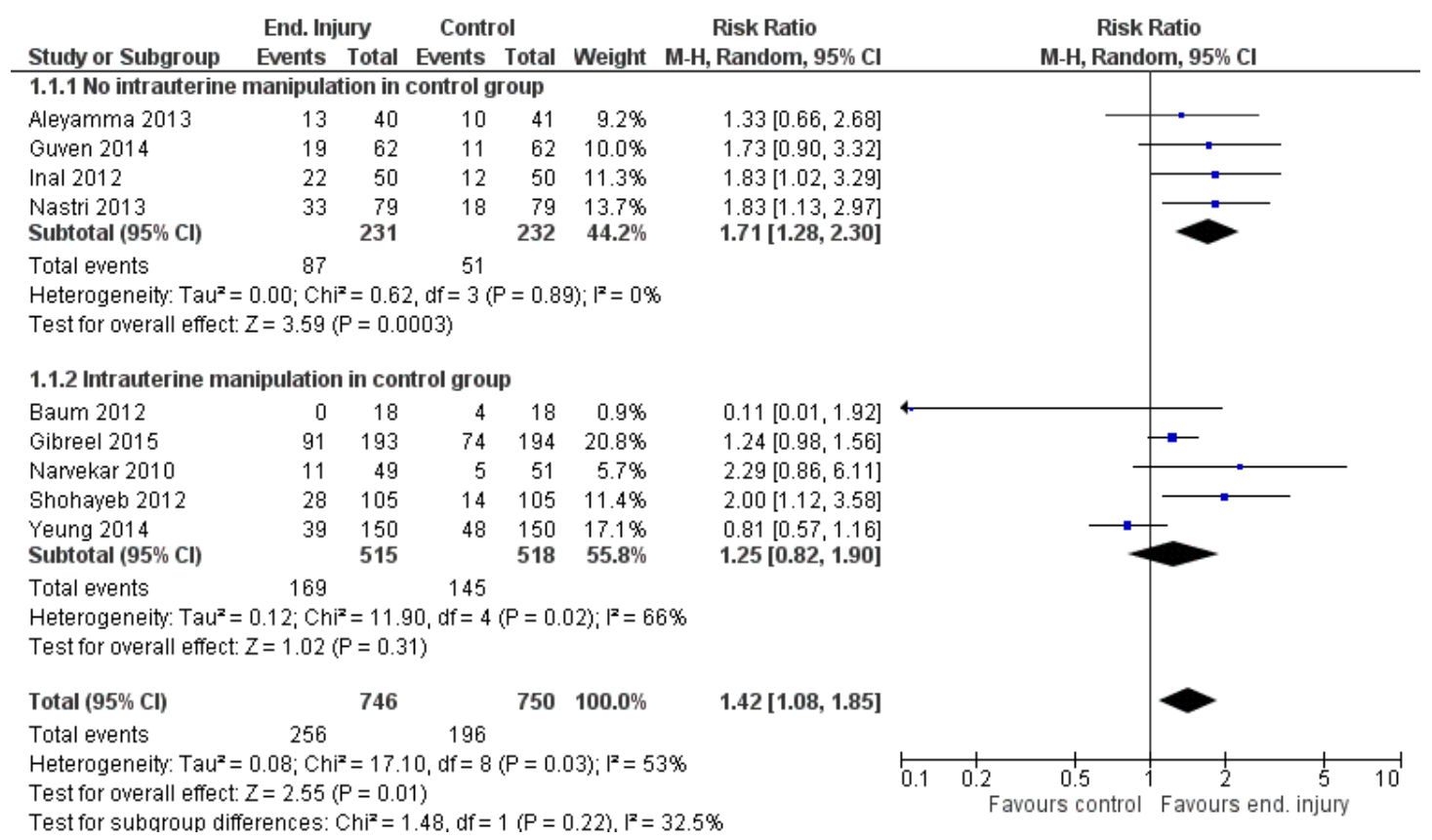

As substantial heterogeneity was observed, we conducted a priori subgroup analysis based on the presence of RIF and an a posteriori defined subgroup analysis based on performance of intrauterine manipulation in the control group.
1.1 Subgroup analysis: presence of intrauterine manipulation in the control group 


\subsubsection{No intrauterine manipulation in the control group}

An increase in the live birth/ongoing pregnancy rate was noted: RR 1.71, 95\% CI 1.28 to 2.30; P value 0.0003; four RCTs; 463 women; $\mathrm{I}^{2}=0 \%$; moderate-quality evidence (Analysis 1.1 ; Figure 4).

\subsubsection{Intrauterine manipulation in the control group}

As the estimate was imprecise, it was not possible to ascertain whether this intervention was related to harm, to no effect or to benefit: RR 1.25 , 95\% CI 0.82 to 1.90 ; P value 0.31 ; five RCTs;
1033 women; $\mathrm{I}^{2}=66 \%$; very low-quality evidence (Analysis 1.1; Figure 4).

\subsection{Subgroup analysis: presence of RIF}

\subsection{1 $\leq 1$ previous attempt}

As the estimate was imprecise, it was not possible to ascertain whether this intervention was related to no effect or benefit: RR 1.10 , 95\% CI 0.91 to 1.33 ; P value 0.32 ; four RCTs; 650 women; $\mathrm{I}^{2}=0 \%$; low-quality evidence (Analysis 1.2 ; Figure 5).

Figure 5. Forest plot of comparison: I Effectiveness, outcome: I. I Live birth per randomly assigned woman.

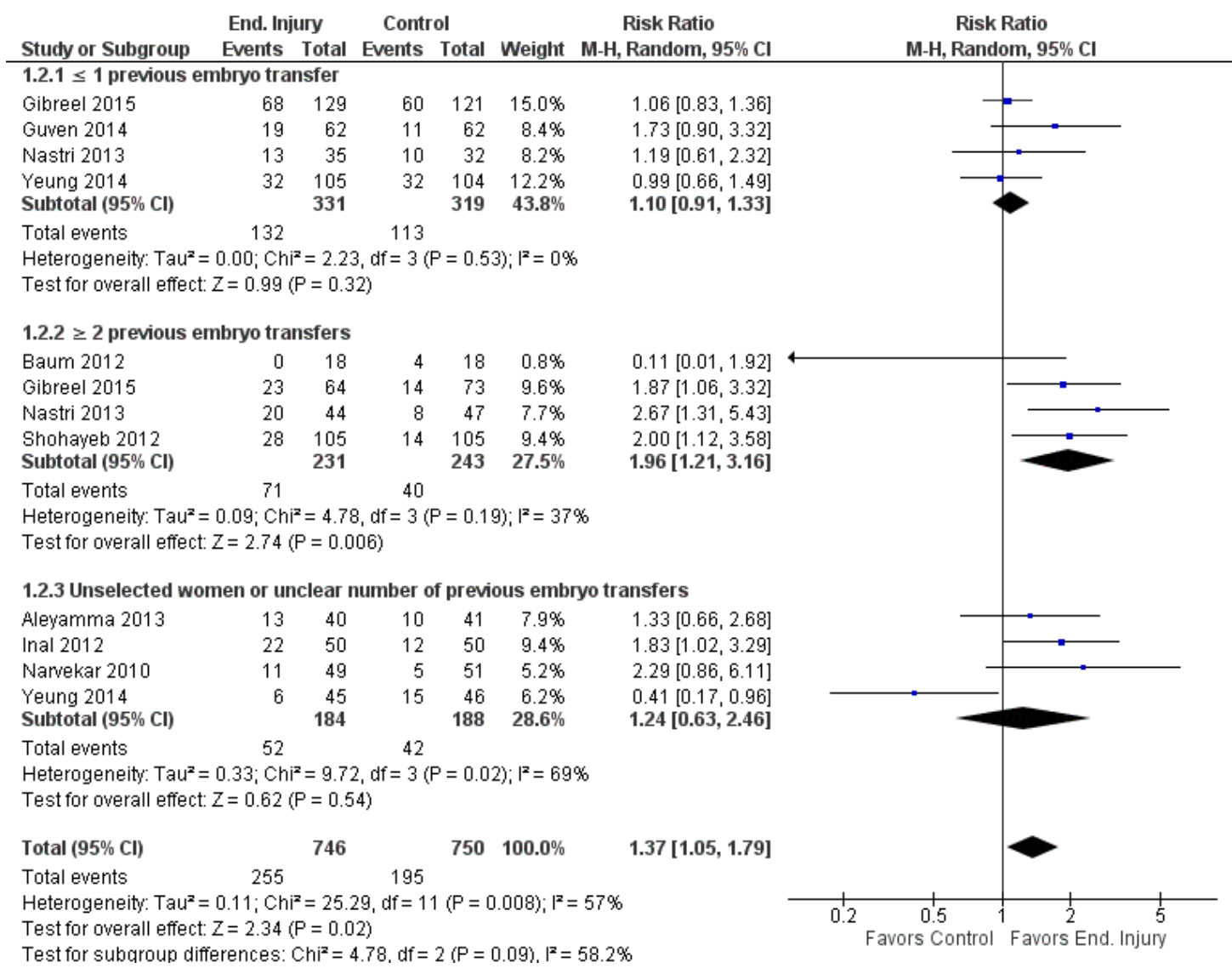

\subsubsection{2 previous attempts}

An increase in live birth/ongoing pregnancy rates was seen in 3.16; P value 0.006; four RCTs; 474 women; $I^{2}=37 \%$; low-quality evidence (Analysis 1.2; Figure 5). women with $\geq 2$ previous attempts: RR 1.96 , 95\% CI 1.21 to 


\subsubsection{Unselected women or unclear number of previous cycles}

As the estimate was imprecise, it was not possible to ascertain whether this intervention was related to harm, to no effect or to benefit: RR 1.24, 95\% CI 0.63 to 2.46; P value 0.54; four RCTs; 372 women; $\mathrm{I}^{2}=69 \%$; very low-quality evidence (Analysis 1.2; Figure 5).

\subsection{Miscarriage per clinical pregnancy}

As the estimate was imprecise, it was not possible to ascertain whether this intervention was related to harm, to no effect or to benefit: RR $0.98,95 \%$ CI 0.61 to 1.55 ; P value 0.92 ; eight RCTs; 501 clinical pregnancies; $\mathrm{I}^{2}=13 \%$; low-quality evidence (Analysis 1.3; Figure 6). Only one study remained after performing sensitivity analysis which excluded seven studies at high risk of bias:: RR $0.71,95 \%$ CI 0.24 to 2.06; one RCT; 62 pregnancies.

Figure 6. Forest plot of comparison: I Endometrial injury vs no injury, outcome: I.3 Miscarriage per clinical pregnancy.

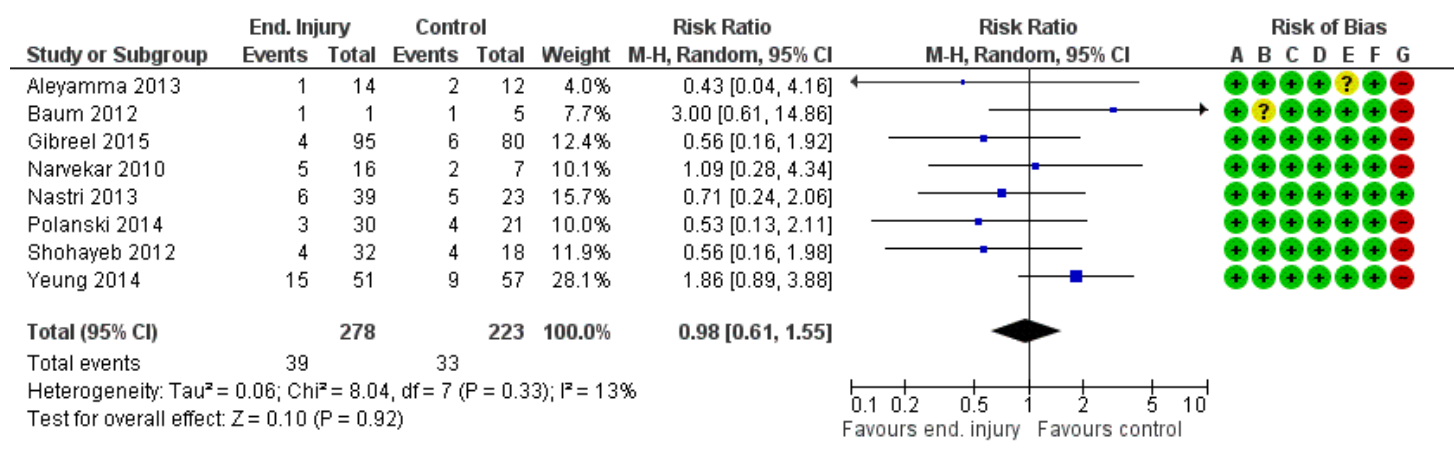

Risk of bias legend

(A) Random sequence generation (selection bias)

(B) Allocation concealment (selection bias)

(C) Blinding of participants and personnel (performance bias)

(D) Blinding of outcome assessment (detection bias)

(E) Incomplete outcome data (attrition bias)

(F) Selective reporting (reporting bias)

(G) Other bias

Secondary outcomes

\section{4 and 1.5 Clinical pregnancy per randomly assigned} woman

Endometrial injury was associated with an increased clinical pregnancy rate: RR $1.34,95 \%$ CI 1.11 to 1.62 ; P value 0.002 ; 13 RCTs; 1972 women; $\mathrm{I}^{2}=46 \%$; moderate-quality evidence (Analysis 1.4; Figure 7). Sensitivity analysis excluding the eight studies at high risk of bias showed similar estimates: RR 1.63 , 95\% CI 1.23 to 2.17; P value 0.0007; five RCTs; 597 women; $\mathrm{I}^{2}=19 \%$. 
Figure 7. Forest plot of comparison: I Endometrial injury between day $\mathbf{7}$ of the previous cycle and day 7 of the ET cycle vs control, outcome: I.4 Clinical pregnancy per randomly assigned woman (by manipulation/no manipulation in control group).

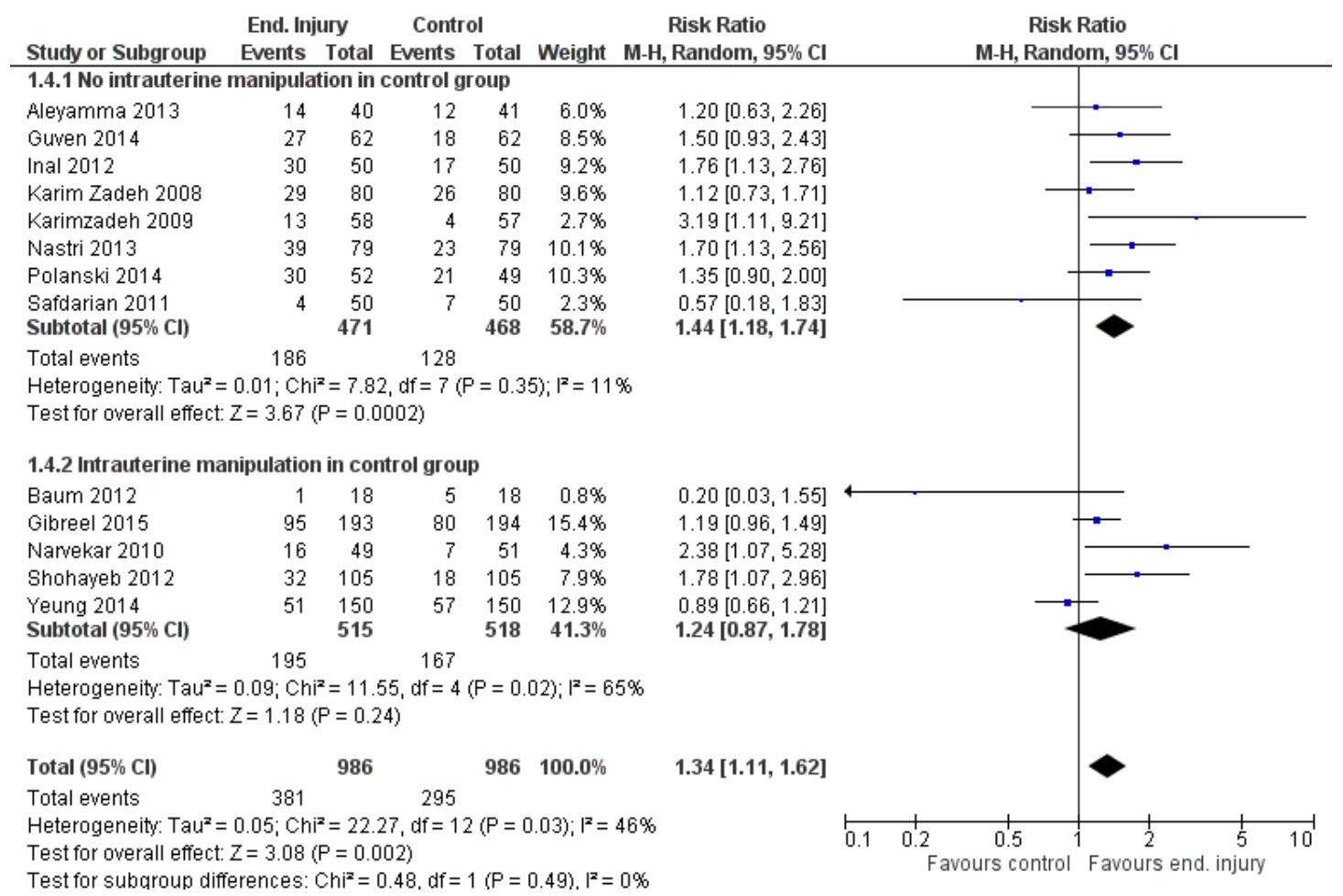

We conducted a priori subgroup analysis based on the presence of RIF (Analysis 1.5; Figure 8) and an a posteriori defined subgroup analysis based on the performance of intrauterine manipulation in the control group (Analysis 1.4; Figure 7). 
Figure 8. Forest plot of comparison: I Endometrial injury vs no injury, outcome: I.4 Clinical pregnancy per randomly assigned woman.

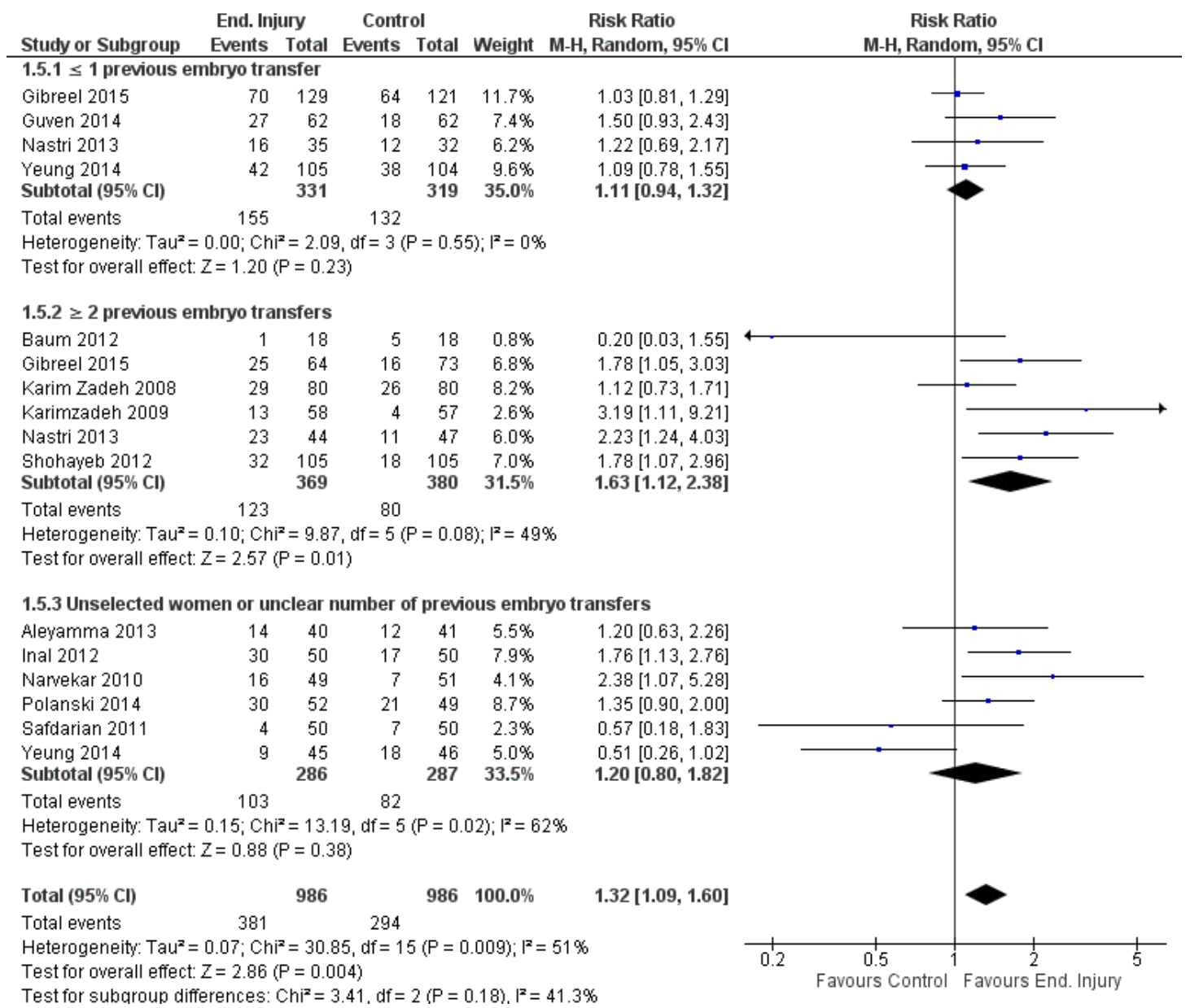

1.4 Subgroup analysis: presence of intrauterine manipulation in the control group

\subsubsection{No intrauterine manipulation in the control group}

An increase in clinical pregnancy rate was observed: RR 1.44, 95\% CI 1.18 to 1.74 ; $\mathrm{P}$ value 0.0002 ; eight RCTs; 939 women; $\mathrm{I}^{2}=$ 11\%; moderate-quality evidence. (Analysis 1.4; Figure 7)

\subsubsection{Intrauterine manipulation in the control group}

As the estimate was imprecise, it was not possible to ascertain whether this intervention was related to harm, to no effect or to benefit: RR 1.25, 95\% CI 0.88 to 1.78 ; P value 0.22 ; five RCTs;
1033 women; $\mathrm{I}^{2}=64 \%$; very low-quality evidence (Analysis 1.4 ; Figure 7)

1.5 Subgroup analysis: presence of RIF

\subsection{1 $\leq 1$ previous attempt}

As the estimate was imprecise, it was not possible to ascertain whether this intervention was related to no effect or benefit: RR $1.11,95 \%$ CI 0.94 to 1.32 ; P value 0.23 ; four RCTs; 650 women; $\mathrm{I}^{2}=0 \%$; low-quality evidence (Analysis 1.5; Figure 8). 


\subsection{2 $\geq 2$ previous attempts}

An increase in clinical pregnancy rate was noted: RR 1.63, 95\% CI 1.12 to 2.38; P value 0.01 ; six RCTs; 749 women; $\mathrm{I}^{2}=49 \%$; low-quality evidence (Analysis 1.5; Figure 8).

\subsubsection{Unselected women or unclear number of previous cycles}

As the estimate was imprecise, it was not possible to ascertain whether this intervention was related to harm, to no effect or to benefit: RR 1.20 , 95\% CI 0.80 to 1.82 ; P value 0.38 ; six RCTs; 573 women; $\mathrm{I}^{2}=62 \%$; very low-quality evidence (Analysis 1.5 ; Figure 8).

\subsection{Multiple pregnancy per clinical pregnancy}

As the estimate was imprecise, it was not possible to ascertain whether this intervention was related to harm, to no effect or to benefit: RR $1.17,95 \%$ CI 0.77 to 1.77 ; P value 0.46 ; four RCTs; 367 clinical pregnancies; $\mathrm{I}^{2}=0 \%$; very low-quality evidence (Analysis 1.6).

\section{7 and 1.8 Pain}

Endometrial injury was associated with increased pain; however the evidence was of very low quality. One study reported increased pain assessed by a visual analogue scale (MD 4.60, 95\% CI 3.98 to 5.22 ; P value $<0.00001$; one RCT; 158 women; Analysis 1.7). Two studies reported the number of pain complaints after the procedure: In one study, endometrial injury increased pain complaints (odds ratio (OR) 8.65, 95\% CI 2.49 to 30.10; P value 0.0007; one RCT; 101 women), and in the other, no complaints of pain were reported in either group (Analysis 1.8). Data were not pooled, and the evidence was of very low quality.

\subsection{Bleeding}

No case of bleeding was described among the 262 women undergoing endometrial injury and 272 controls. Bleeding data were reported by three studies and no case of bleeding was described among the 262 women undergoing endometrial injury and 272 controls.(Analysis 1.9).

\section{Endometrial injury on the day of oocyte retrieval versus control}

Only one study was included in this comparison, and it included only women undergoing their first IVF/ICSI attempt (Karimzade 2010). No sensitivity analysis was performed.

\section{Primary outcomes}

\subsection{Live birth or ongoing pregnancy per randomly assigned woman}

Endometrial injury performed on the day of oocyte retrieval in women undergoing the first IVF/ICSI attempt markedly decreased live birth: RR $0.31,95 \%$ CI 0.14 to 0.69 ; P value 0.004 ; one RCT; 156 women; low-quality evidence (Analysis 2.1).

\subsection{Miscarriage per clinical pregnancy}

The included study did not report this outcome.

\section{Secondary outcomes}

\subsection{Clinical pregnancy per randomly assigned woman}

Endometrial injury performed on the day of oocyte retrieval in women undergoing the first IVF/ICSI attempt markedly decreased clinical pregnancy: RR $0.36,95 \%$ CI 0.18 to 0.71 ; P value 0.003 ; one RCT; 156 women; low-quality evidence (Analysis 2.3).

\subsection{Multiple pregnancy per clinical pregnancy}

The included study did not report this outcome.

\subsection{Pain}

The included study did not report this outcome.

\subsection{Bleeding}

The included study did not report this outcome. 
ADDITIONAL SUMMARY OF FINDINGS [Explanation]

Patient or population: subfertile women undergoing IVF/ICSI

Settings: academic

Intervention: endometrial injury performed on the day of oocyte retrieval vs no injury

\begin{tabular}{|c|c|c|c|c|c|c|c|}
\hline \multirow[t]{2}{*}{ Outcomes } & \multicolumn{2}{|c|}{ Illustrative comparative risks* $(95 \% \mathrm{Cl})$} & \multirow{2}{*}{$\begin{array}{l}\text { Relative effect } \\
(95 \% \text { CI) }\end{array}$} & \multirow{2}{*}{$\begin{array}{l}\text { Number of partici- } \\
\text { pants } \\
\text { (studies) }\end{array}$} & \multirow{2}{*}{$\begin{array}{l}\text { NNTH } \\
(95 \% \text { Cl) }\end{array}$} & \multirow{2}{*}{$\begin{array}{l}\text { Quality of the evidence } \\
\text { (GRADE) }\end{array}$} & \multirow{2}{*}{$\begin{array}{l}\text { Comments } \\
\text { (study authors' interpre- } \\
\text { tation) }\end{array}$} \\
\hline & Control & $\begin{array}{l}\text { Endometrial injury on } \\
\text { the day of oocyte re- } \\
\text { trieval }\end{array}$ & & & & & \\
\hline $\begin{array}{ll}\text { Live birth } & \text { per ran- } \\
\text { domly } & \text { assigned } \\
\text { woman } & \end{array}$ & 29 per 100 & $\begin{array}{l}9 \text { per } 100 \\
(4-20)\end{array}$ & $\begin{array}{l}\text { RR } \mathbf{0 . 3 1} \\
(0.14-0.69)\end{array}$ & $\begin{array}{l}156 \\
\text { (1 study) }\end{array}$ & $\begin{array}{l}5.0 \\
(4.0-11.1)\end{array}$ & $\begin{array}{l}\oplus \oplus \bigcirc \bigcirc \\
\text { Low }^{a}\end{array}$ & Harm \\
\hline $\begin{array}{l}\text { Clinical pregnancy } \\
\text { per randomly as- } \\
\text { signed woman }\end{array}$ & 33 per 100 & $\begin{array}{l}12 \text { per } 100 \\
(6-23)\end{array}$ & $\begin{array}{l}\text { RR } \mathbf{0 . 3 6} \\
(0.18-0.71)\end{array}$ & $\begin{array}{l}156 \\
\text { (1 study) }\end{array}$ & $\begin{array}{l}4.8 \\
(3.7-10.0)\end{array}$ & $\begin{array}{l}\oplus \oplus \bigcirc \bigcirc \\
\mathbf{L} \mathbf{w}^{a}\end{array}$ & Harm \\
\hline
\end{tabular}

*The assumed risk in the control group was determined as the median value across studies. The assumed risk in the endometrial injury group (and its $95 \% \mathrm{Cl}$ ) is based on the assumed risk in the comparison group and the relative effect of the intervention (and its $95 \% \mathrm{Cl}$ ).

Cl: Confidence interval; OR: oocyte retrieval; RR: Risk ratio; NNTH: number needed to treat for an additional harmful outcome.

GRADE Working Group grades of evidence.

High quality: Further research is very unlikely to change our confidence in the estimate of effect.

Moderate quality: Further research is likely to have an important impact on our confidence in the estimate of effect and may change the estimate.

Low quality: Further research is very likely to have an important impact on our confidence in the estimate of effect and is likely to change the estimate.

Very low quality: We are very uncertain about the estimate.

Both outcomes were downgraded by 2 levels because of very serious imprecision due to very large $95 \% \mathrm{Cl}$ and evidence from only 1

small study. 


\section{ISCUSSION}

\section{Summary of main results}

\section{Comparison I. Endometrial injury performed between day 7 of the previous cycle and day 7 of the ET cycle versus no injury}

Moderate-quality evidence indicates that endometrial injury performed between day 7 of the previous cycle and day 7 of the ET cycle, increases the likelihood of live birth/ongoing pregnancy and clinical pregnancy (Summary of findings for the main comparison). Although most of the included studies were deemed to be at high risk of 'other bias', sensitivity analysis performed while excluding those studies showed similar estimates. However, these estimates are somewhat imprecise and the true effect size is uncertain. Regarding evaluated adverse events, the estimates were very imprecise and therefore it was not possible to ascertain whether endometrial injury was related to harm, to no effect or to benefit for miscarriage (low-quality evidence) and multiple pregnancy (very low-quality evidence) (Summary of findings for the main comparison). Endometrial injury appears to be a somewhat painful procedure but does not appear to cause abnormal bleeding (Analysis 1.7; Analysis 1.8; very low-quality evidence).

\section{Comparison 2. Endometrial injury on the day of oocyte retrieval versus no injury}

When endometrial injury was performed on the day of oocyte retrieval, a moderate to large detrimental effect was observed on both live birth/ongoing pregnancy and clinical pregnancy (evidence of low quality; Summary of findings 2).

\section{Overall completeness and applicability of evidence}

Although endometrial injury was associated with an improvement in reproductive outcomes, the applicability of this evidence may vary in different subgroups of women.For example, the beneficial effect was observed only when endometrial injury was performed between day 7 of the previous cycle and day 7 of the ET cycle. No evidence is available regarding performance of the procedure before this period. Endometrial injury seems to have been detrimental when it was performed with a Novak curette on the day of oocyte retrieval. Additionally, although an overall benefit was observed, subgroup analysis suggests that endometrial injury might benefit only women with two or more previous failures. It does not appear that the procedure is beneficial in women undergoing their first or second cycle.

All of the included studies evaluated the effects of endometrial injury in women undergoing treatments that included controlled ovarian stimulation followed by IVF/ICSI and fresh embryo transfer. It follows that all conclusions must be restricted to this context, for example, no RCT has studied the effect of endometrial injury on non-stimulated cycles, with the transfer of cryopreserved or donated embryos or in cases of gestational surrogacy.

Moreover, the evidence compiled so far does not allow conclusions to be made about the number of procedures or the degree of disturbance needed to achieve an optimal effect, or the best timing of this intervention relative to the ART cycle or embryo transfer If any benefit was observed from multiple procedures compared with one procedure, this would have to be described in the context of the pain experienced by participants. Additionally, women with suspected or proven uterine anomalies were excluded from most studies, so these findings cannot be generalised to all women undergoing ART.

\section{Quality of the evidence}

We have included published and unpublished randomised clinical trials, resulting in 14 trials involving 2128 women; however, only clinical pregnancy was reported by all studies. For this reason, clinical pregnancy was considered to be an important outcome in this review, along with the primary outcomes of live birth and miscarriage.

\section{Endometrial injury between day 7 of the previous cycle and day 7 of the ET cycle versus control}

\section{Live birth or ongoing pregnancy and clinical pregnancy per randomly assigned woman}

The overall evidence for live birth or ongoing pregnancy and clinical pregnancy is of moderate quality. It was downgraded one level because of serious imprecision, as the $95 \%$ confidence intervals are wide and range from no clinically relevant effect/small effect to large benefit. Although most of the included studies were deemed to be at high risk of 'other bias', the sensitivity analysis removing those studies showed similar estimates; therefore evidence quality was not downgraded because of the quality of included studies.

\section{Miscarriage and multiple pregnancy per clinical pregnancy}

The overall evidence for the effect of endometrial injury on miscarriage and multiple pregnancy was graded as of low quality. It was downgraded two levels for very serious imprecision, as the $95 \%$ confidence intervals were very wide owing to very few events. It was downgraded one additional level because of the poor quality of the studies: all but one of the included studies were at high risk of 'other bias'; and a sensitivity analysis yielded only one study. 


\section{Pain and bleeding}

Evidence for these outcomes was considered of very low quality and was downgraded two levels because of serious imprecision, and one level because of study quality.

\section{Endometrial injury on the day of oocyte retrieval versus no injury}

\section{Live birth and ongoing pregnancy per randomly assigned woman}

Evidence for these outcomes was considered of low quality: It was downgraded two levels because of very serious imprecision due to few events from only one small study.

\section{Potential biases in the review process}

The review authors tried to avoid publication bias by conducting comprehensive searches, including searches of ongoing trial registers. Some ongoing trials were identified, and preliminary results from two of them were included; this might have introduced some sort of bias. We performed the sensitivity analysis while excluding these trials along with other trials deemed to be at high risk of bias. Restructuring of the comparisons may also have introduced bias, as included studies were reclassified. Additionally, all but one of the review authors (SB) are currently involved in clinical studies evaluating endometrial injury.

\section{Agreements and disagreements with other studies or reviews}

Overall, the effect of the intervention is greater in the observational studies than in the RCTs; such studies were included in other reviews, thus increasing the estimate of effect (El-Toukhy 2012; Potdar 2012) or the perception of effect (Almog 2010; Li 2009; Segev 2010) described by these review authors. Some discussion involved a possibly beneficial effect of interventions that cause unintentional endometrial injury (Nastri 2014b), as, for example, hysteroscopy (El-Toukhy 2014; Nastri 2014; Pundir 2014) or even intracervical procedures that might pass the internal os (Nastri 2013b).

\section{A U THORS' CONCLUSIONS}

\section{Implications for practice}

Endometrial injury before controlled ovarian stimulation, IVF/ ICSI and fresh embryo transfer is a somewhat painful procedure that appears to improve live birth/ongoing pregnancy and clinical pregnancy rates, without evidence of effect on miscarriage, multiple pregnancy or bleeding. However, endometrial injury on the day of oocyte retrieval seems to reduce clinical and ongoing pregnancy rates.

\section{Implications for research}

The body of evidence regarding the use of endometrial injury is growing, but several uncertainties remain.

\section{Population}

Although moderate-quality evidence shows a benefit of the intervention for live birth or ongoing pregnancy and clinical pregnancy, the extent of any beneficial effect seems to exist only in women with previous implantation failures. Further research is needed to confirm this observation. Further, the effect of endometrial injury in non-stimulated cycles, with transfer of cryopreserved or donated embryos, or in gestational surrogacy remains to be studied.

\section{Intervention}

It is not clear what would be the optimal degree of disturbance produced in the endometrium. In some studies, the procedure is performed in a mild manner using the more delicate Pipelle de Cornier, whilst in others, the procedure is performed in a more aggressive manner using the Novak curette, or by repeating the endometrial injury procedures. Additionally, the optimal time of endometrial injury relative to the date of embryo transfer or ART cycle is not clear.

\section{Comparison}

There may be important implications of these results for studies of other interventions that are not considered to be intentional endometrial injury, but do cause some injury to the endometrium (e.g. hysteroscopy, endometrial polyp resection, endometrial biopsies for other reasons). Future studies evaluating interventions which may cause some unintentional endometrial injury should consider using intentional endometrial injury as a control.

As blinding is considered less important for reproductive outcomes in the ART context, future studies might consider comparing endometrial injury versus no intervention rather than a sham procedure, or a sham procedure which does not involve any intracervical or intrauterine manipulation as this is a possible confounding factor that should be avoided.

\section{Outcomes}

Live birth and miscarriage were considered the primary outcomes for this review; however, they were not reported by all studies. In summary, we need additional evidence from well-designed trials that avoid instrumentation of the uterus in the preceding three 
months, do not cause endometrial injury in the control group, stratify the results for women with and without RIF and report live birth.

\section{ACKNOWLEDGEMENTS}

We would like to express our appreciation to Dra Abha Maheshwari for her important authorial contribution to the previous version of this review. We also acknowledge the important help provided by the Cochrane Menstrual Disorders and Subfertility Group team, specially by Marian Showell, Trials Search Co-ordinator; by Helen Nagels, Managing Editor; and by Prof. Cindy Farquhar, Co-ordinating Editor. Finally, we would like to express our gratitude to the following investigators, who provided essential information for the preparation of this review: TK Aleyamma, Erin F Wolff, Lukasz Polanski, Nava Dekel, Neeta Singh, Suleyman Guven and Tracy Yeung.

\section{R E F E R E N C E S}

\section{References to studies included in this review}

Aleyamma 2013 \{unpublished data only\}

Aleyamma TK, Acharya M. Local endometrial injury in women undergoing repeat in-vitro fertilization / intracytoplasmic sperm injection (IVF/ICSI)-embryo transfer (ET). Clinical Trials Registry - India 2013. [: CTRI/2013/04/003564]

Baum 2012 \{published data only\}

* Baum M, Yerushalmi GM, Maman E, Kedem A, Machtinger R, Hourvitz A, et al. Does local injury to the endometrium before IVF cycle really affect treatment outcome? Results of a randomized placebo controlled trial. Gynecological Endocrinology 2012;28(12):933-6. [PUBMED: 22943664]

Gibreel 2015 \{published and unpublished data\}

Gibreel A. Endometrial scratching prior to controlled ovarian stimulation $(\mathrm{COH})$ in women undergoing invitro fertilization with previous IVF failure (ESICOHF). ClinicalTrials.gov 2014. [: NCT01245309]

* Gibreel A, El-Adawi N, Elgindy E, Al-Inany H, Allakany $\mathrm{N}$, Tournaye H. Endometrial scratching for women with previous IVF failure undergoing IVF treatment. Gynecological Endocrinology 2015; [Epub ahead of print]. [PUBMED: 25561347]

Guven 2014 \{published and unpublished data\} Guven S, Kart C, Unsal MA, Yildirim O, Odaci E, Yulug E. Endometrial injury may increase the clinical pregnancy rate in normoresponders undergoing agonist protocol ICSI cycles with single embryo transfer. European Journal of Obstetrics \& Gynecology and Reproductive Biology 2014;173: 58-62. [PUBMED: 24289893]

Inal 2012 \{published data only\} Inal ZHO, Görkemli H, Inal HA. The effect of local injury to the endometrium for implantation and pregnancy rates in ICSI-ET cycles with implantation failure: a randomised controlled study. European Journal of General Medicine 2012;9(4):223-9.

Karimzade 2010 \{published data only\}

Karimzade MA, Oskouian H, Ahmadi S, Oskouian L. Local injury to the endometrium on the day of oocyte retrieval has a negative impact on implantation in assisted reproductive cycles: a randomized controlled trial. Archives of Gynecology and Obstetrics 2010;281(3):499-503. [PUBMED: 19568761]

Karim Zadeh 2008 \{published data only\} Karim Zadeh Meybodi M, Ayazi M, Tabibnejad N. Effect of endometrium local injury on pregnancy outcome in patients with IVF/ICSI. Human Reproduction 2008;23 (Suppl 1):i126.

\section{Karimzadeh 2009 \{published data only\}}

Karimzadeh MA, Ayazi Rozbahani M, Tabibnejad N. Endometrial local injury improves the pregnancy rate among recurrent implantation failure patients undergoing in vitro fertilisation/intra cytoplasmic sperm injection: a randomised clinical trial. The Australian and New Zealand Journal of Obstetrics and Gynaecology 2009;49(6):677-80. [PUBMED: 20070722]

Narvekar 2010 \{published data only\} Narvekar SA, Gupta N, Shetty N, Kottur A, Srinivas M, Rao KA. Does local endometrial injury in the nontransfer cycle improve the IVF-ET outcome in the subsequent cycle in patients with previous unsuccessful IVF? A randomized controlled pilot study. Journal of Human Reproductive Sciencess 2010;3(1):15-9. [PUBMED: 20607003]

Nastri 2013 \{published data only (unpublished sought but not used)\} Nastri CO, Ferriani RA, Martins WP. The effect of local injury to the endometrium performed previously to the ovulation induction in assisted reproduction techniques: preliminary report [Efeito da injúria local ao endométrio prévia a indução da ovulação em técnicas de reprodução assistida: resultados preliminares]. JBRA Assisted Reproduction 2011;15(5):54.

Nastri CO, Ferriani RA, Raine-Fenning N, Martins WP. Endometrial scratching performed in the non-transfer cycle and outcome of assisted reproduction: a randomized controlled trial. Ultrasound in Obstetrics and Gynecology 2013;42(4):375-82. [PUBMED: 23754314]

Polanski 2014 \{unpublished data only\}

Polanski LT, Raine-Fenning N. A study to assess if scratching the lining of the womb prior to IVF treatment 
increases the chances of pregnancy. ClinicalTrials.gov 2013. [: NCT01882842]

\section{Safdarian 2011 \{published data only\}}

Safdarian L, Movahedi S, Aleyasine A, Aghahosaini M, Fallah P, Rezaiian Z. Local injury to the endometrium does not improve the implantation rate in good responder patients undergoing in-vitro fertilization. Iranian Journal of Reproductive Medicine 2011;9(4):285-8.

Shohayeb 2012 \{published data only\}

Shohayeb A, El-Khayat W. Does a single endometrial biopsy regimen (S-EBR) improve ICSI outcome in patients with repeated implantation failure? A randomised controlled trial. European Journal of Obstetrics \& Gynecology and Reproductive Biology 2012;164(2):176-9. [PUBMED: 22835632]

Yeung 2014 \{published and unpublished data\} Yeung TW, Chai J, Li RH, Lee VC, Ho PC, Ng EH. The effect of endometrial injury on ongoing pregnancy rate in unselected subfertile women undergoing in vitro fertilization: a randomized controlled trial. Human Reproduction 2014;29(11):2474-81. [PUBMED: 25205759]

Yeung TWY, Chai J, Li RHW, Lee VCY, Ho PC, Ng EHY. The effect of endometrial injury on ongoing pregnancy rate in unselected subfertile women undergoing in-vitro fertilization: a randomized controlled trial. Human Reproduction 2014.

\section{References to studies excluded from this review}

Matsumoto 2014 \{published data only\} Matsumoto Y, Yata M, Ogata H, Ogata S, Kokeguchi S, Shiotani M. The effects of endometrial injury for frozen thawed blastocyst transfer in hormone replacement cycles. Fertility and Sterility 2014;102(Suppl):e56.

Yoldemir 2011 \{published data only\} Yoldemir T, Erenus M. Does the timing of mock embryo transfer trial improve implantation in intracytoplasmic sperm injection cycles?. Gynecological Endocrinology 2011; 27(6):396-400.

Zhou 2008 \{published data only (unpublished sought but not used)\} Zhou L, Li R, Wang R, Huang HX, Zhong K. Local injury to the endometrium in controlled ovarian hyperstimulation cycles improves implantation rates. Fertility and Sterility 2008;89(5):1166-76. [PUBMED: 17681303]

\section{References to studies awaiting assessment}

Hur 2012 \{published data only\} Hur CY, Lim KS, Shin YK, Kang YJ, Lee WD, Lim JH. Improving pregnancy rates by single local injury of the endometrium in patients undergoing fresh cycle in vitro fertilization. Building Consensus in Gynecology, Infertility and Perinatology - Controversies in Obstetrics, Gynecology and Infertility. Barcelona, Spain, 2012.

\section{References to ongoing studies}

\section{ACTRN12611001222932 \{unpublished data only\}}

McChesney P. A randomised, single blind controlled study assessing the effect of luteal phase pipelle endometrial

biopsy versus sham biopsy on live birth rate in women who are undergoing an IVF/ICSI cycle. Australian New Zealand Clinical Trials Registry (ACTRN) 2011.

\section{ACTRN12613001046796 \{unpublished data only\}} ACTRN12613001046796. A comparison of local endometrial trauma (LET) versus no trauma on failed implantation rates in IVF patients with recurrent implantation failure. Australian New Zealand Clinical Trials Registry (ACTRN) 2013.

\section{ACTRN12614000626662 \{published data only\}}

Lensen S. A randomised controlled trial assessing the effect of endometrial pipelle biopsy vs. no intervention on live birth rate in women undergoing autologous embryo transfer. ACTRN12614000626662 2014.

ChiCTR-TRC-12002389 \{unpublished data only\} Cheung ML, Chan C. The effect of local injury to the endometrium on pregnancy rate for patients undergoing natural-cycle frozen-thawed embryo transfer: a randomized study. Chinese Clinical Trial Register (ChiCTR) 2012.

\section{CTRI/2013/12/004206 \{unpublished data only\}}

Singh N, Varnit. To evaluate the role of endometrial scratching in the outcome of in vitro fertilisation cycles (IVF-ET). Clinical Trials Registry - India (CTRI) 2014. [: CTRI/2013/12/004206; : CTRI/2014/01/004307]

\section{ISRCTN63112626 \{unpublished data only\}}

$\mathrm{Ma}$ C. Effect of endometrial injury on repeat implantation failure following in vitro fertilization embryo transfer or frozen embryo transfer: a randomized controlled study. ISRCTN 2012.

NCT01064193 \{unpublished data only\} Benard A, Blancpain S. Impact of local biopsy to the endometrium prior to controlled ovarian stimulation on clinical pregnancy (NIDABRECHE). ClinicalTrials.gov 2013.

NCT01798862 \{unpublished data only\} Kreatsa M, Siristatidis C. Endometrial injury and IVF outcome parameters in patients with failed IVF cycles. ClinicalTrials.gov 2013.

NCT01800513 \{unpublished data only\} Wolff E. Endometrial biopsy prior to IVF in those patients with prior implantation failure (EMBX/IVF). ClinicalTrials.gov 2013.

NCT01844453 \{unpublished data only\} Nayot D, Tulandi T, Holzer H. Local endometrial injury in fresh embryo transfer cycles (LEI). ClinicalTrials.gov 2013.

\section{NCT01955356 \{unpublished data only\}} Vidal C. Embryo implantation after induced endometrial injury. ClinicalTrials.gov 2031.

\section{NCT01963819 \{unpublished data only\}}

Olesen MS, Forman A. Therapeutic endometrial biopsy. ClinicalTrials.gov 2014. 


\section{NCT01983423 \{unpublished data only\}}

Havelock JC, Liu K. Effect of endometrial biopsy on in vitro fertilization pregnancy rates - a multicenter study (EndoBx-IVF). ClinicalTrials.gov.

\section{NCT02061228 \{unpublished data only\}}

Santos-Ribeiro S. REFRESH: receptivity enhancement by follicular-phase renewal after endometrial scratching. ClinicalTrials.gov 2014.

\section{Additional references}

\section{Almog 2010}

Almog B, Shalom-Paz E, Dufort D, Tulandi T. Promoting implantation by local injury to the endometrium. Fertility and Sterility 2010;94(6):2026-9. [PUBMED: 20171615]

\section{Barash 2003}

Barash A, Dekel N, Fieldust S, Segal I, Schechtman E, Granot I. Local injury to the endometrium doubles the incidence of successful pregnancies in patients undergoing in vitro fertilization. Fertility and Sterility 2003;79(6): 1317-22. [PUBMED: 12798877]

\section{El-Toukhy 2012}

El-Toukhy T, Sunkara S, Khalaf Y. Local endometrial injury and IVF outcome: a systematic review and meta-analysis. Reproductive BioMedicine Online 2012;25(4):345-54. [PUBMED: 22885017]

\section{El-Toukhy 2014}

El-Toukhy T, Pundir J. Response: the overlooked endometrial injury underlying hysteroscopy procedures. Reproductive BioMedicine Online 2014;29(1):141. [PUBMED: 24857194]

\section{Gnainsky 2010}

Gnainsky Y, Granot I, Aldo PB, Barash A, Or Y, Schechtman E, et al. Local injury of the endometrium induces an inflammatory response that promotes successful implantation. Fertility and Sterility 2010;94(6):2030-6. [PUBMED: 20338560]

\section{Gunby 2010}

Gunby J, Bissonnette F, Librach C, Cowan L. Assisted reproductive technologies (ART) in Canada: 2006 results from the Canadian ART Register. Fertility and Sterility 2010;93(7):2189-201. [PUBMED: 19439295]

\section{Higgins 2011}

Higgins J, Green S, editors. Cochrane Handbook for Systematic Reviews of Interventions [Version 5.1.0]. The Cochrane Collaboration. www.cochrane-handbook.org, 2011.

Junovich 2011

Junovich G, Mayer Y, Azpiroz A, Daher S, Iglesias A, Zylverstein C, et al. Ovarian stimulation affects the levels of regulatory endometrial NK cells and angiogenic cytokine VEGF. American Journal of Reproductive Immunology 2011; 65(2):146-53. [PUBMED: 20618181]

\section{Lass 1998}

Lass A, Peat D, Avery S, Brinsden P. Histological evaluation of endometrium on the day of oocyte retrieval after gonadotrophin-releasing hormone agonist-follicle stimulating hormone ovulation induction for in-vitro fertilization. Human Reproduction 1998;13(11):3203-5. [PUBMED: 9853881]

\section{Li 2009}

Li R, Hao G. Local injury to the endometrium: its effect on implantation. Current Opinion in Obstetrics and Gynecology 2009;21(3):236-9. [PUBMED: 19352180]

\section{Luke 2012}

Luke B, Brown MB, Wantman E, Lederman A, Gibbons W, Schattman GL, et al. Cumulative birth rates with linked assisted reproductive technology cycles. The New England Journal of Medicine 2012;366(26):2483-9. [PUBMED: 22738098]

\section{Nastri 2013b}

Nastri CO, Teixeira DM, Martins WP. Endometrial injury in the menstrual cycle prior to assisted reproduction techniques to improve reproductive outcomes. Gynecological Endocrinology 2013;25(9):401-2. [PUBMED: 23339704]

\section{Nastri 2014}

Nastri CO, Teixeira DM, Ferriani RA, Martins WP. The overlooked endometrial injury underlying hysteroscopy procedures. Reproductive BioMedicine Online 2014;29(1): 140. [PUBMED: 24835342]

\section{Nastri 2014b}

Nastri CO, Polanski LT, Raine-Fenning N, Martins WP. Endometrial scratching for women with repeated implantation failure. Human Reproduction 2014;29(12): 2855-6. [PUBMED: 25316455]

\section{Polanski 2014}

Polanski LT, Baumgarten MN, Quenby S, Brosens J, Campbell BK, Raine-Fenning NJ. What exactly do we mean by 'recurrent implantation failure'? A systematic review and opinion. Reproductive BioMedicine Online 2014; 28(4):409-23. [PUBMED: 24581986]

\section{Potdar 2012}

Potdar N, Gelbaya T, Nardo LG. Endometrial injury to overcome recurrent embryo implantation failure: a systematic review and meta-analysis. Reproductive BioMedicine Online 2012;25(6):561-71. [PUBMED: 23063812]

\section{Pundir 2014}

Pundir J, Pundir V, Omanwa K, Khalaf Y, El-Toukhy T. Hysteroscopy prior to the first IVF cycle: a systematic review and meta-analysis. Reproductive BioMedicine Online 2014;28(2):151-61. [PUBMED: 24365027]

\section{Segev 2010}

Segev Y, Carp H, Auslender R, Dirnfeld M. Is there a place for adjuvant therapy in IVF?. Obstetrical and Gynecological Survey 2010;65(4):260-72. [PUBMED: 20403217]

\section{Siristatidis 2014}

Siristatidis C, Vrachnis N, Vogiatzi P, Chrelias C, Retamar AQ, Bettocchi S, et al. Potential pathophysiological mechanisms of the beneficial role of endometrial injury in 
in vitro fertilization outcome. Reproductive Sciences 2014; 21(8):955-65. [PUBMED: 24604231]

\section{Ubaldi 1997}

Ubaldi F, Bourgain C, Tournaye H, Smitz J, Van Steirteghem A, Devroey P. Endometrial evaluation by aspiration biopsy on the day of oocyte retrieval in the embryo transfer cycles in patients with serum progesterone rise during the follicular phase. Fertility and Sterility 1997; 67(3):521-6. [PUBMED: 9091341]

\section{Vail 2003}

Vail A, Gardener E. Common statistical errors in the design and analysis of subfertility trials. Human Reproduction 2003;18(5):1000-4. [PUBMED: 12721176]

\section{Zegers-Hochschild 2009}

Zegers-Hochschild F, Adamson GD, de Mouzon J, Ishihara O, Mansour R, Nygren K, et al. The International Committee for Monitoring Assisted Reproductive Technology (ICMART) and the World Health Organization (WHO) Revised Glossary on ART Terminology. Human Reproduction 2009;24(11):2683-7. [PUBMED: 19801627]

* Indicates the major publication for the study 


\title{
CHARACTERISTICS OF STUDIES
}

\section{Characteristics of included studies [ordered by study ID]}

\author{
Aleyamma 2013
}

Methods

2-parallel-group study conducted in India at a private university

Comparison: Endometrial injury vs No intervention

Participants

Inclusion criteria: age 21-38; FSH < 10; BMI 20-29 kg/m²; 1 previous failed IVF when at least 2 grade 1 embryos were transferred; suspected implantation failure

Exclusion criteria: poor responders ( $<4$ oocytes in a previous IVF cycle); local uterine pathology (adhesions, polyp, etc); endometriosis/adenomyosis; uterine malformations; systemic disease

Interventions

Study group: In addition to standard IVF protocol, women in this group underwent a Pipelle biopsy done twice in the luteal phase of the month before the start of controlled ovarian stimulation

Control group: no additional intervention

Outcomes

Live birth, clinical pregnancy, miscarriage, bleeding episodes

Notes

Ongoing trial, enrolment from 2008 to present, preliminary results included Age: study: $34 \pm 4.6$ years/control: $33.8 \pm 3.1$ years

Implantation: study: $27 \% /$ control: $22 \%$

\section{Risk of bias}

\begin{tabular}{|c|c|c|}
\hline Bias & Authors' judgement & Support for judgement \\
\hline $\begin{array}{l}\text { Random sequence generation (selection } \\
\text { bias) }\end{array}$ & Low risk & $\begin{array}{l}\text { Computer-generated block randomisation } \\
\text { method was used }\end{array}$ \\
\hline Allocation concealment (selection bias) & Low risk & $\begin{array}{l}\text { Sealed opaque envelopes was used for allo- } \\
\text { cation of randomisation sequences, which } \\
\text { would be opened after consent }\end{array}$ \\
\hline
\end{tabular}

Blinding of participants and personnel Low risk (performance bias)

All outcomes

Blinding of outcome assessment (detection Low risk bias)

All outcomes

Incomplete outcome data (attrition bias) Unclear risk All outcomes
No blinding was employed; however it is unlikely that blinding of participants and personnel would affect reproductive outcome measures

It is unlikely that blinding of outcome assessment would cause detection bias of reproductive outcomes

Loss of follow-up was not reported 


\section{Aleyamma 2013 (Continued)}

\begin{tabular}{|c|c|c|}
\hline Selective reporting (reporting bias) & Low risk & Outcomes were stated as in the protocol \\
\hline Other bias & High risk & $\begin{array}{l}\text { Preliminary reports described an ongoing } \\
\text { study }\end{array}$ \\
\hline
\end{tabular}

Baum 2012

\begin{tabular}{|c|c|c|}
\hline Methods & \multicolumn{2}{|c|}{$\begin{array}{l}\text { 2-parallel-group study conducted in Israel in an academic setting } \\
\text { Comparison: Endometrial injury vs No intervention }\end{array}$} \\
\hline Participants & \multicolumn{2}{|c|}{$\begin{array}{l}\text { Inclusion criteria: age } 18-41 \text {; diagnosis of RIF ( } 3 \text { or more unsuccessful cycles of IVF- } \\
\text { ET with good ovarian response in previous cycles); scheduled for IVF with fresh embryo } \\
\text { transfer on the next cycle } \\
\text { Exclusion criteria: uterine malformation; presence of endometrioma; ultrasound evi- } \\
\text { dence of hydrosalpinx }\end{array}$} \\
\hline Interventions & \multicolumn{2}{|c|}{$\begin{array}{l}\text { Study group: endometrial biopsy with a Pipelle de Cornier (Prodimed, Neuillyen-Thelle, } \\
\text { France) twice, on days } 9-12 \text { and } 21-24 \text { of the spontaneous menstrual cycle preceding } \\
\text { the IVF treatment cycle } \\
\text { Control group: Cervical Pipelle was done by introducing the biopsy catheter into the } \\
\text { cervix without scraping or taking a biopsy specimen } \\
\text { ART: IVF/ICSI }\end{array}$} \\
\hline Outcomes & \multicolumn{2}{|c|}{ Live birth, clinical pregnancy, miscarriage } \\
\hline Notes & \multicolumn{2}{|c|}{$\begin{array}{l}\text { Enrolment: July } 2006 \text {-June } 2009 \\
\text { Age: study: } 34.8 \pm 4.3 \text { years/control: } 34.4 \pm 5.4 \text { years } \\
\text { Implantation rate: study: } 2.08 \% / \text { control: } 11.11 \% \\
\text { Number of previous failures: study: } 8.5 \pm 3.5 / \text { control: } 8.8 \pm 4.6 \\
\text { Number of embryos transferred: study: } 2.9 \pm 1.2 / \text { control: } 2.9 \pm 0.7\end{array}$} \\
\hline \multicolumn{3}{|l|}{ Risk of bias } \\
\hline Bias & Authors' judgement & Support for judgement \\
\hline $\begin{array}{l}\text { Random sequence generation (selection } \\
\text { bias) }\end{array}$ & Low risk & Table of random numbers was used \\
\hline Allocation concealment (selection bias) & Unclear risk & $\begin{array}{l}\text { No attempt to conceal the table used was } \\
\text { described }\end{array}$ \\
\hline $\begin{array}{l}\text { Blinding of participants and personnel } \\
\text { (performance bias) } \\
\text { All outcomes }\end{array}$ & Low risk & $\begin{array}{l}\text { Participants were blinded by use of a cer- } \\
\text { vical Pipelle procedure. It is unlikely that } \\
\text { blinding of personnel would affect repro- } \\
\text { ductive outcomes }\end{array}$ \\
\hline
\end{tabular}


Baum 2012 (Continued)

\begin{tabular}{|c|c|c|}
\hline $\begin{array}{l}\text { Blinding of outcome assessment (detection } \\
\text { bias) } \\
\text { All outcomes }\end{array}$ & Low risk & $\begin{array}{l}\text { It is unlikely that blinding of outcome as- } \\
\text { sessment would cause detection bias of re- } \\
\text { productive outcomes }\end{array}$ \\
\hline $\begin{array}{l}\text { Incomplete outcome data (attrition bias) } \\
\text { All outcomes }\end{array}$ & Low risk & $\begin{array}{l}\text { Analysis as undertaken considered all } \\
\text { women randomly assigned }\end{array}$ \\
\hline Selective reporting (reporting bias) & Low risk & All expected outcomes were reported \\
\hline Other bias & High risk & $\begin{array}{l}\text { In the published protocol the study authors } \\
\text { scheduled to include } 70 \text { women in a cross- } \\
\text { over trial; however in the published study, } \\
\text { only } 36 \text { women were included and only } 1 \\
\text { phase of the study was described. Reasons } \\
\text { for the early stop are not stated } \\
\text { The sham procedure was performed by in- } \\
\text { serting a Pipelle into the cervix while try- } \\
\text { ing not to pass the internal os. By doing } \\
\text { this, researchers may have caused some de- } \\
\text { gree of unintentional endometrial injury; } \\
\text { this could have introduced a systematic er- } \\
\text { ror, altering the observed effect of the in- } \\
\text { tervention }\end{array}$ \\
\hline
\end{tabular}

Gibreel 2015

Methods

2-parallel-group study conducted in Egypt at 2 academic unit and 3 private centres Comparison: Endometrial injury vs No intervention

Participants

Inclusion criteria: women younger than 40 years of age with previous IVF failure undergoing IVF treatment

Exclusion criteria: women who were described as poor responders after previous IVF treatment (produced fewer than 3 oocytes after $\mathrm{COH}$ or had their cycles cancelled because of poor follicular growth); women with known endocrinopathy; women undergoing tubal disconnection for hydrosalpinx; history of endometrial curettage within 3 months of the study; fibroids and other uterine factors (polyps, adhesions)

Interventions

Study group: 2 endometrial scrapings with a Pipelle biopsy catheter between days 21 and 26 of the cycle before the IVF index cycle and after initiation of the GnRHa in long agonist protocols

Control group: placebo procedure using the uterine sound inserted into the cervix until the internal os on the same days of the cycle, as in women in the intervention group

OBS: When the Pipelle or the sound could not be introduced, a hysteroscopy was performed at the second appointment, in both groups

Outcomes

Live birth, clinical pregnancy, miscarriage, multiple pregnancy

Endometrial injury in women undergoing assisted reproductive techniques (Review)

Copyright (c) 2015 The Cochrane Collaboration. Published by John Wiley \& Sons, Ltd. 
Gibreel 2015 (Continued)

\begin{tabular}{|c|c|c|}
\hline Notes & \multicolumn{2}{|c|}{$\begin{array}{l}\text { Enrolment: December } 2010 \text { to May } 2013 \text { (finished and so far unpublished trial) } \\
\text { Age: study: } 30.2 \pm 4.2 \text { years/control: } 30.6 \pm 3.9 \text { years } \\
\text { Number of embryos transferred: study: } 1.7 \pm 0.42 / \text { control: } 1.8 \pm 0.37 \\
\text { Ahmed Gibreel is a co-author for both the Cochrane review and the included trial }\end{array}$} \\
\hline \multicolumn{3}{|l|}{ Risk of bias } \\
\hline Bias & Authors' judgement & Support for judgement \\
\hline $\begin{array}{l}\text { Random sequence generation (selection } \\
\text { bias) }\end{array}$ & Low risk & $\begin{array}{l}\text { Computer-generated table of random } \\
\text { numbers was used }\end{array}$ \\
\hline Allocation concealment (selection bias) & Low risk & Sealed opaque envelopes were used \\
\hline $\begin{array}{l}\text { Blinding of participants and personnel } \\
\text { (performance bias) } \\
\text { All outcomes }\end{array}$ & Low risk & Participants but not clinicians were blinded \\
\hline $\begin{array}{l}\text { Blinding of outcome assessment (detection } \\
\text { bias) } \\
\text { All outcomes }\end{array}$ & Low risk & $\begin{array}{l}\text { Outcome assessors were blinded to partic- } \\
\text { ipant assignment }\end{array}$ \\
\hline $\begin{array}{l}\text { Incomplete outcome data (attrition bias) } \\
\text { All outcomes }\end{array}$ & Low risk & $\begin{array}{l}\text { All randomly assigned women could be } \\
\text { analysed }\end{array}$ \\
\hline Selective reporting (reporting bias) & Low risk & All expected outcomes were reported \\
\hline Other bias & High risk & $\begin{array}{l}\text { By introducing a sound into the cervix un- } \\
\text { til the internal os - sham procedure - re- } \\
\text { searchers may have caused some degree of } \\
\text { unintentional endometrial injury. In addi- } \\
\text { tion, } 15 / 193 \text { women in the intervention } \\
\text { group and } 12 / 194 \text { in the control group un- } \\
\text { derwent hysteroscopy because of difficul- } \\
\text { ties associated with insertion of the device } \\
\text { It could have introduced a systematic error, } \\
\text { altering the observed effect of the interven- } \\
\text { tion }\end{array}$ \\
\hline
\end{tabular}

Guven 2014

Methods

2-parallel-group study conducted in Turkey in an academic setting

Comparison: Endometrial injury vs No intervention

Participants

Inclusion criteria: age < 35; history of primary infertility; normal responder (antral follicle count of 5 to 10 in 1 ovary at early follicular phase); grade I or II embryos for transfer, first IVF cycle

Exclusion criteria: endocrinopathies; any systemic disease; history of neoplasm; high risk

Endometrial injury in women undergoing assisted reproductive techniques (Review)

Copyright @ 2015 The Cochrane Collaboration. Published by John Wiley \& Sons, Ltd. 
for or history of ovarian hyperstimulation syndrome; use of any concurrent medication; failure to proceed to follicle retrieval; severe male infertility requiring testicular sperm aspiration; Mullerian tract anomalies; history of endometrial instrumentation or surgery within 1 month of the study; fibroids and other uterine factors (polyps, adhesions); lack of agreement to undergo endometrial biopsy during the $\mathrm{COH}$ cycle

Interventions

Study group: Endometrial injury was performed on day 3 of the menstrual cycle following downregulation; the scratching was done in 2 defined (anterior and posterior) portions of the uterine cavity under sterile conditions with the use of a biopsy catheter (Gynetics 4164 Probet Pipella, HD Aksu Medical, Ankara, Turkey)

Control group: no intervention

ART: ICSI (long protocol with leuprolide acetate)

Outcomes

Notes
Live birth, clinical pregnancy

Enrolment: September 2010 to April 2011

Age: study: $30.83 \pm 2.90$ years/control: $31.14 \pm 2.95$ years

BMI: study: $20.97 \pm 1.70 \mathrm{~kg} / \mathrm{m}^{2} /$ control: $21.55 \pm 1.55 \mathrm{~kg} / \mathrm{m}^{2}$

Single embryo transfer

6 women in the treatment group were excluded from the analysis as they had no embryos to transfer. They were included in our analyses per randomly assigned woman

\section{Risk of bias}

\section{Bias}

Random sequence generation (selection Low risk bias)

\begin{tabular}{ll}
\hline Allocation concealment (selection bias) & Low risk \\
\hline $\begin{array}{l}\text { Blinding of participants and personnel } \\
\text { (performance bias) }\end{array}$ & Low risk \\
All outcomes &
\end{tabular}

Blinding of outcome assessment (detection Low risk bias)

All outcomes

\begin{tabular}{l|ll}
\hline $\begin{array}{l}\text { Incomplete outcome data (attrition bias) } \\
\text { All outcomes }\end{array}$ & Low risk & $\begin{array}{l}\text { Study authors claim to have had no loss to } \\
\text { follow-up }\end{array}$ \\
\hline Selective reporting (reporting bias) & Low risk & All expected outcomes were reported \\
\hline Other bias & Low risk & Not suspected \\
\hline
\end{tabular}

\section{Support for judgement}

Computer-assisted randomisation was performed (non-published information)

Sealed envelopes were used

No blinding was employed; however it is unlikely that blinding of participants and personnel would affect reproductive outcome measures

No blinding was employed; however it is unlikely that blinding would affect outcome measures

Study authors claim to have had no loss to . .

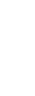


Methods

2-parallel-group study conducted in Turkey in an academic setting Comparison: Endometrial injury vs No intervention

Participants

Inclusion criteria: women considered to be good responders to hormonal stimulation who failed to conceive during 1 or more cycles of IVF and embryo transfer (ET); age between 25 and 36 years

Exclusion criteria: hydrosalpinx; thrombophilia; submucous myoma and factors found to have a negative impact on implantation

Interventions

Study group: 2 consecutive endometrial biopsies at 1-week intervals during the luteal phase of the non-transfer cycle, when on GnRH analogue for downregulation. Endometrial biopsy was performed with a biopsy catheter (Pipelle de Cornier, Prodimed, Neuillyen-Thelle, France) introduced through the cervical os and rotated within the uterine cavity 3-4 times after withdrawal of the piston. Antibiotics were administered after the procedure

Control group: no intervention

ART: ICSI (long protocol with leuprolide acetate)

\begin{tabular}{|c|c|}
\hline Outcomes & Live birth, clinical pregnancy \\
\hline \multirow[t]{7}{*}{ Notes } & Enrolment: Jamuary 2008-March 2009 \\
\hline & Age: study: $29.6 \pm 3.8$ years/control: $30.8 \pm 4.5$ years \\
\hline & Implantation rate: study: $34.67 \% /$ control: $30.88 \%$ \\
\hline & The number of embryos transferred is not clear; however study authors state that it was \\
\hline & similar between groups \\
\hline & Study authors did not reply to e-mails sent to the institution \\
\hline & $\begin{array}{l}\text { Although the intervention model was described as cross-over in the published protocol, } \\
\text { the study was described as a parallel-group study }\end{array}$ \\
\hline
\end{tabular}

Risk of bias

\begin{tabular}{lll}
\hline Bias & Authors judgement & Support for judgement \\
\hline $\begin{array}{l}\text { Random sequence generation (selection } \\
\text { bias) }\end{array}$ & Low risk & $\begin{array}{l}\text { Computer-generated random } \\
\text { were used }\end{array}$ \\
\hline $\begin{array}{l}\text { Allocation concealment (selection bias) } \\
\text { Blinding of participants and personnel } \\
\text { (performance bias) } \\
\text { All outcomes }\end{array}$ & Low risk & $\begin{array}{l}\text { No attempt to conceal the sequence used } \\
\text { was described }\end{array}$ \\
\hline
\end{tabular}

Blinding of outcome assessment (detection Low risk bias)

All outcomes
No blinding was employed; however it is unlikely that blinding would affect outcome measures 


\section{Inal 2012 (Continued)}

\begin{tabular}{lll}
\hline $\begin{array}{l}\text { Incomplete outcome data (attrition bias) } \\
\text { All outcomes }\end{array}$ & Low risk & $\begin{array}{l}\text { Analysis as undertaken considered all ran- } \\
\text { domly assigned women }\end{array}$ \\
\hline Selective reporting (reporting bias) & Low risk & All expected outcomes were reported \\
\hline Other bias & Low risk & No other source of bias was identified \\
\hline
\end{tabular}

Karim Zadeh 2008

\begin{tabular}{ll} 
Methods & $\begin{array}{l}\text { 2-parallel-group study conducted in Iran in an academic setting } \\
\text { Comparison: Endometrial injury vs No intervention }\end{array}$ \\
\hline Participants & $\begin{array}{l}\text { Inclusion criteria: at least } 2 \text { prior implantation failures } \\
\text { Exclusion criteria: none mentioned }\end{array}$ \\
\hline Interventions & $\begin{array}{l}\text { Study group: Novak endometrial suction curettage during the secretory phase in a non- } \\
\text { medicated cycle before IVF/ICSI } \\
\text { Control group: no intervention } \\
\text { ART: IVF/ICSI; long protocol; Buserelin used for all }\end{array}$ \\
\hline Outcomes & \begin{tabular}{l} 
Clinical pregnancy \\
\hline Notes
\end{tabular} \\
$\begin{array}{l}\text { Age: overall mean: } 35 \pm 6.7 \text { years } \\
\text { Embryos transferred: overall mean: } 2.0 \pm 0.6 \\
\text { Implantation rate: study: } 42.4 \pm 7.8 \% / \text { control: } 39.6 \pm 5.4 \% \\
\text { The study found no significant differences and was published only as a conference abstract }\end{array}$ \\
\hline
\end{tabular}

\section{Risk of bias}

\begin{tabular}{l|l|l}
\hline Bias & Authors judgement & Support for judgement \\
\hline $\begin{array}{l}\text { Random sequence generation (selection } \\
\text { bias) }\end{array}$ & Unclear risk & $\begin{array}{l}\text { Method of randomisation was not de- } \\
\text { scribed }\end{array}$ \\
\hline $\begin{array}{l}\text { Allocation concealment (selection bias) } \\
\text { Blinding of participants and personnel } \\
\text { (performance bias) } \\
\text { All outcomes }\end{array}$ & Low risk & $\begin{array}{l}\text { Method of randomisation was not de- } \\
\text { scribed }\end{array}$ \\
\hline
\end{tabular}

Blinding of outcome assessment (detection Low risk bias)

All outcomes

Incomplete outcome data (attrition bias) Low risk All outcomes
No blinding was employed; however it is unlikely that blinding would affect outcome measures

Analysis as undertaken considered all randomly assigned women 
Karim Zadeh 2008 (Continued)

\begin{tabular}{|c|c|c|}
\hline Selective reporting (reporting bias) & Unclear risk & $\begin{array}{l}\text { Neither live birth nor miscarriage was re- } \\
\text { ported }\end{array}$ \\
\hline Other bias & High risk & $\begin{array}{l}\text { Published only as a conference abstract; } \\
\text { no further information could be retrieved } \\
\text { from study authors }\end{array}$ \\
\hline
\end{tabular}

Karimzade 2010

Methods

2-parallel-group study conducted in Iran in an academic setting

Comparison: Endometrial injury vs No intervention

Participants

Inclusion criteria: age $<38$ years; BMI $>19 \mathrm{~kg} / \mathrm{m}^{2}$ and $<30 \mathrm{~kg} / \mathrm{m}^{2}$; day $3 \mathrm{FSH}<$ $12 \mathrm{mIU} / \mathrm{mL}$; triple-layer endometrium with thickness $>8 \mathrm{~mm}$ on the day of hCG administration; normal ovarian response to COH (E2 on the day of hCG between 500 and $3000 \mathrm{pg} / \mathrm{mL}$ and between 4 and 14 retrieved oocytes

Exclusion criteria: any uterine anomaly such as myoma and endometrial polyp on USTV; endometrioma with a diameter $>3 \mathrm{~cm}$; visible hydrosalpinges

Interventions

Study group: 1 endometrial injury procedure using Novak curette on the day of oocyte retrieval

Control group: no intervention

Outcomes Ongoing pregnancy, clinical pregnancy

As this study did not report live birth, ongoing pregnancy was used as a surrogate for the outcome

Notes

Age: study: $29.3 \pm 3$ years/control: $28.5 \pm 3.3$ years

BMI: study: $23.3 \pm 2.4 \mathrm{~kg} / \mathrm{m}^{2} /$ control: $23.7 \pm 2.5 \mathrm{~kg} / \mathrm{m}^{2}$

Number of embryos transferred: study: $2.2 \pm 0.4 /$ control: $2.1 \pm 0.3$

Implantation rate: study: $7.9 \% /$ control: $22.9 \%$

Enrolment: June 2008 to January 2009

Study was stopped early because of significant reduction in successful outcomes

Risk of bias

\begin{tabular}{l|ll} 
Bias & Authors' judgement & Support for judgement \\
\hline $\begin{array}{l}\text { Random sequence generation (selection } \\
\text { bias) }\end{array}$ & Unclear risk & $\begin{array}{l}\text { Method of randomisation was not de- } \\
\text { scribed }\end{array}$ \\
\hline Allocation concealment (selection bias) & Unclear risk & $\begin{array}{l}\text { Method of randomisation was not de- } \\
\text { scribed }\end{array}$ \\
\hline
\end{tabular}

Blinding of participants and personnel Low risk (performance bias)

All outcomes

No blinding was employed; however it is unlikely that blinding of participants and personnel would affect reproductive outcome measures 
Karimzade 2010 (Continued)

\begin{tabular}{ll|l}
$\begin{array}{l}\text { Blinding of outcome assessment (detection } \\
\text { bias) } \\
\text { All outcomes }\end{array}$ & Low risk & $\begin{array}{l}\text { No blinding was employed; however it is } \\
\text { unlikely that blinding would affect out- } \\
\text { come measures }\end{array}$ \\
\hline $\begin{array}{l}\text { Incomplete outcome data (attrition bias) } \\
\text { All outcomes }\end{array}$ & Low risk & $\begin{array}{l}\text { Analysis as undertaken considered all ran- } \\
\text { domly assigned women }\end{array}$ \\
\hline $\begin{array}{l}\text { Selective reporting (reporting bias) } \\
\text { Other bias }\end{array}$ & Low risk & $\begin{array}{l}\text { Miscarriage was not reported; however the } \\
\text { study was stopped early because of reduc- } \\
\text { tion in successful outcomes }\end{array}$ \\
\hline
\end{tabular}

Karimzadeh 2009

\begin{tabular}{ll} 
Methods & $\begin{array}{l}\text { 2-parallel-group study conducted in Iran in an academic setting } \\
\text { Comparison: Endometrial injury vs No intervention }\end{array}$ \\
\hline Participants & $\begin{array}{l}\text { Inclusion criteria: age between } 20 \text { and } 40 \text { years; no history of blood disease; recurrent } \\
\text { implantation failure (defined as } 2 \text { to } 6 \text { unsuccessful cycles of IVF-ET with previous } \\
\text { transfer of at least } 10 \text { high-grade embryos without achievement of clinical pregnancy) } \\
\text { Exclusion criteria: age }>40 \text { years; poor response in previous cycles (defined as day } 3 \mathrm{FSH} \\
>10 \text { IU mL or }<4 \text { follicles on the day of hCG in previous cycle); uterine malformation; } \\
\text { presence of endometrioma; ultrasound evidence of hydrosalpinx }\end{array}$ \\
\hline
\end{tabular}

Interventions

Study group: 1 endometrial injury procedure using Pipelle de Cornier on days 21-26 of spontaneous cycle

Control group: no intervention

\begin{tabular}{ll}
\hline Outcomes & Clinical pregnancy \\
\hline \multirow{2}{*}{ Notes } & Age: study: $29.96 \pm 3.93$ years/control: $29.73 \pm 3.92$ years \\
& $\begin{array}{l}\text { Number of embryos transferred: study: } 2.48 \pm 0.77 / \text { control: } 2.65 \pm 0.86 \\
\text { Implantation rate: study: } 10.9 \% / \text { control: } 3.4 \%\end{array}$ \\
\hline
\end{tabular}

Risk of bias

\begin{tabular}{l|ll}
\hline Bias & Authors' judgement & Support for judgement \\
\hline $\begin{array}{l}\text { Random sequence generation (selection } \\
\text { bias) }\end{array}$ & Low risk & $\begin{array}{l}\text { A piece of paper was drawn from a bag con- } \\
\text { taining equal numbers of printed pages for } \\
\text { each method }\end{array}$ \\
\hline $\begin{array}{l}\text { Allocation concealment (selection bias) } \\
\text { Blinding of participants and personnel } \\
\text { (performance bias) } \\
\text { All outcomes }\end{array}$ & Low risk & A piece of paper was drawn from a bag \\
\hline
\end{tabular}

Endometrial injury in women undergoing assisted reproductive techniques (Review)

Copyright @ 2015 The Cochrane Collaboration. Published by John Wiley \& Sons, Ltd. 
come measures

Blinding of outcome assessment (detection Low risk bias)

All outcomes

Incomplete outcome data (attrition bias) Low risk All outcomes

Selective reporting (reporting bias) Unclear risk
No blinding was employed; however it is unlikely that blinding would affect outcome measures

Analysis as undertaken considered all randomly assigned women

Study authors did not report either miscarriage or live birth

No other source of bias was identified

\section{Narvekar 2010}

\begin{tabular}{ll}
\hline Methods & $\begin{array}{l}\text { 2-parallel-group study conducted in India at a private clinic } \\
\text { Comparison: Higher vs lower degree of endometrial injury }\end{array}$ \\
\hline Participants & $\begin{array}{l}\text { Inclusion criteria: } \text { women with at least } 1 \text { previous ART-ET failure; good responders in } \\
\text { the previous IVF cycle (development of at least } 4 \text { good-quality embryos); } \leq 37 \text { years } \\
\text { Exclusion criteria: endometrial tuberculosis in the past; intramural fibroid distorting the } \\
\text { endometrial cavity/submucous myoma; Asherman's syndrome; evidence of hydrosalpinx }\end{array}$ \\
\hline Interventions & $\begin{array}{l}\text { Study group: } 2 \text { endometrial injury procedures using Pipelle de Cornier: The first was } \\
\text { done along with hysteroscopy on days } 7-10, \text { and the second on days } 24-25 \text { of the cycle } \\
\text { before ART-ET } \\
\text { Control group: hysteroscopy on days } 7-10\end{array}$ \\
\hline Outcomes & \begin{tabular}{l} 
Live birth, clinical pregnancy, miscarriage \\
\hline Notes
\end{tabular} \\
\hline $\begin{array}{l}\text { Age: study: } 32.1 \pm 3.4 \text { years/control: } 32.3 \pm 3.3 \text { years } \\
\text { BMI: study: } 25.2 \pm 2.8 \mathrm{~kg} / \mathrm{m}^{2} / \text { control: } 25.9 \pm 3.8 \mathrm{~kg} / \mathrm{m}^{2} \\
\text { Number of embryos transferred: study: } 3.4 \pm 0.5 / \text { control: } 3.3 \pm 0.5 \\
\text { Implantation rate: study: } 13.1 \% / \text { control: } 7.1 \%\end{array}$ \\
$\begin{array}{l}\text { Enrolment: May } 2007 \text { to July } 2008 \\
\text { Numbers of previous attempts were } 2.3 \pm 0.52 \text { and } 2.5 \pm 0.7 \text {, so the study was classified } \\
\text { in the subgroup 'Two or more previous failures' }\end{array}$ \\
\hline
\end{tabular}

\section{Risk of bias}

\begin{tabular}{lll} 
Bias & Authors' judgement & Support for judgement \\
\hline $\begin{array}{l}\text { Random sequence generation (selection } \\
\text { bias) }\end{array}$ & Low risk & $\begin{array}{l}\text { Computer-generated random numbers } \\
\text { were used }\end{array}$ \\
\hline Allocation concealment (selection bias) & Low risk & $\begin{array}{l}\text { Sealed and consecutively numbered opaque } \\
\text { envelopes were used }\end{array}$
\end{tabular}




\section{Narvekar 2010 (Continued)}

\begin{tabular}{l|l|l}
$\begin{array}{l}\text { Blinding of participants and personnel } \\
\text { (performance bias) } \\
\text { All outcomes }\end{array}$ & Low risk & $\begin{array}{l}\text { No blinding was employed; however it is } \\
\text { unlikely that blinding of participants and } \\
\text { personnel would affect reproductive out- } \\
\text { come measures }\end{array}$ \\
\hline $\begin{array}{l}\text { Blinding of outcome assessment (detection } \\
\text { bias) } \\
\text { All outcomes }\end{array}$ & Low risk & $\begin{array}{l}\text { No blinding was employed; however it is } \\
\text { unlikely that blinding would affect out- } \\
\text { come measures }\end{array}$ \\
\hline $\begin{array}{l}\text { Incomplete outcome data (attrition bias) } \\
\text { All outcomes }\end{array}$ & Low risk & No loss to follow-up was reported \\
\hline Selective reporting (reporting bias) & Low risk & $\begin{array}{l}\text { Outcomes were reported according to the } \\
\text { published protocol }\end{array}$ \\
\hline Other bias & High risk & $\begin{array}{l}\text { Both groups underwent hysteroscopy after } \\
\text { they were randomly assigned for the trial. } \\
\text { Hysteroscopy in the control group caused } \\
\text { some degree of unintentional endometrial } \\
\text { injury; this could have introduced a system- } \\
\text { atic error, altering the observed effect of the } \\
\text { intervention }\end{array}$ \\
\hline
\end{tabular}

Nastri 2013

Methods

Participants

Interventions 2-parallel-group study conducted in Brazil in an academic setting

Comparison: Endometrial injury vs No intervention
Inclusion criteria: all women undergoing ART with planned fresh embryo transfer aged $<38$ years

Exclusion criteria: none

Study group: 1 endometrial injury procedure with Pipelle de Cornier, 7 to 14 days before the start of ovulation induction

Control group: sham procedure comprising drying of the cervix

ART: IVF/ICSI. Women were using combined oral contraceptives at the moment of procedures

Outcomes

Live birth, clinical pregnancy, miscarriage, multiple pregnancy, pain, bleeding
Age: study: $32.4 \pm 3.2$ years/control: $32.1 \pm 3.1$ years

Number of embryos transferred: similar between groups (numbers given as frequency) Implantation rate: study: $35.82 \% /$ control: $21.32 \%$

Enrolment: June 2010 to March 2012

\section{Risk of bias}

Bias

Authors' judgement

Support for judgement

Endometrial injury in women undergoing assisted reproductive techniques (Review)

Copyright $\Subset 2015$ The Cochrane Collaboration. Published by John Wiley \& Sons, Ltd. 


\section{Nastri 2013 (Continued)}

\begin{tabular}{|c|c|c|}
\hline $\begin{array}{l}\text { Random sequence generation (selection } \\
\text { bias) }\end{array}$ & Low risk & $\begin{array}{l}\text { Computer-generated random numbers } \\
\text { were used }\end{array}$ \\
\hline Allocation concealment (selection bias) & Low risk & $\begin{array}{l}\text { Sealed envelopes were used; information } \\
\text { was obtained from the previously published } \\
\text { protocol }\end{array}$ \\
\hline $\begin{array}{l}\text { Blinding of participants and personnel } \\
\text { (performance bias) } \\
\text { All outcomes }\end{array}$ & Low risk & Participants and personnel were blinded \\
\hline $\begin{array}{l}\text { Blinding of outcome assessment (detection } \\
\text { bias) } \\
\text { All outcomes }\end{array}$ & Low risk & Outcome assessors were blinded \\
\hline $\begin{array}{l}\text { Incomplete outcome data (attrition bias) } \\
\text { All outcomes }\end{array}$ & Low risk & $\begin{array}{l}\text { Analysis as undertaken considered all ran- } \\
\text { domly assigned women }\end{array}$ \\
\hline Selective reporting (reporting bias) & Low risk & $\begin{array}{l}\text { Outcomes were reported according to the } \\
\text { published protocol }\end{array}$ \\
\hline Other bias & Low risk & No other source of bias was identified \\
\hline
\end{tabular}

\section{Polanski 2014}

$\begin{array}{ll}\text { Methods } & \text { 2-parallel-group study conducted in the United Kingdom in an academic setting } \\ \text { Comparison: Endometrial injury vs No intervention }\end{array}$

Comparison: Endometrial injury vs No intervention

Participants

Inclusion criteria: women younger than 49 years with history of primary or secondary infertility undergoing fresh IVF/ICSI treatment or frozen embryo replacement cycle

Exclusion criteria: non-ovulatory cycle; absent uterus; uterine instrumentation within previous 3 menstrual cycles; women in the oocyte donation programme

Interventions

Study group: endometrial biopsy procedure using Pipelle endometrial sampler (Pipelle de Cornier, Laboratoire CCD, Paris, France) or Wallace/Wallach endometrial sampler as an alternative device; ultrasound performed before the procedure. Procedure performed on cycle day $\mathrm{LH}+7$ to $\mathrm{LH}+9$ of the cycle directly preceding commencement of downregulation before IVF or ICSI treatment

Control group: no intervention

ART: IVF/ICSI

Outcomes

Clinical pregnancy, miscarriage

Notes

Age: study: $33.5 \pm 3.9$ years/control: $32.6 \pm 4.2$ years

BMI: study: $26.5 \pm 3.8 \mathrm{~kg} / \mathrm{m}^{2} /$ control: $26.9 \pm 3.2 \mathrm{~kg} / \mathrm{m}^{2}$

Implantation rate: study: $63.8 \% /$ control: $38.2 \%$

Enrolment: February 2013 to present 
Polanski 2014 (Continued)

\section{Risk of bias}

\begin{tabular}{l|l|l}
\hline Bias & Authors' judgement & Support for judgement \\
\hline $\begin{array}{l}\text { Random sequence generation (selection } \\
\text { bias) }\end{array}$ & Low risk & $\begin{array}{l}\text { A computer-generated pseudo-random } \\
\text { code used random permuted blocks of ran- } \\
\text { domly varying size; } 1: 1 \text { randomisation ra- } \\
\text { tio was based on date of birth only }\end{array}$ \\
\hline Allocation concealment (selection bias) & Low risk & $\begin{array}{l}\text { Participants were told the allocation on the } \\
\text { day of the procedure }\end{array}$ \\
\hline
\end{tabular}

Blinding of participants and personnel Low risk (performance bias)

No blinding was employed; however it is All outcomes unlikely that blinding of participants and personnel would affect reproductive outcome measures

Blinding of outcome assessment (detection Low risk bias)

No blinding was employed; however it is unlikely that blinding of outcome assessors

All outcomes would affect reproductive outcome measures

Incomplete outcome data (attrition bias) Low risk All outcomes

Analysis as undertaken considered all randomly assigned women

Selective reporting (reporting bias) Low risk

Live birth was not reported because of the time frame

Other bias

High risk

Ongoing trial with preliminary results

Safdarian 2011

Methods

2-parallel-group study conducted in Iran in an academic setting

Comparison: Endometrial injury vs No intervention

Participants

Inclusion criteria: 20 - to 39-year-old infertile women who were referred to the fertility centre

Exclusion criteria: women older than 39 years of age; FSH > 11; endometriosis; hypothalamic amenorrhoea; azoospermic male

Interventions

Study group: endometrial biopsy with a Pipelle de Cornier (Prodimed, Neuilly-enThelle, France) on day 21 of previous menstrual cycle with use of contraceptive pill before IVF-ET treatment

Control group: no intervention

ART: IVF

Outcomes

Clinical pregnancy 
Safdarian 2011 (Continued)

\begin{tabular}{|c|c|c|}
\hline Notes & \multicolumn{2}{|c|}{$\begin{array}{l}\text { Age: study: } 29 \pm 4.6 \text { years/control: } 30.2 \pm 4.8 \text { years } \\
\text { BMI: study: } 26.5 \pm 3.8 \mathrm{~kg} / \mathrm{m}^{2} / \text { control: } 26.9 \pm 3.2 \mathrm{~kg} / \mathrm{m}^{2} \\
\text { Number of embryos transferred: study: } 3.7 / \text { control: } 3.6 \\
\text { Impantation rates: study: } 4.9 \% / \text { control: } 6.7 \% \\
\text { Enrolment: July } 2008 \text { to March } 2009\end{array}$} \\
\hline \multicolumn{3}{|l|}{ Risk of bias } \\
\hline Bias & Authors' judgement & Support for judgement \\
\hline $\begin{array}{l}\text { Random sequence generation (selection } \\
\text { bias) }\end{array}$ & Unclear risk & $\begin{array}{l}\text { Computerised; participants were randomly } \\
\text { selected on the basis of agreement to un- } \\
\text { dergo endometrial biopsy expressed in a } \\
\text { written informed consent before the start } \\
\text { of the IVF cycle }\end{array}$ \\
\hline Allocation concealment (selection bias) & Unclear risk & $\begin{array}{l}\text { No attempt to conceal the selection used } \\
\text { was described }\end{array}$ \\
\hline $\begin{array}{l}\text { Blinding of participants and personnel } \\
\text { (performance bias) } \\
\text { All outcomes }\end{array}$ & Low risk & $\begin{array}{l}\text { No blinding was reported; however it is un- } \\
\text { likely that blinding of participants and per- } \\
\text { sonnel would affect reproductive outcome } \\
\text { measures }\end{array}$ \\
\hline $\begin{array}{l}\text { Blinding of outcome assessment (detection } \\
\text { bias) } \\
\text { All outcomes }\end{array}$ & Low risk & $\begin{array}{l}\text { No blinding was employed; however it is } \\
\text { unlikely that blinding of outcome assessors } \\
\text { would affect reproductive outcome mea- } \\
\text { sures }\end{array}$ \\
\hline $\begin{array}{l}\text { Incomplete outcome data (attrition bias) } \\
\text { All outcomes }\end{array}$ & Low risk & $\begin{array}{l}\text { Analysis as undertaken considered all ran- } \\
\text { domly assigned women }\end{array}$ \\
\hline Selective reporting (reporting bias) & Unclear risk & $\begin{array}{l}\text { Study authors did not report live birth or } \\
\text { miscarriage. No protocol was available and } \\
\text { no adverse effects were reported }\end{array}$ \\
\hline Other bias & Unclear risk & The whole study is under-reported \\
\hline
\end{tabular}

\section{Shohayeb 2012}

$\begin{array}{ll}\text { Methods } & \text { 2-parallel-group study conducted in Egypt and Saudia Arabia in both academic and } \\ \text { private settings } \\ \text { Comparison: Higher vs lower degree of endometrial injury }\end{array}$

Participants

Inclusion criteria: women with history of 2 or more failed ICSI cycles despite transfer of high-quality embryos; normal thin endometrium $(<5 \mathrm{~mm})$ on day 4 of menstruation; younger than 39 years of age

Exclusion criteria: abnormal endometrial cavity (submucous myoma encroaching on the 
Shohayeb 2012 (Continued)

cavity, endometrial polyp, intrauterine synechia); septate or bicornuate uterus diagnosed by transvaginal ultrasound or by hysterosalpingography

Interventions

Study group: Hysteroscopy and endometrial scraping were done once in the follicular phase at days 4-7 (D4-D7) in the cycle preceding the embryo transfer cycle using a Novak curette

Control group: Hysteroscopy was done without endometrial scraping ART: ICSI

\begin{tabular}{ll} 
Outcomes & Live birth, clinical pregnancy, miscarriage \\
\hline \multirow{2}{*}{ Notes } & Age: study: $30.7 \pm 4.5$ years/control: $30.6 \pm 4.5$ years \\
& BMI: study: $26.5 \pm 3.8 \mathrm{~kg} / \mathrm{m}^{2} /$ control: $26.9 \pm 3.2 \mathrm{~kg} / \mathrm{m}^{2}$ \\
& Number of embryos transferred: study: $3.2 \pm 0.6 /$ control: $3.3 \pm 0.5$ embryos \\
& Implantation rate: study: $12 \% /$ control: $7 \%$
\end{tabular}

Risk of bias

\begin{tabular}{|c|c|c|}
\hline Bias & Authors' judgement & Support for judgement \\
\hline $\begin{array}{l}\text { Random sequence generation (selection } \\
\text { bias) }\end{array}$ & Low risk & $\begin{array}{l}\text { Computer-generated random numbers } \\
\text { were used }\end{array}$ \\
\hline Allocation concealment (selection bias) & Low risk & Opaque sealed envelopes were used \\
\hline $\begin{array}{l}\text { Blinding of participants and personnel } \\
\text { (performance bias) } \\
\text { All outcomes }\end{array}$ & Low risk & $\begin{array}{l}\text { No blinding was reported; however it is un- } \\
\text { likely that blinding of participants and per- } \\
\text { sonnel would affect reproductive outcome } \\
\text { measures }\end{array}$ \\
\hline $\begin{array}{l}\text { Blinding of outcome assessment (detection } \\
\text { bias) } \\
\text { All outcomes }\end{array}$ & Low risk & $\begin{array}{l}\text { No blinding was employed; however it is } \\
\text { unlikely that blinding of outcome assessors } \\
\text { would affect reproductive outcome mea- } \\
\text { sures }\end{array}$ \\
\hline $\begin{array}{l}\text { Incomplete outcome data (attrition bias) } \\
\text { All outcomes }\end{array}$ & Low risk & $\begin{array}{l}\text { Analysis as undertaken considered all ran- } \\
\text { domly assigned women }\end{array}$ \\
\hline Selective reporting (reporting bias) & Low risk & All expected outcomes were reported \\
\hline Other bias & High risk & $\begin{array}{l}\text { Both groups underwent hysteroscopy after } \\
\text { they were randomly assigned for the trial. } \\
\text { Hysteroscopy in the control group caused } \\
\text { some degree of unintentional endometrial } \\
\text { injury; this could have introduced a system- } \\
\text { atic error, altering the observed effect of the } \\
\text { intervention }\end{array}$ \\
\hline
\end{tabular}




\begin{tabular}{|c|c|}
\hline Methods & $\begin{array}{l}\text { 2-parallel-group study conducted in Hong Kong } \\
\text { Comparison: Endometrial injury vs No intervention }\end{array}$ \\
\hline Participants & $\begin{array}{l}\text { Inclusion criteria: women undergoing IVF for tubal; unexplained or male factor sub- } \\
\text { fertility with normal uterine cavity as shown on saline sonography/hysteroscopy done at } \\
\text { baseline } \\
\text { Exclusion criteria: presence of hydrosalpinx, endometrial polyp or fibroid distorting } \\
\text { uterine cavity; IVF cycles carried out for preimplantation genetic diagnosis; use of donor } \\
\text { gametes }\end{array}$ \\
\hline Interventions & $\begin{array}{l}\text { Study group: endometrial aspiration by Pipelle performed on LH+7 in the cycle pre- } \\
\text { ceding scheduled IVF treatment } \\
\text { Control group: no intervention }\end{array}$ \\
\hline Outcomes & $\begin{array}{l}\text { Live birth, ongoing pregnancy, clinical pregnancy, miscarriage (reported as miscarriage } \\
\text { per chemical pregnancy), multiple pregnancy }\end{array}$ \\
\hline Notes & $\begin{array}{l}\text { Enrolment: March 2011-August } 2013 \\
\text { Age: study: } 36 \text { (34-38) years/control: } 37(34-38) \text { years } \\
\text { Implantation rate: study: } 32.8 \% / \text { control: } 29.7 \% \\
\text { Number of embryos transferred: study: } 1.5 \pm 0.7 / \text { control: } 1.6 \pm 0.7 \\
\text { All women underwent either hysteroscopy or saline sonography within the } 3 \text { months } \\
\text { before their IVF cycle (information upheld by corresponding author during study pre- } \\
\text { sentation at ESHRE } 2014)\end{array}$ \\
\hline
\end{tabular}

\section{Risk of bias}

\begin{tabular}{|c|c|c|}
\hline Bias & Authors' judgement & Support for judgement \\
\hline $\begin{array}{l}\text { Random sequence generation (selection } \\
\text { bias) }\end{array}$ & Low risk & $\begin{array}{l}\text { Computer-generated random numbers } \\
\text { were used }\end{array}$ \\
\hline Allocation concealment (selection bias) & Low risk & Opaque sealed envelopes were used \\
\hline $\begin{array}{l}\text { Blinding of participants and personnel } \\
\text { (performance bias) } \\
\text { All outcomes }\end{array}$ & Low risk & $\begin{array}{l}\text { No blinding was employed; however it is } \\
\text { unlikely that blinding of participants and } \\
\text { personnel would affect reproductive out- } \\
\text { come measures }\end{array}$ \\
\hline $\begin{array}{l}\text { Blinding of outcome assessment (detection } \\
\text { bias) } \\
\text { All outcomes }\end{array}$ & Low risk & $\begin{array}{l}\text { No blinding was employed; however it is } \\
\text { unlikely that blinding of outcome assessors } \\
\text { would affect reproductive outcome mea- } \\
\text { sures }\end{array}$ \\
\hline $\begin{array}{l}\text { Incomplete outcome data (attrition bias) } \\
\text { All outcomes }\end{array}$ & Low risk & $\begin{array}{l}\text { All randomly assigned women were anal- } \\
\text { ysed }\end{array}$ \\
\hline Selective reporting (reporting bias) & Low risk & $\begin{array}{l}\text { All expected outcomes were reported, in ac- } \\
\text { cordance with the trial register }\end{array}$ \\
\hline
\end{tabular}




\begin{tabular}{|c|c|c|}
\hline Other bias & High risk & $\begin{array}{l}\text { All women underwent either hysteroscopy } \\
\text { or saline sonography within the } 3 \text { months } \\
\text { before their IVF cycle. Those procedures } \\
\text { may cause some degree of unintentional en- } \\
\text { dometrial injury in all study participants; } \\
\text { this could have introduced a systematic er- } \\
\text { ror, altering the observed effect of the in- } \\
\text { tervention }\end{array}$ \\
\hline
\end{tabular}

\section{Characteristics of excluded studies [ordered by study ID]}

\begin{tabular}{l|l}
\hline Study & Reason for exclusion \\
\hline Matsumoto 2014 & Study was not truly randomised \\
\hline Yoldemir 2011 & $\begin{array}{l}\text { Study does not seem to be truly randomised, as women in one group 'consisted of women with the injury } \\
\text { performed at least two menstrual cycles ago'. The intervention, a mock embryo transfer, is unlikely to produce } \\
\text { any endometrial injury }\end{array}$ \\
\hline Zhou 2008 & $\begin{array}{l}\text { Study seems to be pseudo-randomised; it is unclear whether all women in the intervention group received the } \\
\text { intervention. We sought additional information, but we could not get in touch with study authors }\end{array}$ \\
\hline
\end{tabular}

\section{Characteristics of studies awaiting assessment [ordered by study ID]}

Hur 2012

\begin{tabular}{ll}
\hline Methods & RCT or pseudo-randomised CT \\
\hline Participants & Women undergoing the first ART cycle \\
\hline Interventions & Pipelle on the day FSH was started vs No intervention \\
\hline Outcomes & Clinical pregnancy \\
\hline Notes & $\begin{array}{l}\text { We attempted to contact trial authors to establish whether the study was randomised. A decision on inclusion or } \\
\text { exclusion of this trial cannot be made until further details are received }\end{array}$ \\
\hline
\end{tabular}




\section{Characteristics of ongoing studies [ordered by study ID]}

\section{ACTRN12611001222932}

Trial name or title A randomised, single-blind, controlled study assessing the effect of luteal phase Pipelle endometrial biopsy versus sham biopsy on live birth rate in women who are undergoing an IVF/ICSI cycle

Methods

RCT. Individual allocations will be kept in sequentially numbered opaque envelopes and opened on the day of the intervention to determine treatment allocation. A computer-generated block randomisation schedule will be used for each fertility centre to allow allocation of endometrial biopsy or a sham procedure. This will be known only to the clinician performing the procedure

New Zeland

Participants

Inclusion criteria: woman requiring IVF/ICSI; 18-39 years of age (up to 40th birthday); underwent at least 2 embryo transfers without conceiving a clinical pregnancy; ordered a starting dose of $\mathrm{r}$-FSH of $\leq 300 \mathrm{IU}$; all previous IVF cycles resulted in $\geq 3$ oocytes; BMI $\leq 35$; both ovaries present; uterine cavity without abnormality as assessed by ultrasound, hysteroscopy or hysterosalpingography

Exclusion criteria: hysteroscopy or hysterosalpingography or endometrial biopsy within the 3 months before the study; participating in complementary medical intervention; undergoing assisted hatching; current smoker; previous chemotherapy or radiotherapy

Interventions

Study group: Participants in the treatment group will undergo speculum examination; the cervix will be wiped with chlorhexidine and a Pipelle endometrial biopsy will be taken between luteal days 7 and 10 (days 21 to 24 of a spontaneous 28-day cycle) preceding the IVF-stimulated cycle or 4 to 7 days before cessation of the combined oral contraceptive pill if a pill cross-over cycle is used. This intervention will occur only once and will take approximately 5 minutes to complete

Control group: Participants in the control group will undergo sham biopsy, whereby they are given a speculum examination; the cervix will be wiped with chlorhexidine and the biopsy catheter placed beside the cervix (not into the uterus) between luteal days 7 and 10 preceding the IVF-stimulated cycle or 4 to 7 days before cessation of the combined oral contraceptive pill if a pill cross-over cycle is used

Outcomes Live birth, clinical pregnancy, implantation rate, biochemical pregnancy, endometrial thickness on retrieval day

\begin{tabular}{ll}
\hline Starting date & Unknown \\
\hline Contact information & $\begin{array}{l}\text { Dr. Phillip McChesney } \\
\text { pmcchesney@fertilityassociates.co.nz }\end{array}$ \\
\hline Notes & No response obtained \\
\hline
\end{tabular}

\section{ACTRN12613001046796}

Trial name or title Comparison of [effects of] local endometrial trauma (LET) versus no trauma on failed implantation rates in IVF patients with recurrent implantation failure

\begin{tabular}{ll}
\hline Methods & RCT \\
\hline
\end{tabular}

Participants

Inclusion criteria: patients about to undergo a cycle of IVF/ICSI treatment involving fresh embryo transfer, with history of recurrent implantation failure in IVF/ICSI treatment 


\section{ACTRN12613001046796 (Continued)}

Exclusion criteria: patients younger than 21 or older than 39 years of age; known uterine abnormality; medical contraindication to superovulation, oocyte collection or embryo transfer; inability to give informed consent

Intervention

Study group: local endometrial trauma (LET) with randomised timed Pipelle endometrial biopsy. This would be done in the mid-luteal phase of the month immediately preceding IVF treatment

Control group: randomised timed placebo biopsy whereby the participant would undergo insertion of the Pipelle device into the cervix - not into the uterine cavity - with no vacuum drawn, thereby avoiding endometrial trauma whilst giving the impression of a biopsy. This would be done in the mid-luteal phase of the month immediately preceding IVF treatment

Outcomes Clinical pregnancy, chemical pregnancy, pregnancy outcome up to delivery, endometrial activin A, activin B, folistatin and receptors

\begin{tabular}{ll}
\hline Starting date & Unknown \\
\hline Contact information & $\begin{array}{l}\text { Prof. William Ledger } \\
\text { w.ledger@unsw.edu.au }\end{array}$ \\
\hline Notes & Not yet recruiting in April 2014
\end{tabular}

\section{ACTRN12614000626662}

Trial name or title Pipelle for pregnancy in women undergoing single autologous embryo transfer

\begin{tabular}{ll}
\hline Methods & RCT \\
\hline Participants & Women undergoing single autologous embryo transfer \\
\hline $\begin{array}{l}\text { Interventions } \\
\text { Women randomly assigned to the intervention arm will undergo a single endometrial Pipelle biopsy performed } \\
\text { between day } 4 \text { of the natural menstrual cycle preceding the embryo transfer cycle and day } 3 \text { of the menstrual } \\
\text { cycle for which embryo transfer is planned }\end{array}$ \\
\hline Outcomes & $\begin{array}{l}\text { Live birth, miscarriage, ongoing pregnancy, clinical pregnancy, multiple pregnancy, pain during the procedure, } \\
\text { bleeding following the procedure }\end{array}$ \\
\hline Starting date & June 2014 \\
\hline Contact information & Sarah Lensen; s.lensen@auckland.ac.nz \\
\hline Notes & $\begin{array}{l}\text { A randomised controlled trial assessing the effects of endometrial Pipelle biopsy vs no intervention on live } \\
\text { birth rate in women undergoing autologous embryo transfer }\end{array}$ \\
\hline
\end{tabular}




\begin{tabular}{ll} 
Trial name or title & $\begin{array}{l}\text { Effect of local injury to the endometrium on pregnancy rate for patients undergoing natural-cycle frozen- } \\
\text { thawed embryo transfer: a randomised study }\end{array}$ \\
\hline Methods & RCT, Hong Kong
\end{tabular}

Inclusion criteria: All natural cycle frozen-thawed embryo transfer (FET) cycles using non-donor oocytes
will be recruited
Exclusion criteria: Patients who had any uterine anomaly or pathology such as endometrial polyp, endometri-
oma with a diameter of $4 \mathrm{~cm}$ or visible hydrosalpinx on transvaginal ultrasound scan will be excluded

Interventions Study group: Endometrial biopsy will be performed in the experimental group at the luteal phase on days 21-26 of spontaneous preceding menstrual cycle before frozen-thawed embryo transfer

Control group: no intervention

\begin{tabular}{ll}
\hline Outcomes & Ongoing and clinical pregnancy and implantation rates \\
\hline Starting date & July 2012 \\
\hline Contact information & $\begin{array}{l}\text { Carol Chan: carolchan@cuhk.edu.hk } \\
\text { Dr. Mei Ling Cheung: irenecheung@cuhk.edu.hk }\end{array}$ \\
\hline Notes & No response obtained \\
\hline
\end{tabular}

\section{CTRI/2013/12/004206}

Trial name or title Impact of local endometrial injury (LEI) on the outcome of IVF cycle with previous failed implantation: exploring the genome-wide transcriptomic basis

Methods RCT; computer-generated randomisation; sequentially numbered, sealed, opaque envelopes

Participants Inclusion criteria: women younger than 38 years of age; $>1$ previous failed IVF-ET cycle; good ovarian reserve (AFC > 8, AMH 2-6 ng/mL, FSH level $<8 \mathrm{mIU} / \mathrm{mL}$ ); no uterine manipulation within past 3 months (e.g. hysteroscopy, myomectomy); willing to participate in the trial

Exclusion criteria: women older than 38 years of age with confounding factors (e.g. poor ovarian reserve) ; grade III and IV endometriosis; history of septal resection; adhesiolysis and abnormal uterine cavity, with possible causes for failure of implantation such as diabetes mellitus, hypertension and autoimmune disease

Interventions Study group: Endometrial scratching will be done once from days 14-18 of menstrual cycle within the same IVF cycle. Anterior and posterior walls of endometrium will be scratched gently by a 4-mm disposable Karman's cannula inserted through the cervical os, and endometrial tissue will be sent for genetic analysis. Oral antibiotic ciprofloxacin $500 \mathrm{mg}$ will be given for 5 days after the procedure

Control group: no intervention. To avoid the possible confounding effect of antibiotic on IVF success, the control group will be administered the same antibiotic

Outcomes Clinical pregnancy, genome-wide transcriptomic basis, ongoing pregnancy, biochemical pregnancy, implantation rate, endometrial thickness during stimulation

Starting date Unknown

Endometrial injury in women undergoing assisted reproductive techniques (Review)

Copyright @ 2015 The Cochrane Collaboration. Published by John Wiley \& Sons, Ltd. 


\section{CTRI/2013/12/004206 (Continued)}

Contact information Dr. Neeta Singh: drneetasingh@yahoo.com

Notes $\quad$ Same trial as CTRI/2014/01/004307

Recruiting in April 2014

\section{ISRCTN63112626}

Trial name or title Effect of endometrial injury on repeat implantation failure following in vitro fertilisation embryo transfer or frozen embryo transfer: a randomised controlled study

\begin{tabular}{ll}
\hline Methods & RCT \\
\hline Participants & $\begin{array}{l}\text { Inclusion criteria: patients with repeated implantation failure (3 or more) undergoing in vitro fertilisation } \\
\text { embryo transfer (IVF-ET) or frozen embryo transfer (FET); patients with normal preoperative routine checks; } \\
\text { patients } \leq 40 \text { years of age with basal follicle-stimulating hormone }(\mathrm{FSH})<10 \mathrm{IU} / \mathrm{L} \text { and }>5 \text { follicles in } \\
\text { bilateral ovaries; patients without history of uterine cavity operation within } 2 \text { months } \\
\text { Exclusion criteria: patients with hydrosalpinx; patients with history of endometrial adhesion; patients with } \\
\text { uterine malformation; patients with acute genital tract inflammation; patients with history of using hormone } \\
\text { such as oral contraceptive within } 3 \text { months }\end{array}$
\end{tabular}

Interventions $\quad$ Study group: endometrial scratching on fifth day after ovulation before IVF or FET cycle in study group. No extra administration before IVF or FET cycle in control group

Control group: no intervention

\begin{tabular}{l|l}
\hline Outcomes & Not reported \\
\hline Starting date & November 2011 \\
\hline Contact information & Prof. Caihong Ma \\
\hline Notes & $\begin{array}{l}\text { In the trial register, study status is completed; however we could not find the researcher contact and could } \\
\text { not locate the published trial }\end{array}$ \\
\hline
\end{tabular}

\section{NCT01064193}

Trial name or title Impact of local biopsy to the endometrium prior to controlled ovarian stimulation on clinical pregnancy (NIDABRECHE)

\begin{tabular}{|c|c|}
\hline Methods & RCT, open \\
\hline Participants & $\begin{array}{l}\text { Inclusion criteria: } 18-38 \text { years of age; primary or secondary infertility; first or second IVF attempt; regular } \\
\text { menstrual cycles; FSH } \leq 12 \mathrm{IU} / \mathrm{L} \text {; signed informed consent } \\
\text { Exclusion criteria: ovocyte donor; pathology of the uterus or annexes; BMI > 35; ongoing vaginal infection; } \\
\text { undetermined vaginal bleeding; contraindication to the Cornier Pipelle or to these treatments: Gonal } \mathrm{F}^{\circledR} \text {, } \\
\text { Puregon }{ }^{\circledR} \text {, Ovitrelle }{ }^{\circledR} \text {, Utrogestan }{ }^{\circledR} \text {; women included in another study on medically assisted procreation; any } \\
\text { administrative or legal supervision }\end{array}$ \\
\hline
\end{tabular}




\section{NCT01064193 (Continued)}

\begin{tabular}{|c|c|}
\hline Interventions & $\begin{array}{l}\text { Study group: The biopsy is realised with a Pipelle de Cornier, moving the Pipelle in and out while twisting, } \\
\text { twisting the Pipelle to cover an angle of } 360^{\circ} \text { and making several "in and out" cycles to collect a complete } \\
\text { sample of the endometrium } \\
\text { Control group: no intervention }\end{array}$ \\
\hline Outcomes & Clinical pregnancy, implantation rate, miscarriage, multiple pregnancy, pain, any adverse event \\
\hline Starting date & February 2010 \\
\hline Contact information & Olivier Delorme: olivier.delorme@chu-bordeaux.fr \\
\hline Notes & Recruiting in April 2014 \\
\hline \multicolumn{2}{|l|}{ NCT01798862 } \\
\hline Trial name or title & Endometrial injury and IVF outcome parameters in patients with failed IVF cycles \\
\hline Methods & RCT, open; Greece \\
\hline Participants & $\begin{array}{l}\text { Inclusion criteria: } 25-42 \text { years of age; personal history of } 2 \text { or more failed IVF/ICSI cycles; good response } \\
\text { with good-quality embryos on previous attempts } \\
\text { Exclusion criteria: personal history of endometrial tuberculosis/antituberculous treatment; sonographically } \\
\text { detected hydrosalpinges; intramural fibroids distorting the endometrial cavity; submucous myoma or Asher- } \\
\text { man's syndrome; thrombophilia }\end{array}$ \\
\hline Interventions & $\begin{array}{l}\text { Study group: endometrial sampling by Pipelle or hysteroscopy performed once between } 6 \text { th and } 10 \text { th days } \\
\text { in the cycle before the fresh IVF/ICSI cycle } \\
\text { Control group: no intervention }\end{array}$ \\
\hline Outcomes & Live birth, clinical pregnancy, implantation rate, biochemical pregnancy, miscarriage, pregnancy complications \\
\hline Starting date & March 2013 \\
\hline Contact information & $\begin{array}{l}\text { Maria Kreatsa: mar_kreatsa@yahoo.gr } \\
\text { Charalampos Siristatidis: harrysiri@yahoo.gr }\end{array}$ \\
\hline Notes & No response obtained \\
\hline
\end{tabular}

\section{NCT01800513}

Trial name or title Endometrial biopsy prior to IVF in those patients with prior implantation failure (EMBX/IVF)

\begin{tabular}{ll}
\hline Methods & RCT, single-blind \\
\hline
\end{tabular}

Participants

Inclusion criteria: women $18-37$ years of age; $\geq 1$ previous implantation failures with autologous fresh or frozen blastocyst transfer; undergoing fresh autologous IVF cycle; no other current uterine (i.e. uterine 


\section{NCT01800513 (Continued)}

fibroids, polyps), haematological or genetic causes of infertility and implantation failure; $\geq 1$ good-quality blastocyst(s) available for transfer

Exclusion criteria: unable to comprehend the investigational nature of the proposed study; positive pregnancy test; possible reasons for impaired implantation (systemic disease, endometriosis, ultrasound evidence of current hydrosalpinx, uterine polyps, uterine myomas (fibroids), uterine cavity malformations, Asherman's syndrome); poor responders, defined as FSH > 12 on day 3 or fewer than 4 follicles in a previous IVF cycle; $\mathrm{BMI}>30$ or $<18$

Interventions

Study group: Participants will have a vaginal speculum placed and visualisation of the cervix will be obtained. The cervix will be cleaned with betadine (or hibiclens for those with an iodine allergy). Those randomly assigned to the treatment arm (endometrial biopsy) will have an endometrial Pipelle (Endocell, Wallach, Orange, Connecticut) inserted gently through the cervix into the uterus. 2 passes will be performed with the Pipelle catheter. For each pass, the catheter will be rotated and scraped 4 times - once in each quadrant Control group: Those randomly assigned to the control group will have a small cotton swab placed gently into the cervix. No tissue will be obtained by this method. Randomisation to a placebo control is necessary to prove that any positive effects seen are due to the biopsy and are not just the result of random chance

Outcomes Clincial pregnancy, live birth, implantation rate, miscarriage, multiple pregnancy, endometrial thickness during stimulation

Starting date $\quad$ February 2013

Contact information Erin F Wolff, MD: wolffe@mail.nih.gov

Notes $\quad$ Recruiting in April 2014

\section{NCT01844453}

Trial name or title Local endometrial injury in fresh embryo transfer cycles (LEI)

Methods RCT, open

Participants

Inclusion criteria: infertile patients $\geq 36$ years of age; patients who are planned to undergo a second fresh IVF cycle; patients who have previously had a fresh IVF-ET and $\geq 1$ frozen-thawed ET in the past and did not achieve a clinical pregnancy ( 2 or more failed embryo transfers); ovarian stimulation with a "microdose flare" protocol; patients who are scheduled to undergo a single embryo transfer; consent in writing to participate in the study

Exclusion criteria: known or suspected intrauterine factor on ultrasound imaging (submucosal fibroid, endometrial polyp, intrauterine adhesions or intramural fibroids causing uterine distortion); endometriosis (documented by laparoscopy or known endometrioma by ultrasound); previous hysteroscopy (since the start of their first IVF cycle); patients who do not speak English or French; patients who will have more than 1 embryo transferred

Interventions

Study group: Local endometrial injury will be performed using the standard technique and a Pipelle sampling catheter in the outpatient department. After a speculum examination is performed and the cervix is well visualised, the Pipelle will be inserted gently through the cervical canal into the uterine cavity and will be advanced slowly until resistance is noted. At this point, the internal piston will be withdrawn to create negative suction and the Pipelle gently manoeuvred up and down alongside the uterine cavity wall. The Pipelle catheter 


\section{NCT01844453 (Continued)}

will then be withdrawn gently, and any obtained specimen (uterine lining) will be sent for histopathological examination

Control group: no intervention

\begin{tabular}{ll}
\hline Outcomes & Implantation rate, biochemical pregnancy, clinical pregnancy, live birth, miscarriage \\
\hline Starting date & Not started yet \\
\hline Contact information & Dr. Dan Nayot: dan.nayot@gmail.com \\
\hline Notes & Recruiting in April 2014 \\
\hline
\end{tabular}

\section{NCT01955356}

\begin{tabular}{ll}
\hline Trial name or title & Embryo implantation after induced endometrial injury \\
\hline Methods & RCT \\
\hline Participants & $\begin{array}{l}\text { Inclusion criteria: recipients of egg donation; 19- to 44-year-old women; } 19-28 \mathrm{~kg} / \mathrm{m}^{2} ; \text { first or second fresh } \\
\text { embryo transfer; } 1 \text { or } 2 \text { blastocysts available; written agreement; } \geq 6 \mathrm{~mm} \text { endometrial thickness } \\
\text { Exclusion criteria: premature ovarian failure; endometrial pathology; insufficient endometrial development; } \\
\text { hydrosalpinx; Mullerian malformation }\end{array}$ \\
\hline Interventions & $\begin{array}{l}\text { Study group: endometrial biopsy } \\
\text { Control group: no intervention }\end{array}$ \\
\hline Outcomes & Implantation rate, live birth \\
\hline Starting date & Octuber 2013 \\
\hline Contact information & Carmina Vidal, MD: carmina.vidal@ivi.es \\
\hline Notes & Recruiting in April 2014 \\
\hline
\end{tabular}

\section{NCT01963819}

Trial name or title Therapeutic endometrial biopsy

Methods RCT, open; no interim analysis

Participants $\quad$ Inclusion criteria: $18-40$ years of age; $\geq 1$ previous failed implantation despite transfer of good-quality embryons/blastocysts in a fresh IVF/ICSI treatment; planned antagonist treatment; planned standardised hormone treatment; FSH 2-12 IU/L; BMI 18-32; regular menstrual cycles; written consent

Exclusion criteria: patients in need of an interpreter; suspected intrauterine abnormalities (fibromes, polyps, adenomyosis, sacrosalpinges); planned use of assisted hatching or use of specialised media; previous inclusion in the study 


\section{NCT01963819 (Continued)}

\begin{tabular}{l|l}
\hline Interventions & $\begin{array}{l}\text { Study group: Endometrial biopsy will be done in the luteal phase (cycle days 18-22) before the treatment } \\
\text { cycle (antagonist) } \\
\text { Control group: no intervention }\end{array}$ \\
\hline Outcomes & Clinical pregnancy, biochemical pregnancy, implantation rate, live birth \\
\hline Starting date & October 2013 \\
\hline Contact information & $\begin{array}{l}\text { Mia Steengaard Olesen: miaolsen@rm.dk } \\
\text { Axel Forman, MD, DMsc: axel.forman@ki.au.dk }\end{array}$ \\
\hline Notes & Recruiting in May 2014 \\
\hline
\end{tabular}

\section{NCT01983423}

Trial name or title Effect of endometrial biopsy on in vitro fertilization pregnancy rates - a multicenter study (EndoBx-IVF)

\begin{tabular}{ll}
\hline Methods & RCT, open \\
\hline Participants & $\begin{array}{l}\text { Inclusion criteria: } 18-39 \text { years of age; BMI } 18-35 \mathrm{~kg} / \mathrm{m}^{2} \text {; uterine cavity evaluation (hysterosalpingogram, } \\
\text { sonohysterogram, hysteroscopy) in the preceding } 24 \mathrm{months} \text {; early follicular phase (day } 2 \text { or day } 3 \text { ); serum }\end{array}$ \\
$\begin{array}{l}\text { FSH evaluated in the preceding } 6 \text { months. One of the following: non-oral contraceptive pill (non-OCP) } \\
\text { patients: documented LH surge 9-11 days before enrolment; current OCP patients: OCP use for } \geq 10 \text { days } \\
\text { Exclusion criteria: prior enrolment in this study; prior early follicular phase serum FSH level } \geq 12 \text { IU/ } \\
\text { L; previous poor ovarian response, defined as prior IVF cycle cancelled for poor response, or } \leq 4 \text { oocytes } \\
\text { retrieved; IVF for preimplantation genetic diagnosis (PGD) or fertility preservation; diabetes mellitus or } \\
\text { uncontrolled thyroid disease; abnormal uterine cavity, such as unresected submucosal fibroids, uterine septum } \\
\text { or Mullerian anomaly such as bicornuate or unicornuate; uterus or intrauterine adhesions; hydrosalpinx that } \\
\text { has not been removed or surgically ligated; any contraindication to endometrial biopsy; office hysteroscopy } \\
\text { or other uterine procedure planned or performed during cycle preceding IVF stimulation; use of surgically } \\
\text { retrieved sperm }\end{array}$
\end{tabular}

Interventions $\quad$ Study group: An endometrial biopsy is performed by using a sampling device known as a Pipelle catheter, which is introduced into the uterine cavity. The inner core is withdrawn, creating suction pressure into the hollow bore of the cavity, which allows acquisition of endometrial tissue upon rotation within the cavity. This is removed and the tissue sent for pathological examination

Control group: no intervention

Outcomes Clinical pregnancy, implantation rate, live birth, fertilisation rate, endometrial thickness, endometrial pattern embryos cryopreserved

\begin{tabular}{ll}
\hline Starting date & Unknown \\
\hline Contact information & $\begin{array}{l}\text { Jon C Havelock, MD: JHavelock@pacificfertility.ca } \\
\text { Kimberly Liu, MD: KLiu@mtsinai.on.ca }\end{array}$ \\
\hline Notes & Recruiting in April 2014 \\
\hline
\end{tabular}

Endometrial injury in women undergoing assisted reproductive techniques (Review)

Copyright $\Subset 2015$ The Cochrane Collaboration. Published by John Wiley \& Sons, Ltd. 
Trial name or title

REFRESH: Receptivity Enhancement by Follicular-phase Renewal After Endometrial ScratcHing

\begin{tabular}{|c|c|}
\hline Methods & RCT, open \\
\hline Participants & $\begin{array}{l}\text { Inclusion criteria: } 18-40 \text { years of age; fresh IVF/ICSI cycle; antagonist downregulation; signed informed } \\
\text { consent } \\
\text { Exclusion criteria: other known reasons for impaired implantation (i.e. hydrosalpinx, fibroid distorting } \\
\text { the endometrial cavity, Asherman's syndrome, thrombophilia, endometrial tuberculosis); oocyte donation } \\
\text { acceptors; frozen egg transfers; embryos planned to undergo preimplantation genetic diagnosis (PGD); BMI } \\
>35 \text { or < } 18 \text {; women already recruited for another trial on medically assisted procreation during the same } \\
\text { cycle; women previously enrolled in the trial; those unable to comprehend the investigational nature of the } \\
\text { proposed study }\end{array}$ \\
\hline
\end{tabular}

Intervention

Study group: Women in the intervention group will undergo an endometrial biopsy on the sixth day of ovarian stimulation using a Pipelle de Cornier (CCD International, Paris, France)

Control group: no intervention

Outcomes Clinical pregnancy, live birth, complication rate, endometrial histology

Starting date April 2014

Contact information Samuel Santos-Ribeiro, MD: samuel.ribeiro@uzbrussel.be

Notes $\quad$ Recruiting in April 2014 
DATA AND ANALYSES

Comparison 1. Endometrial injury between day 7 of the previous cycle and day 7 of the ET cycle vs control

\begin{tabular}{|c|c|c|c|c|}
\hline Outcome or subgroup title & $\begin{array}{l}\text { No. of } \\
\text { studies }\end{array}$ & $\begin{array}{c}\text { No. of } \\
\text { participants }\end{array}$ & Statistical method & Effect size \\
\hline $\begin{array}{l}1 \text { Live birth or ongoing pregnancy } \\
\text { per randomly assigned } \\
\text { woman (by manipulation/no } \\
\text { manipulation in control group) }\end{array}$ & 9 & 1496 & Risk Ratio (M-H, Random, 95\% CI) & $1.42[1.08,1.85]$ \\
\hline $\begin{array}{l}1.1 \text { No intrauterine } \\
\text { manipulation in control group }\end{array}$ & 4 & 463 & Risk Ratio (M-H, Random, 95\% CI) & $1.71[1.28,2.30]$ \\
\hline $\begin{array}{l}1.2 \text { Intrauterine manipulation } \\
\text { in control group }\end{array}$ & 5 & 1033 & Risk Ratio (M-H, Random, 95\% CI) & $1.25[0.82,1.90]$ \\
\hline $\begin{array}{l}2 \text { Live birth or ongoing pregnancy } \\
\text { per randomly assigned woman } \\
\text { (by embryo transfer history) }\end{array}$ & 9 & 1496 & Risk Ratio (M-H, Random, 95\% CI) & $1.37[1.05,1.79]$ \\
\hline $\begin{array}{l}2.1 \leq 1 \text { previous embryo } \\
\text { transfer }\end{array}$ & 4 & 650 & Risk Ratio (M-H, Random, 95\% CI) & $1.10[0.91,1.33]$ \\
\hline $\begin{array}{l}2.2 \geq 2 \text { previous embryo } \\
\text { transfers }\end{array}$ & 4 & 474 & Risk Ratio (M-H, Random, 95\% CI) & $1.96[1.21,3.16]$ \\
\hline $\begin{array}{l}2.3 \text { Unselected women or } \\
\text { unclear number of previous } \\
\text { embryo transfers }\end{array}$ & 4 & 372 & Risk Ratio (M-H, Random, 95\% CI) & $1.24[0.63,2.46]$ \\
\hline $\begin{array}{l}3 \text { Miscarriage per clinical } \\
\text { pregnancy }\end{array}$ & 8 & 501 & Risk Ratio (M-H, Random, 95\% CI) & $0.98[0.61,1.55]$ \\
\hline $\begin{array}{l}4 \text { Clinical pregnancy per } \\
\text { randomly assigned woman (by } \\
\text { manipulation/no manipulation } \\
\text { in control group) }\end{array}$ & 13 & 1972 & Risk Ratio (M-H, Random, 95\% CI) & $1.34[1.11,1.62]$ \\
\hline $\begin{array}{l}\text { 4.1 No intrauterine } \\
\text { manipulation in control group }\end{array}$ & 8 & 939 & Risk Ratio (M-H, Random, 95\% CI) & $1.44[1.18,1.74]$ \\
\hline $\begin{array}{l}4.2 \text { Intrauterine manipulation } \\
\text { in control group }\end{array}$ & 5 & 1033 & Risk Ratio (M-H, Random, 95\% CI) & $1.24[0.87,1.78]$ \\
\hline $\begin{array}{l}5 \text { Clinical pregnancy per randomly } \\
\text { assigned woman (by embryo } \\
\text { transfer history) }\end{array}$ & 13 & 1972 & Risk Ratio (M-H, Random, 95\% CI) & $1.32[1.09,1.60]$ \\
\hline $\begin{array}{l}5.1 \leq 1 \text { previous embryo } \\
\text { transfer }\end{array}$ & 4 & 650 & Risk Ratio (M-H, Random, 95\% CI) & $1.11[0.94,1.32]$ \\
\hline $\begin{array}{l}5.2 \geq 2 \text { previous embryo } \\
\text { transfers }\end{array}$ & 6 & 749 & Risk Ratio (M-H, Random, 95\% CI) & $1.63[1.12,2.38]$ \\
\hline $\begin{array}{l}5.3 \text { Unselected women or } \\
\text { unclear number of previous } \\
\text { embryo transfers }\end{array}$ & 6 & 573 & Risk Ratio (M-H, Random, 95\% CI) & $1.20[0.80,1.82]$ \\
\hline $\begin{array}{l}6 \text { Multiple pregnancy per clinical } \\
\text { pregnancy }\end{array}$ & 4 & 367 & Risk Ratio (M-H, Random, 95\% CI) & $1.17[0.77,1.77]$ \\
\hline 7 Pain (visual analogue scale) & 1 & & Mean Difference (IV, Fixed, 95\% CI) & Totals not selected \\
\hline 8 Pain (complaint) & 2 & & Peto Odds Ratio (Peto, Fixed, 95\% CI) & Totals not selected \\
\hline
\end{tabular}


Comparison 2. Endometrial injury on the day of oocyte retrieval vs control

\begin{tabular}{lcccc} 
Outcome or subgroup title & $\begin{array}{c}\text { No. of } \\
\text { studies }\end{array}$ & $\begin{array}{c}\text { No. of } \\
\text { participants }\end{array}$ & Statistical method & Effect size \\
\hline $\begin{array}{l}\text { 1 Live birth or ongoing pregnancy } \\
\text { per randomly assigned woman }\end{array}$ & 1 & & Risk Ratio (M-H, Fixed, 95\% CI) & Totals not selected \\
$\begin{array}{l}\text { Miscarriage per clinical } \\
\text { pregnancy }\end{array}$ & 0 & 0 & Risk Ratio (M-H, Fixed, 95\% CI) & $0.0[0.0,0.0]$ \\
$\begin{array}{l}\text { 3 Clinical pregnancy per randomly } \\
\quad \text { assigned woman }\end{array}$ & 1 & & Risk Ratio (M-H, Fixed, 95\% CI) & Totals not selected \\
$\begin{array}{l}\text { 4 Multiple pregnancy per clinical } \\
\text { pregnancy }\end{array}$ & 0 & 0 & Risk Ratio (M-H, Fixed, 95\% CI) & $0.0[0.0,0.0]$ \\
$\begin{array}{l}\text { 5 Pain } \\
\text { 6 Bleeding }\end{array}$ & 0 & 0 & Risk Ratio (M-H, Fixed, 95\% CI) & $0.0[0.0,0.0]$ \\
\hline
\end{tabular}

\section{Analysis I.I. Comparison I Endometrial injury between day 7 of the previous cycle and day 7 of the ET cycle vs control, Outcome I Live birth or ongoing pregnancy per randomly assigned woman (by manipulation/no manipulation in control group).}

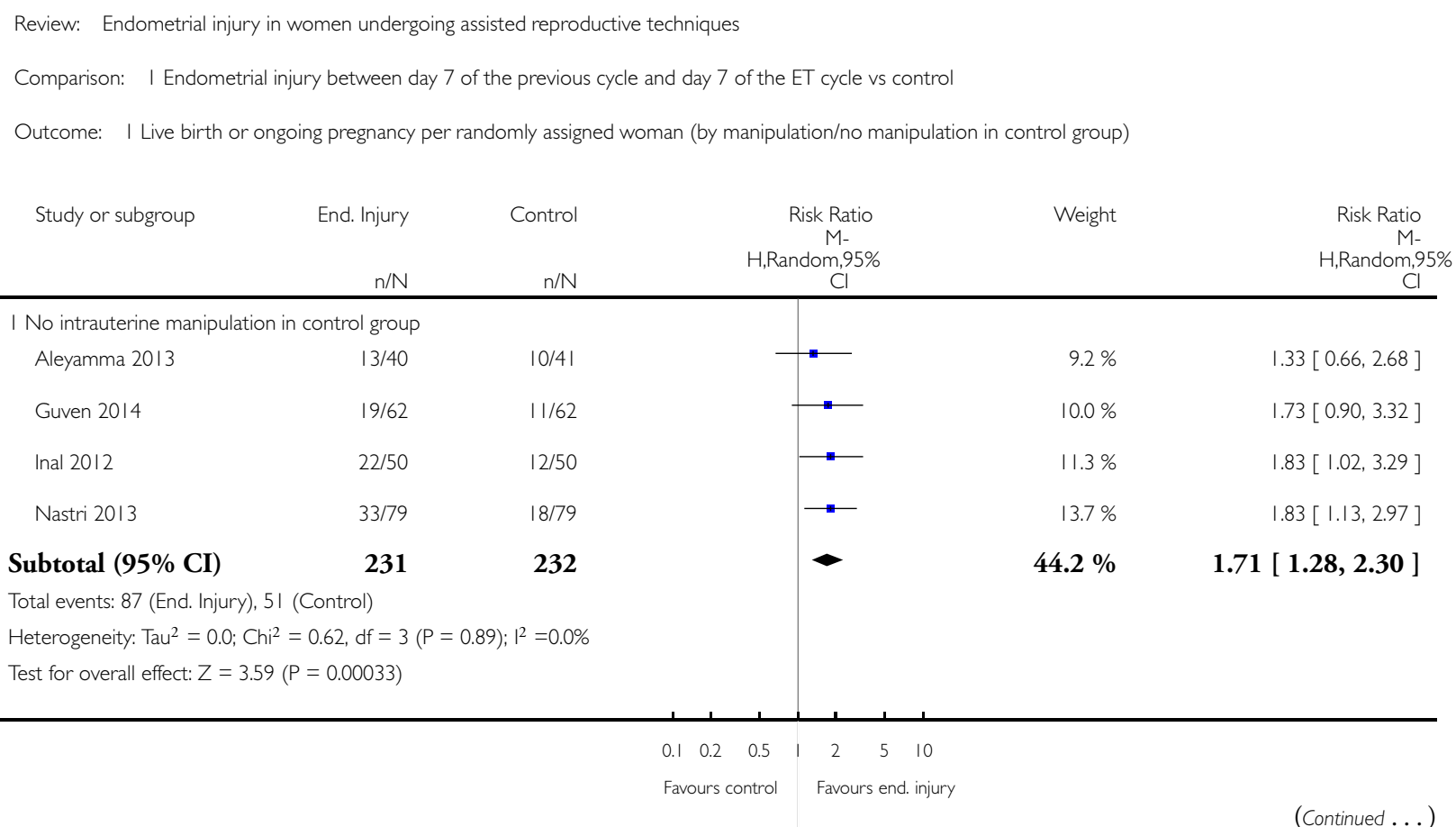




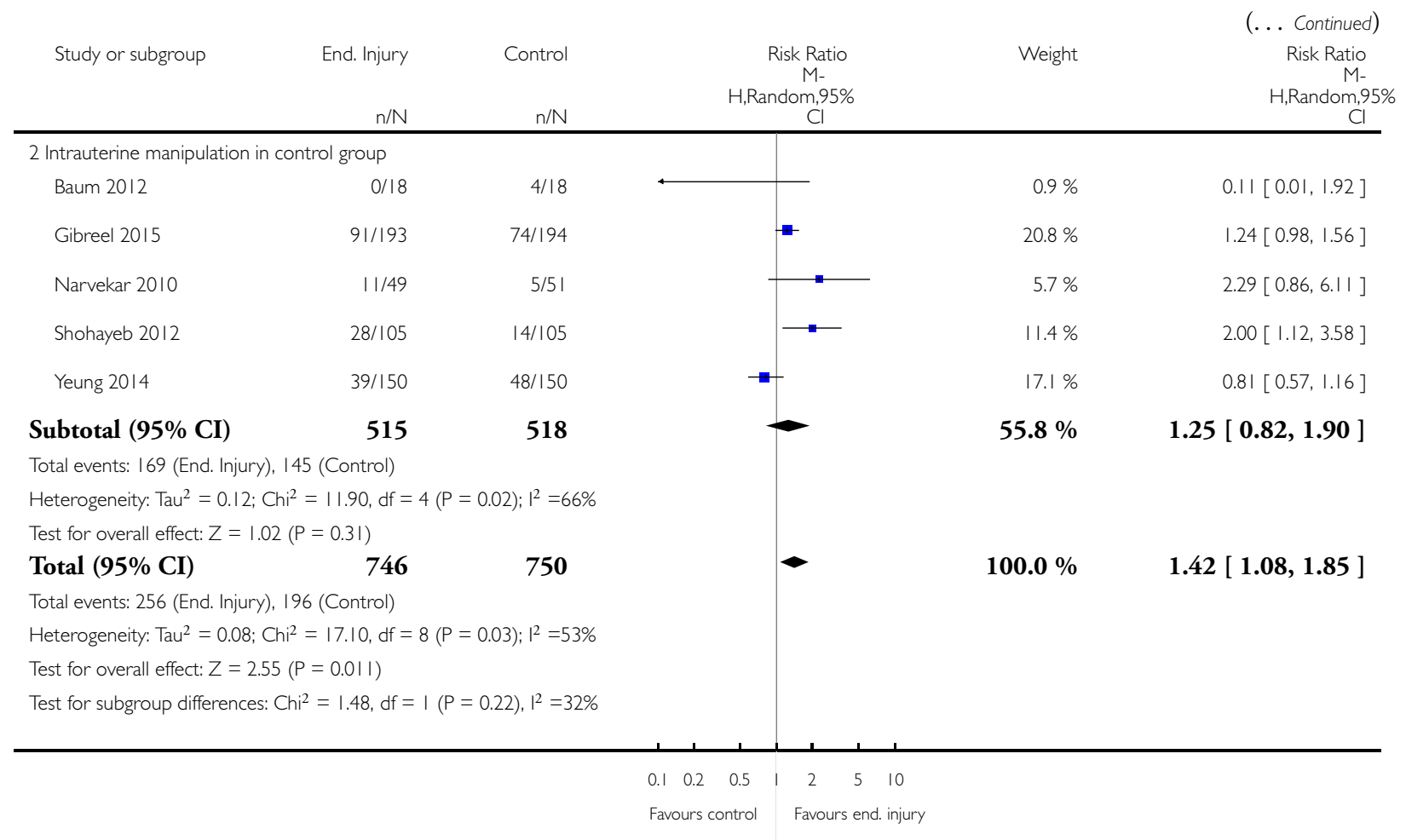


Analysis I.2. Comparison I Endometrial injury between day 7 of the previous cycle and day 7 of the ET cycle vs control, Outcome 2 Live birth or ongoing pregnancy per randomly assigned woman (by embryo transfer history).

Review: Endometrial injury in women undergoing assisted reproductive techniques

Comparison: I Endometrial injury between day 7 of the previous cycle and day 7 of the ET cycle vs control

Outcome: 2 Live birth or ongoing pregnancy per randomly assigned woman (by embryo transfer history)

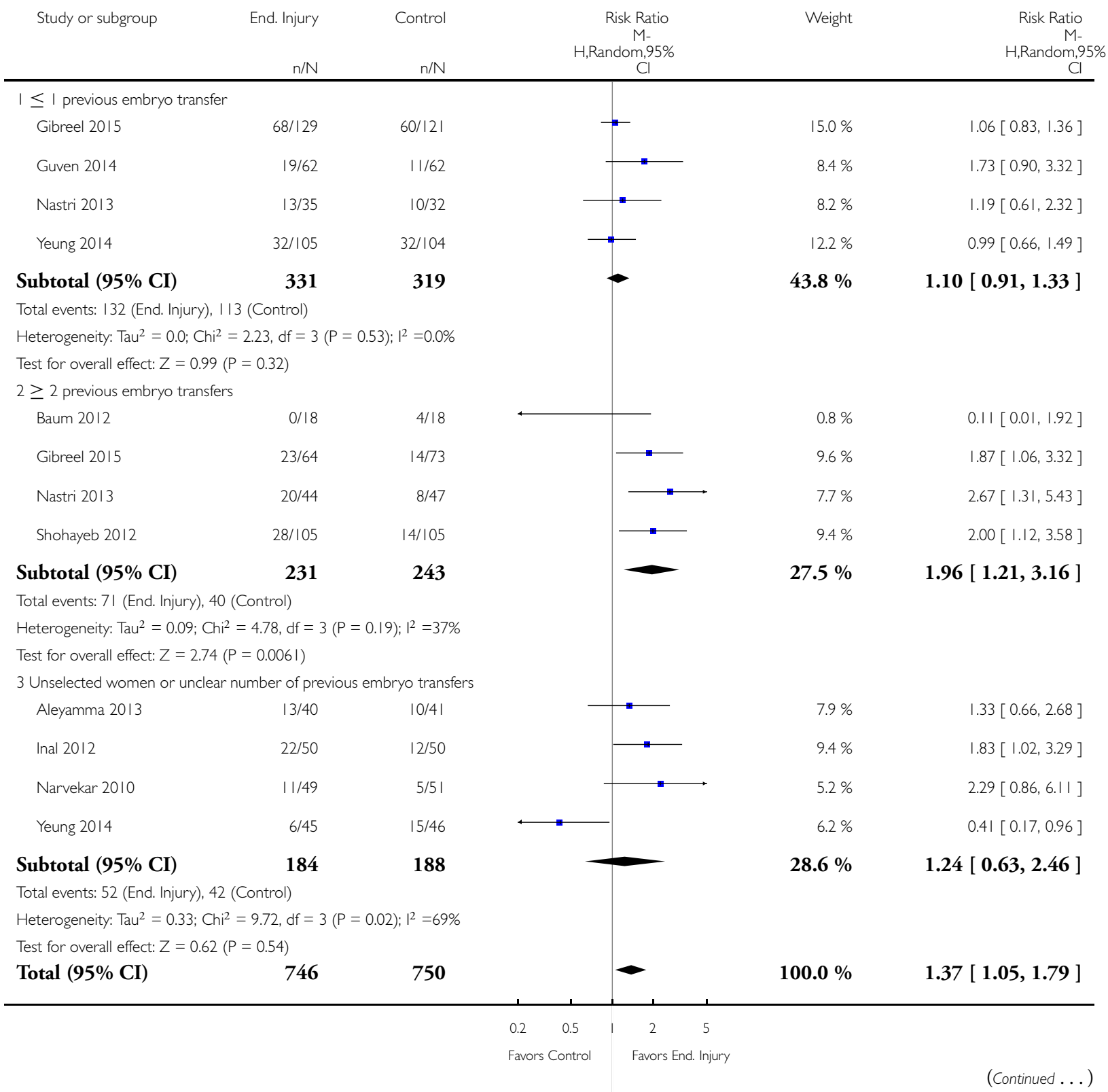




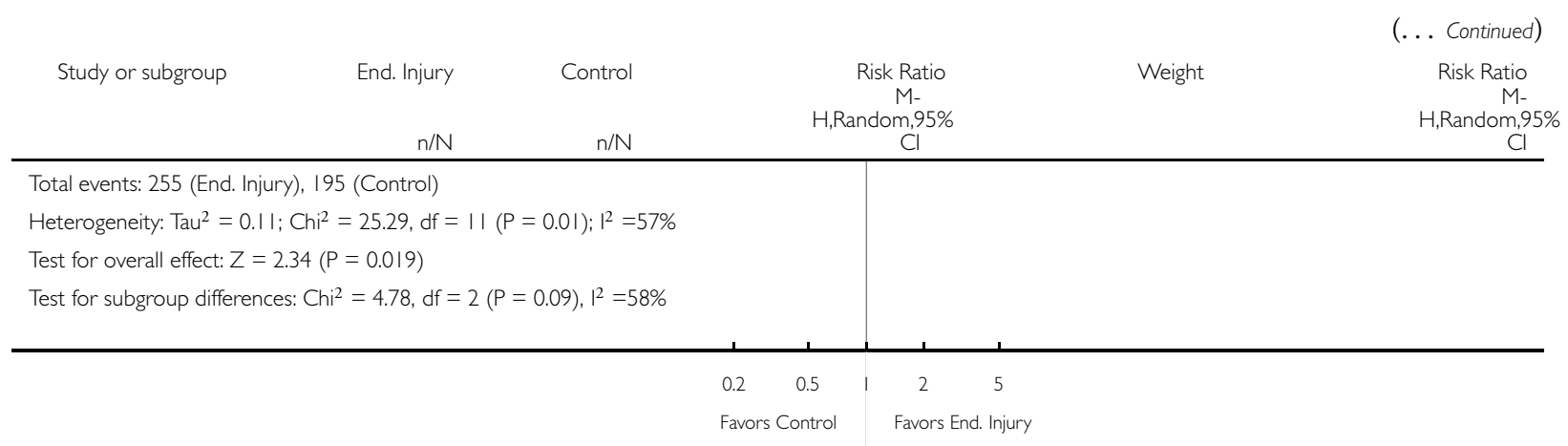

\section{Analysis I.3. Comparison I Endometrial injury between day 7 of the previous cycle and day 7 of the ET cycle vs control, Outcome 3 Miscarriage per clinical pregnancy.}

Review: Endometrial injury in women undergoing assisted reproductive techniques

Comparison: I Endometrial injury between day 7 of the previous cycle and day 7 of the ET cycle vs control

Outcome: 3 Miscarriage per clinical pregnancy

\begin{tabular}{|c|c|c|c|c|c|}
\hline Study or subgroup & End. Injury & Control & $\begin{array}{r}\text { Risk Ratio } \\
\text { M- } \\
\text { H,Random,95\% } \\
\mathrm{Cl} \\
\end{array}$ & Weight & $\begin{array}{c}\text { Risk Ratio } \\
\text { M- } \\
\text { H,Random,95\% } \\
\text { Cl } \\
\end{array}$ \\
\hline Aleyamma 2013 & $1 / 14$ & $2 / 12$ & & $4.0 \%$ & $0.43[0.04,4.16]$ \\
\hline Baum 2012 & $1 / 1$ & $1 / 5$ & & $7.7 \%$ & $3.00[0.6|| 4.86]$, \\
\hline Gibreel 2015 & $4 / 95$ & $6 / 80$ & & $12.4 \%$ & $0.56[0.16,1.92]$ \\
\hline Narvekar 2010 & $5 / 16$ & $2 / 7$ & & $10.1 \%$ & $1.09[0.28,4.34]$ \\
\hline Nastri 2013 & $6 / 39$ & $5 / 23$ & & $15.7 \%$ & $0.71[0.24,2.06]$ \\
\hline Polanski 2014 & $3 / 30$ & $4 / 21$ & & $10.0 \%$ & $0.53[0.13,2.11]$ \\
\hline Shohayeb 2012 & $4 / 32$ & $4 / 18$ & $\because$ & $11.9 \%$ & $0.56[0.16,1.98]$ \\
\hline Yeung 2014 & $|5 / 5|$ & $9 / 57$ & $\rightarrow$ & $28.1 \%$ & $1.86[0.89,3.88]$ \\
\hline
\end{tabular}

Total $(95 \%$ CI $)$

278

223

$100.0 \%$

$0.98[0.61,1.55]$

Total events: 39 (End. Injury), 33 (Control)

Heterogeneity: $\operatorname{Tau}^{2}=0.06 ; \mathrm{Chi}^{2}=8.04, \mathrm{df}=7(\mathrm{P}=0.33) ; \mathrm{I}^{2}=13 \%$

Test for overall effect: $Z=0.10(P=0.92)$

Test for subgroup differences: Not applicable 


\section{Analysis I.4. Comparison I Endometrial injury between day 7 of the previous cycle and day 7 of the ET cycle vs control, Outcome 4 Clinical pregnancy per randomly assigned woman (by manipulation/no manipulation in control group).}

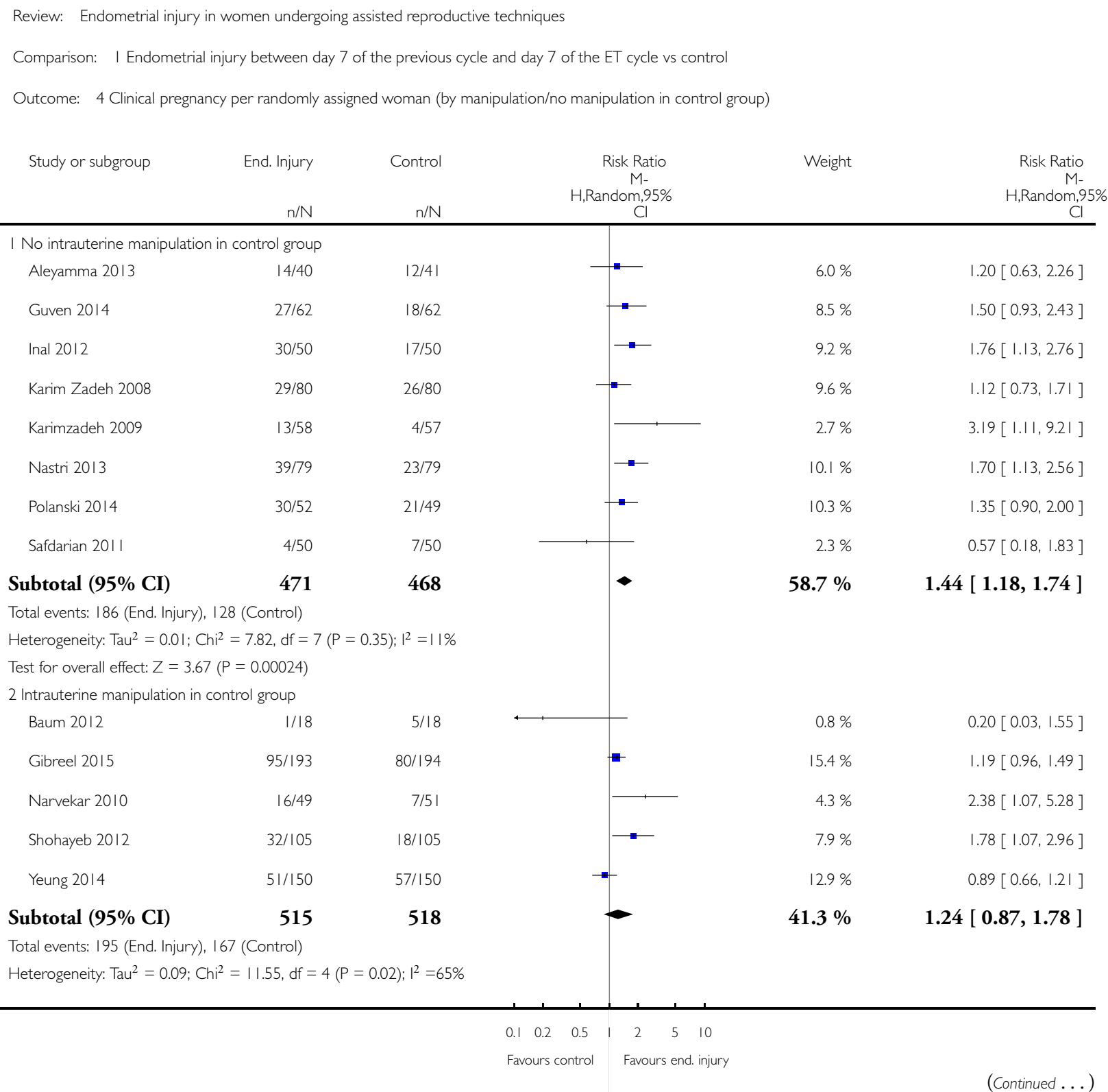




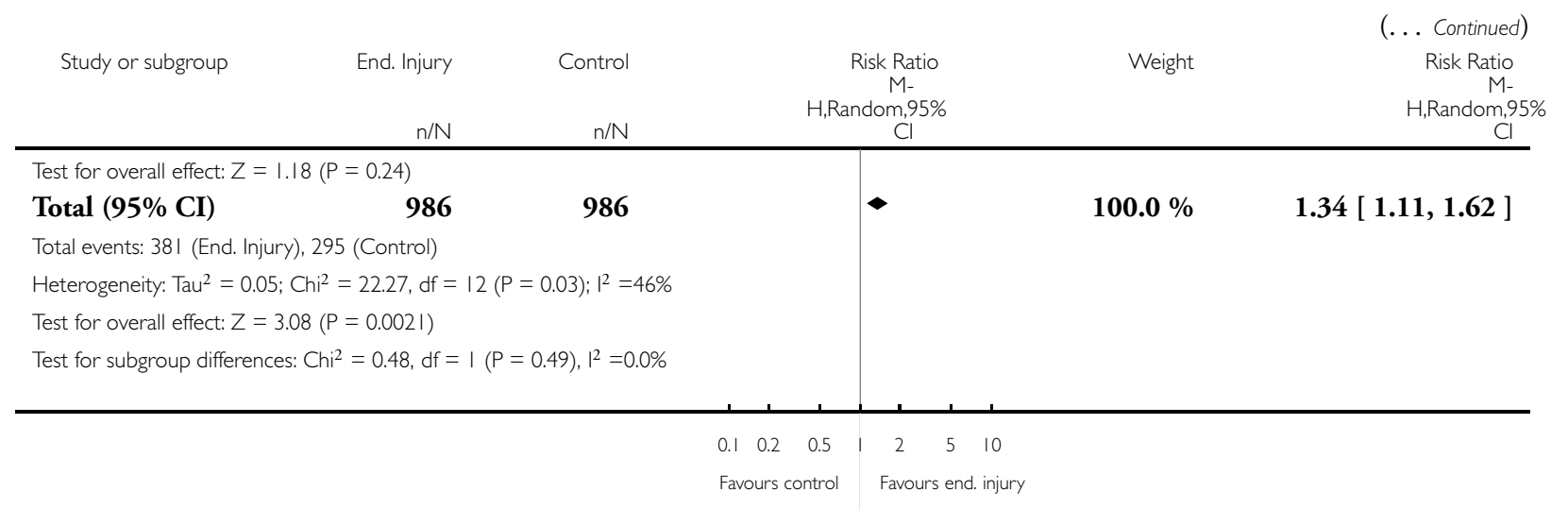

Analysis I.5. Comparison I Endometrial injury between day 7 of the previous cycle and day 7 of the ET cycle vs control, Outcome 5 Clinical pregnancy per randomly assigned woman (by embryo transfer history).

Review: Endometrial injury in women undergoing assisted reproductive techniques

Comparison: I Endometrial injury between day 7 of the previous cycle and day 7 of the ET cycle vs control

Outcome: 5 Clinical pregnancy per randomly assigned woman (by embryo transfer history)

\begin{tabular}{|c|c|c|c|c|c|c|c|}
\hline Study or subgroup & $\begin{array}{r}\text { End. Injury } \\
\text { n/N }\end{array}$ & $\begin{array}{r}\text { Control } \\
\text { n/N }\end{array}$ & \multicolumn{3}{|c|}{$\begin{array}{r}\text { Risk Ratio } \\
\text { M- } \\
\text { H,Random,95\% } \\
\mathrm{Cl} \\
\end{array}$} & Weight & $\begin{array}{c}\text { Risk Ratio } \\
\text { M- } \\
\text { H,Random,95\% } \\
\text { Cl }\end{array}$ \\
\hline \multicolumn{8}{|c|}{$\mathrm{I} \leq \mathrm{I}$ previous embryo transfer } \\
\hline Gibreel 2015 & $70 / 129$ & $64 / 121$ & & & $\rightarrow$ & $11.7 \%$ & $1.03[0.81,1.29]$ \\
\hline Guven 2014 & $27 / 62$ & $18 / 62$ & & & & $7.4 \%$ & $1.50[0.93,2.43]$ \\
\hline Nastri 2013 & $16 / 35$ & $12 / 32$ & & & $\longrightarrow$ & $6.2 \%$ & $1.22[0.69,2.17]$ \\
\hline Yeung 2014 & $42 / 105$ & $38 / 104$ & & & $\longrightarrow$ & $9.6 \%$ & $1.09[0.78,1.55]$ \\
\hline Subtotal (95\% CI) & 331 & 319 & & & - & $35.0 \%$ & $1.11[0.94,1.32]$ \\
\hline \multicolumn{8}{|c|}{ Total events: I 55 (End. Injury), I 32 (Control) } \\
\hline \multicolumn{8}{|c|}{ Heterogeneity: $\operatorname{Tau}^{2}=0.0 ; \mathrm{Chi}^{2}=2.09, \mathrm{df}=3(\mathrm{P}=0.55) ;\left.\right|^{2}=0.0 \%$} \\
\hline \multicolumn{8}{|c|}{ Test for overall effect: $Z=1.20(P=0.23)$} \\
\hline \multicolumn{8}{|c|}{$2 \geq 2$ previous embryo transfers } \\
\hline Baum 2012 & $1 / 18$ & $5 / 18$ & 4 & & & $0.8 \%$ & $0.20[0.03,1.55]$ \\
\hline \multirow[t]{3}{*}{ Gibreel 2015} & $25 / 64$ & $16 / 73$ & & & $\rightleftarrows$ & $6.8 \%$ & $1.78[1.05,3.03]$ \\
\hline & & & 0.2 & 0.5 & 2 & 5 & \\
\hline & & & Favo & Contrc & Favours & d. Injury & (Continued ....) \\
\hline
\end{tabular}




\begin{tabular}{|c|c|c|c|c|c|}
\hline Study or subgroup & End. Injury & $n / N$ & $\begin{array}{c}\text { Risk Ratio } \\
\text { M- } \\
\mathrm{H} \text {,Random,95\% } \\
\mathrm{Cl}\end{array}$ & Weight & $\begin{array}{c}\text { (... Continued) } \\
\text { Risk Ratio } \\
\text { M- } \\
\text { H,Random,95\% } \\
\text { Cl }\end{array}$ \\
\hline Karim Zadeh 2008 & 29/80 & $26 / 80$ & $\longrightarrow$ & $8.2 \%$ & $1.12[0.73,1.71]$ \\
\hline Karimzadeh 2009 & $13 / 58$ & 4/57 & $\longrightarrow$ & $2.6 \%$ & $3.19[1.11,9.21]$ \\
\hline Nastri 2013 & $23 / 44$ & | $1 / 47$ & $\longrightarrow$ & $6.0 \%$ & $2.23[1.24,4.03]$ \\
\hline Shohayeb 2012 & $32 / 105$ & $18 / 105$ & $\longrightarrow$ & $7.0 \%$ & $1.78[1.07,2.96]$ \\
\hline Subtotal $(95 \% \mathrm{CI})$ & 369 & 380 & 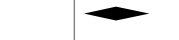 & $31.5 \%$ & $1.63[1.12,2.38]$ \\
\hline \multicolumn{6}{|c|}{ Total events: I23 (End. Injury), 80 (Control) } \\
\hline \multicolumn{6}{|c|}{ Heterogeneity: $\mathrm{Tau}^{2}=0.10 ; \mathrm{Chi}^{2}=9.87, \mathrm{df}=5(\mathrm{P}=0.08) ; \mathrm{I}^{2}=49 \%$} \\
\hline \multicolumn{6}{|c|}{ Test for overall effect: $Z=2.57(P=0.010)$} \\
\hline \multicolumn{6}{|c|}{3 Unselected women or unclear number of previous embryo transfers } \\
\hline Aleyamma 2013 & $14 / 40$ & $|2 / 4|$ & $=$ & $5.5 \%$ & $1.20[0.63,2.26]$ \\
\hline Inal 2012 & $30 / 50$ & $17 / 50$ & $\square$ & $7.9 \%$ & $1.76[1.13,2.76]$ \\
\hline Narvekar 2010 & $16 / 49$ & $7 / 51$ & 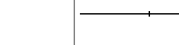 & $4.1 \%$ & $2.38[1.07,5.28]$ \\
\hline Polanski 2014 & $30 / 52$ & $21 / 49$ & $\longrightarrow$ & $8.7 \%$ & $1.35[0.90,2.00]$ \\
\hline Safdarian 2011 & $4 / 50$ & $7 / 50$ & - & $2.3 \%$ & $0.57[0.18,1.83]$ \\
\hline Yeung 2014 & $9 / 45$ & $18 / 46$ & - & $5.0 \%$ & $0.51[0.26,1.02]$ \\
\hline Subtotal $(95 \% \mathrm{CI})$ & 286 & 287 & - & $33.5 \%$ & $1.20[0.80,1.82]$ \\
\hline \multicolumn{6}{|c|}{ Total events: I03 (End. Injury), 82 (Control) } \\
\hline \multicolumn{6}{|c|}{ Heterogeneity: $\mathrm{Tau}^{2}=0.15 ; \mathrm{Chi}^{2}=13.19, \mathrm{df}=5(\mathrm{P}=0.02) ; \mathrm{I}^{2}=62 \%$} \\
\hline \multicolumn{6}{|c|}{ Test for overall effect: $Z=0.88(P=0.38)$} \\
\hline Total $(95 \% \mathrm{CI})$ & 986 & 986 & $\longrightarrow$ & $100.0 \%$ & $1.32[1.09,1.60]$ \\
\hline \multicolumn{6}{|c|}{ Total events: 38I (End. Injury), 294 (Control) } \\
\hline \multicolumn{6}{|c|}{ Heterogeneity: $\operatorname{Tau}^{2}=0.07 ; \mathrm{Ch}^{2}=30.85, \mathrm{df}=15(\mathrm{P}=0.01) ; 1^{2}=51 \%$} \\
\hline \multicolumn{6}{|c|}{ Test for overall effect: $Z=2.86(P=0.0043)$} \\
\hline \multicolumn{6}{|c|}{ Test for subgroup differences: $\mathrm{Chi}^{2}=3.41, \mathrm{df}=2(\mathrm{P}=0.18), \mathrm{I}^{2}=41 \%$} \\
\hline & & & 2 & & \\
\hline & & & trol & & \\
\hline
\end{tabular}




\section{Analysis I.6. Comparison I Endometrial injury between day 7 of the previous cycle and day 7 of the ET cycle vs control, Outcome 6 Multiple pregnancy per clinical pregnancy.}

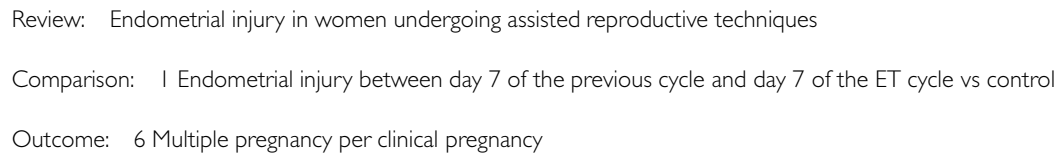

$11 / 80 \quad 33.6 \%$

Total events: 42 (End. Injury), 30 (Control)

\section{Analysis 1.7. Comparison I Endometrial injury between day 7 of the previous cycle and day 7 of the ET} cycle vs control, Outcome 7 Pain (visual analogue scale).

Review: Endometrial injury in women undergoing assisted reproductive techniques

Comparison: I Endometrial injury between day 7 of the previous cycle and day 7 of the ET cycle vs control

Outcome: 7 Pain (visual analogue scale)

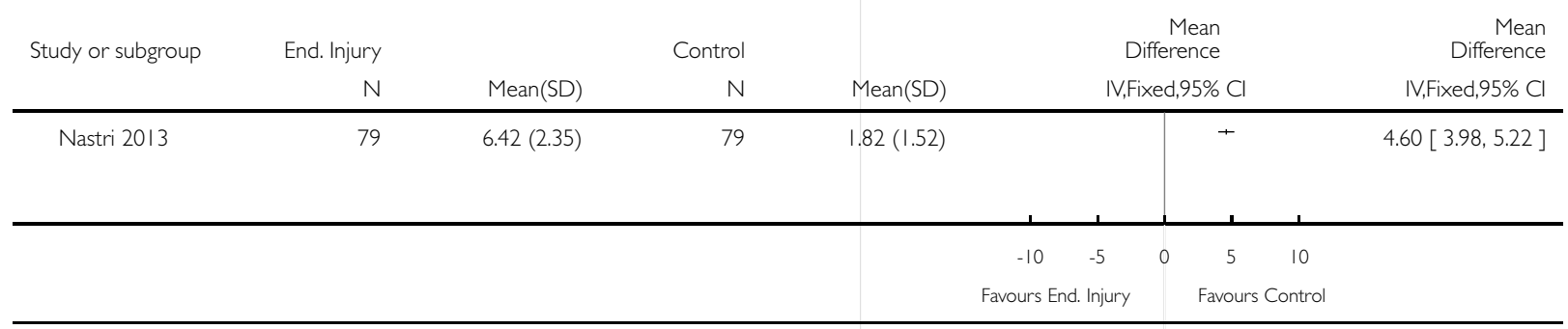


Analysis I.8. Comparison I Endometrial injury between day 7 of the previous cycle and day 7 of the ET cycle vs control, Outcome 8 Pain (complaint).

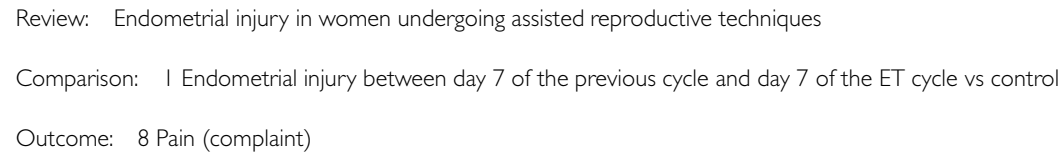

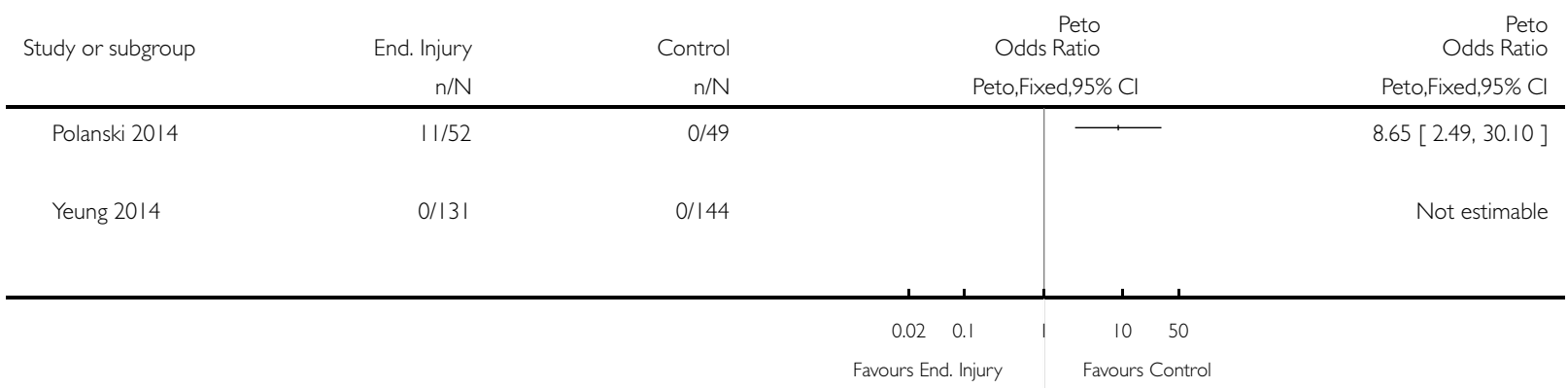




\section{Analysis I.9. Comparison I Endometrial injury between day 7 of the previous cycle and day 7 of the ET}

cycle vs control, Outcome 9 Bleeding.

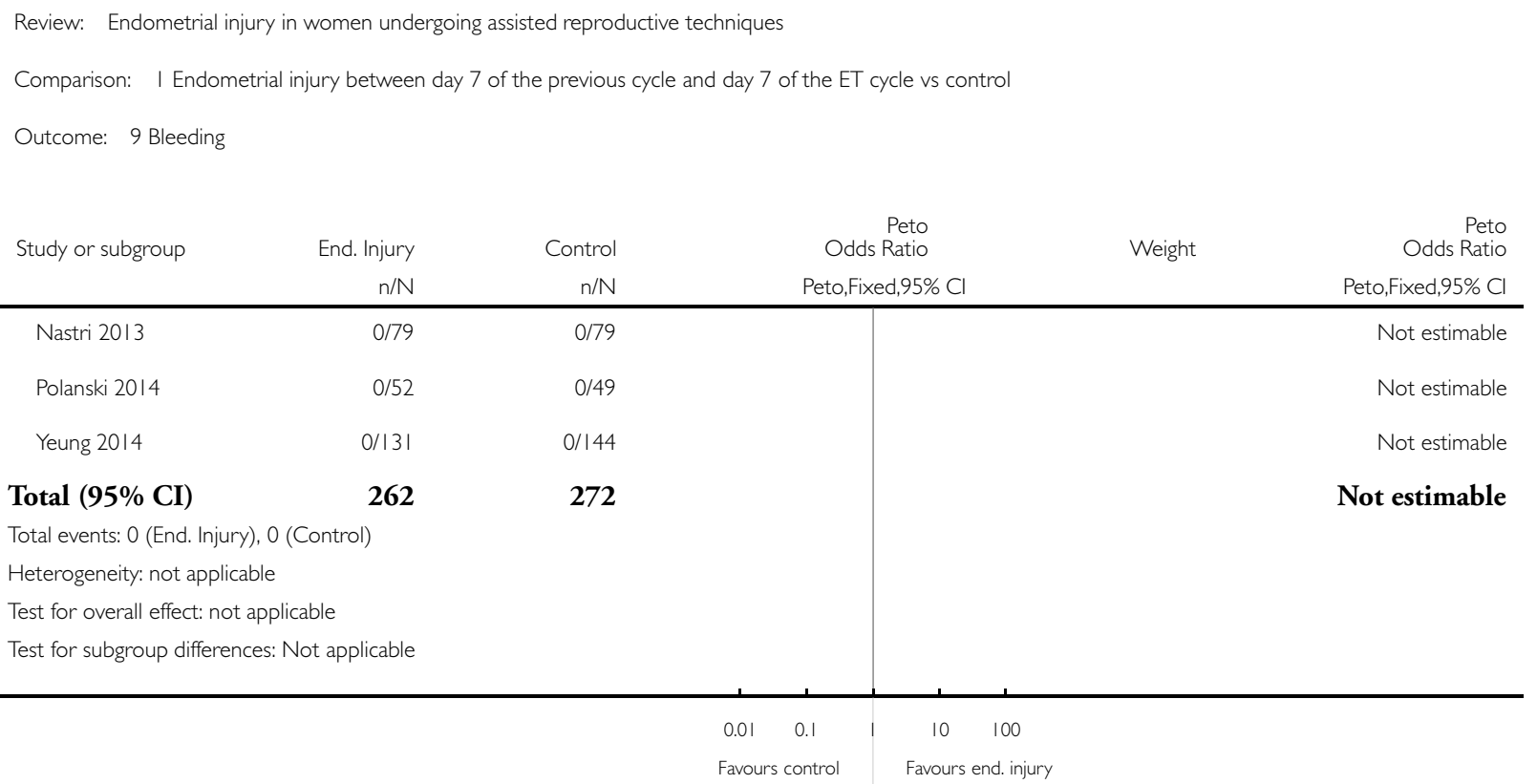

\section{Analysis 2.I. Comparison 2 Endometrial injury on the day of oocyte retrieval vs control, Outcome I Live} birth or ongoing pregnancy per randomly assigned woman.

Review: Endometrial injury in women undergoing assisted reproductive techniques

Comparison: 2 Endometrial injury on the day of oocyte retrieval vs control

Outcome: I Live birth or ongoing pregnancy per randomly assigned woman

\begin{tabular}{|c|c|c|c|c|}
\hline \multirow{2}{*}{$\begin{array}{l}\text { Study or subgroup } \\
\text { Karimzade } 2010\end{array}$} & \multirow{2}{*}{$\begin{array}{r}\begin{array}{r}\text { End. Injury } \\
\text { on OR day } \\
n / N\end{array} \\
7 / 77\end{array}$} & \multirow{2}{*}{$\begin{array}{r}\text { No Injury } \\
n / N\end{array}$} & $\begin{array}{c}\text { Risk Ratio } \\
\text { M-H,Fixed,95\% Cl }\end{array}$ & \multirow{2}{*}{$\begin{array}{r}\text { Risk Ratio } \\
\text { M-H,Fixed,95\% Cl } \\
0.31[0.14,0.69]\end{array}$} \\
\hline & & & $\longrightarrow$ & \\
\hline
\end{tabular}




\section{Analysis 2.3. Comparison 2 Endometrial injury on the day of oocyte retrieval vs control, Outcome 3 Clinical pregnancy per randomly assigned woman.}

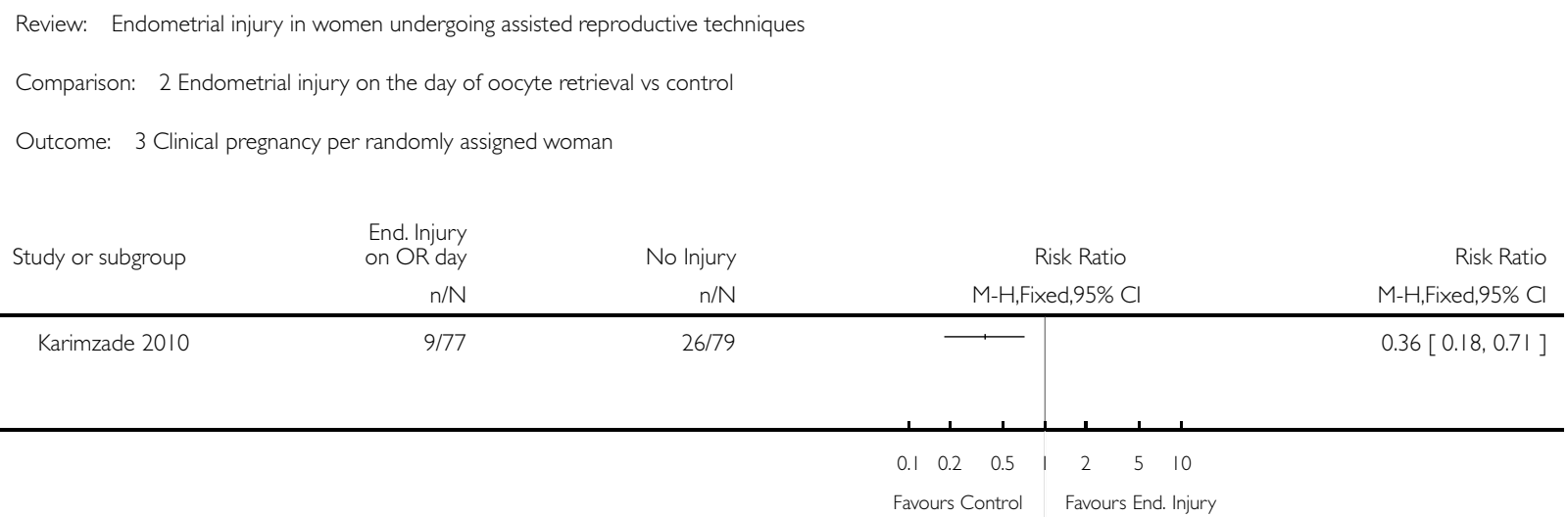

\section{A P P E N D I C ES}

\section{Appendix I. Menstrual Disorders and Subfertility Group search strategy}

Menstrual Disorders and Subfertility Group search strategy for WM1504 inception to present

Keywords CONTAINS "ART" or "assisted conception" or "assisted reproduction" or "IVF" or "in vitro fertilisation" or "in vitro fertilization" or "intracytoplasmic sperm injection" or "ICSI” or "Intrauterine Insemination" or "IUI" or "artificial insemination" or" *Embryo Transfer" or "ET" or "frozen embryo transfer" or "FET" or "implantation failure" or "recurrent implantation failure" or "subfertility" or Title CONTAINS “ART" or "assisted conception" or "assisted reproduction" or "IVF” or "in vitro fertilisation" or "in vitro fertilization" or "intracytoplasmic sperm injection" or "ICSI" or "Intrauterine Insemination” or "IUI” or "artificial insemination" or “* Embryo Transfer" or "ET" or "frozen embryo transfer" or "FET" or "implantation failure" or "recurrent implantation failure" or "subfertility"

AND

Keywords CONTAINS “endometrial biopsy" or "endometrial injury" or "endometrial trauma" or "mock embryo transfer" or Title CONTAINS "endometrial biopsy" or "endometrial injury" or "endometrial trauma” or "mock embryo transfer"

\section{Appendix 2. CENTRAL}

EBM Reviews - Cochrane Central Register of Controlled Trials <4th Quarter 2011>

1 exp embryo transfer/ or exp fertilization in vitro/ or exp sperm injections, intracytoplasmic/ (1548)

2 embryo transfer\$.tw. (867)

3 in vitro fertili?ation.tw. (1298)

4 ivf-et.tw. (248)

5 (ivf or et).tw. (5911)

6 icsi.tw. (639)

7 intracytoplasmic sperm injection\$.tw. (398)

8 (blastocyst adj2 transfer\$).tw. (63)

Endometrial injury in women undergoing assisted reproductive techniques (Review)

Copyright $\Subset 2015$ The Cochrane Collaboration. Published by John Wiley \& Sons, Ltd. 
9 exp reproductive techniques, assisted/ or insemination, artificial/ or exp insemination, artificial, heterologous/ or exp insemination, artificial, homologous/ (2156)

10 artificial insemination.tw. (53)

11 intrauterine insemination.tw. (376)

12 assisted reproducti\$.tw. (378)

13 FET.tw. (70)

14 implantation failure\$.tw. (54)

15 or/1-14 (7962)

16 (endometri\$ adj5 injur\$).tw. (15)

17 (endometri\$ adj5 trauma\$).tw. (4)

18 (endometri\$ adj5 biop\$).tw. (406)

19 (endometri\$ adj5 harm\$).tw. (0)

20 (endometri\$ adj5 damag\$).tw. (4)

21 (endometri\$ adj5 inflammation).tw. (4)

22 (endometri\$ adj5 wound\$).tw. (46)

23 (endometri\$ adj5 lesion\$).tw. (54)

24 (endometri\$ adj5 insult\$).tw. (0)

25 (mock adj3 transfer\$).tw. (4)

26 or/16-25 (523)

2715 and $26(58)$

\section{Appendix 3. DARE}

Cochrane Database of Systematic Reviews 2005 to November 2012

1. embryo transfer\$.tw. (67)

2. in vitro fertili?ation.tw. (104)

3. ivf-et.tw. (17)

4. (ivf or et).tw. (2177)

5. icsi.tw. (74)

6. intracytoplasmic sperm injection\$.tw. (55)

7. (blastocyst adj2 transfer\$).tw. (15)

8. assisted reproducti\$.tw. (90)

9. FET.tw. (18)

10. implantation failure \$.tw. (16)

11. or/1-10 (2214)

12. (endometri\$ adj5 injur\$).tw. (3)

13. (endometri\$ adj5 trauma\$).tw. (6)

14. (endometri\$ adj5 biop\$).tw. (34)

15. (endometri\$ adj5 harm\$).tw. (2)

16. (endometri\$ adj5 damag\$).tw. (5)

17. (endometri\$ adj5 inflammation).tw. (12)

18. (endometri\$ adj5 wound\$).tw. (20)

19. (endometri\$ adj5 lesion\$).tw. (17)

20. (endometri\$ adj5 insult\$).tw. (1)

21. (mock adj3 transfer\$).tw. (3)

22. or/12-21 (78)

23. 11 and $22(34)$ 


\section{Appendix 4. MEDLINE}

Ovid MEDLINE(R) In-Process \& Other Non-Indexed Citations, Ovid MEDLINE(R) Daily and Ovid MEDLINE(R) $<1948$ to Present>

1 exp embryo transfer/ or exp fertilization in vitro/ or exp sperm injections, intracytoplasmic/ (29320)

2 embryo transfer\$.tw. (7179)

3 in vitro fertili?ation.tw. (15011)

4 ivf-et.tw. (1680)

5 (ivf or et).tw. (156606)

6 icsi.tw. (4527)

7 intracytoplasmic sperm injection\$.tw. (4209)

8 (blastocyst adj2 transfer\$).tw. (426)

9 exp reproductive techniques, assisted/ or insemination, artificial/ or exp insemination, artificial, heterologous/ or exp insemination, artificial, homologous/ (47249)

10 artificial insemination.tw. (4378)

11 intrauterine insemination.tw. (1535)

12 assisted reproducti\$.tw. (7314)

13 FET.tw. (962)

14 implantation failure\$.tw. (599)

15 or/1-14 (199606)

16 (endometri\$ adj5 injur\$).tw. (82)

17 (endometri\$ adj5 trauma\$).tw. (75)

18 (endometri\$ adj5 biop\$).tw. (3481)

19 (endometri\$ adj5 harm\$).tw. (18)

20 (endometri\$ adj5 damag\$).tw. (143)

21 (endometri\$ adj5 inflammation).tw. (208)

22 (endometri\$ adj5 wound\$).tw. (140)

23 (endometri\$ adj5 lesion\$).tw. (2074)

24 (endometri\$ adj5 insult\$).tw. (3)

25 (mock adj3 transfer\$).tw. (39)

26 or/16-25 (5967)

2715 and 26 (435)

28 randomized controlled trial.pt. (322384)

29 controlled clinical trial.pt. (84016)

30 randomized.ab. (237455)

31 placebo.tw. (138270)

32 clinical trials as topic.sh. (159410)

33 randomly.ab. (174031)

34 trial.ti. (101982)

35 (crossover or cross-over or cross over).tw. (52738)

36 or/28-35 (789595)

37 exp animals/ not humans.sh. (3715340)

3836 not 37 (729098)

3927 and 38 (59) 


\section{Appendix 5. EMBASE}

EMBASE < 1980 to 2011 Week 45>

1 exp infertility therapy/ or exp artificial insemination/ or exp embryo disposition/ or exp embryo transfer/ or exp fertilization in vitro/ or exp intracytoplasmic sperm injection/ or exp intrauterine insemination/ or exp oocyte donation/ (64331)

2 exp embryo transfer/ (16669)

3 embryo transfer\$.tw. (8851)

4 in vitro fertili?ation.tw. (17231)

5 ivf-et.tw. (2038)

6 (ivf or et).tw. (304095)

7 icsi.tw. (6948)

8 intracytoplasmic sperm injection\$.tw. (5054)

9 (blastocyst adj2 transfer\$).tw. (675)

10 artificial insemination.tw. (4153)

11 intrauterine insemination.tw. (1919)

12 assisted reproducti\$.tw. (9754)

13 FET.tw. (1154)

14 implantation failure $\$ . t w . ~(926)$

15 or/1-14 (357269)

16 (endometri\$ adj5 injur\$).tw. (84)

17 (endometri\$ adj5 trauma\$).tw. (74)

18 (endometri\$ adj5 biop\$).tw. (3835)

19 (endometri\$ adj5 harm\$).tw. (24)

20 (endometri\$ adj5 damag\$).tw. (163)

21 (endometri\$ adj5 inflammation).tw. (232)

22 (endometri\$ adj5 wound\$).tw. (160)

23 (endometri\$ adj5 insult\$).tw. (3)

24 (endometri\$ adj5 lesion\$).tw. (2448)

25 (mock adj3 transfer\$).tw. (52)

26 or/16-25 (6725)

27 Clinical Trial/ (820810)

28 Randomized Controlled Trial/ (292216)

29 exp randomization/ (54949)

30 Single Blind Procedure/ (14402)

31 Double Blind Procedure/ (101570)

32 Crossover Procedure/ (31137)

33 Placebo/ (187119)

34 Randomi?ed controlled trial\$.tw. (66039)

35 Rct.tw. (7970)

36 random allocation.tw. (1064)

37 randomly allocated.tw. (15769)

38 allocated randomly.tw. (1715)

39 (allocated adj2 random).tw. (688)

40 Single blind\$.tw. (11198)

41 Double blind\$.tw. (118974)

42 ((treble or triple) adj blind\$).tw. (249)

43 placebo\$.tw. (161172)

44 prospective study/ (176077)

45 or/27-44 (1154917)

46 case study/ (13740)

47 case report.tw. (209839)

48 abstract report/ or letter/ (798669)

49 or/46-48 (1018157)

Endometrial injury in women undergoing assisted reproductive techniques (Review) 
5045 not 49 (1121429)

5115 and 26 and 50 (111)

$52(2010 \$$ or $2011 \$) . e m .(2338360)$

5351 and $52(32)$

\section{Appendix 6. Psyclnfo}

PsycInfo <1806 to November Week 2 2011>

1 exp infertility/ (1479)

2 exp reproductive technology/ (1107)

3 embryo transfer\$.tw. (80)

4 in vitro fertili?ation.tw. (439)

5 ivf-et.tw. (16)

6 (ivf or et).tw. (79507)

7 icsi.tw. (37)

8 intracytoplasmic sperm injection\$.tw. (30)

9 (blastocyst adj2 transfer\$).tw. (2)

10 artificial insemination.tw. (207)

11 intrauterine insemination.tw. (12)

12 assisted reproducti\$.tw. (386)

13 FET.tw. (34)

14 implantation failure\$.tw. (7)

15 or/1-14 (81750)

16 (endometri\$ adj5 injur\$).tw. (0)

17 (endometri\$ adj5 trauma\$).tw. (1)

18 (endometri\$ adj5 biop\$).tw. (11)

19 (endometri\$ adj5 harm\$).tw. (0)

20 (endometri\$ adj5 damag\$).tw. (1)

21 (endometri\$ adj5 inflammation).tw. (1)

22 (endometri\$ adj5 wound\$).tw. (0)

23 (endometri\$ adj5 insult\$).tw. (0)

24 (endometri\$ adj5 lesion\$).tw. (6)

25 (mock adj3 transfer\$).tw. (0)

26 or/16-25 (20)

2715 and 26 (3)

\section{Appendix 7. CINAHL}

\begin{tabular}{lll}
\hline$\#$ & Query & Results \\
\hline S39 & S24 AND S38 & 13 \\
\hline S38 & $\begin{array}{l}\text { S25 OR S26 or S27 or S28 OR S29 OR S30 OR S31 OR S32 } \\
\text { OR S33 OR S34 OR S35 OR S36 OR S37 }\end{array}$ & 874,605 \\
\hline S37 & TX allocat* random* & 3,822 \\
\hline S36 & (MH “Quantitative Studies”) & 11,629
\end{tabular}

Endometrial injury in women undergoing assisted reproductive techniques (Review)

Copyright $\odot 2015$ The Cochrane Collaboration. Published by John Wiley \& Sons, Ltd. 
(Continued)

\begin{tabular}{|c|c|c|}
\hline S35 & (MH “Placebos”) & 8,626 \\
\hline S34 & TX placebo* & 31,100 \\
\hline S33 & TX random* allocat* & 3,822 \\
\hline S32 & (MH “Random Assignment”) & 36,748 \\
\hline S31 & TX randomi* control $^{*}$ trial $^{*}$ & 69,625 \\
\hline S30 & 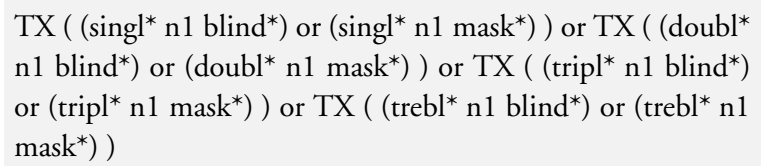 & 703,446 \\
\hline S29 & TX ( (trebl* n1 blind $\left.{ }^{*}\right)$ or $\left(\right.$ trebl $^{*}$ n1 mask*) $)$ & 101 \\
\hline S28 & TX ( (trebl* n1 blind $\left.{ }^{*}\right)$ or $\left(\right.$ trebl $^{*}$ n1 mask*) $\left.{ }^{*}\right)$ & 0 \\
\hline S27 & TX clinic* $\mathrm{n} 1$ trial $^{*}$ & 161,217 \\
\hline S26 & PT Clinical trial & 75,505 \\
\hline S25 & (MH “Clinical Trials+”) & 171,930 \\
\hline S24 & S15 AND S23 & 22 \\
\hline S23 & S16 OR S17 OR S 18 OR S 19 OR S 20 OR S 21 OR S 22 & 3,364 \\
\hline S22 & TX embryo* N3 transfer* & 681 \\
\hline S21 & TX ovar* N3 hyperstimulat* & 296 \\
\hline S20 & TX ovari* N3 stimulat* & 215 \\
\hline S19 & TX IVF or TX ICSI & 1,123 \\
\hline S18 & (MM "Fertilization in Vitro") & 1,316 \\
\hline S17 & TX vitro fertilization & 2,595 \\
\hline S16 & TX vitro fertilisation & 254 \\
\hline S15 & $\begin{array}{l}\text { S1 OR S2 OR S3 OR S4 OR S5 OR S6 OR S7 OR S8 OR } \\
\text { S9 OR S10 OR S11 OR S12 OR S13 OR S14 }\end{array}$ & 546 \\
\hline S14 & TX endometri* N3 wound* & 19 \\
\hline S13 & TX endometri* N5 harm* & 1 \\
\hline
\end{tabular}




\begin{tabular}{lll}
\hline S12 & TX endometri* N3 inflammation & 12 \\
\hline S11 & TX endometri* N3 trauma* & 1 \\
\hline S10 & TX endometri* N3 damage* & 4 \\
\hline S9 & TX(endometri* N5 lesion*) & 108 \\
\hline S8 & TX (endometri* adj5 lesion*) & 1 \\
\hline S7 & TX (endometri* adj5 lesion $\left.{ }^{*}\right)$ & 0 \\
\hline S6 & TX(endometri* N3 insult $\left.{ }^{*}\right)$ & 86 \\
\hline S5 & TX (endometri* N5 sampi*) & 123 \\
\hline S4 & TX mock N3 transfer* & 3 \\
\hline S3 & TX endometri* N3 scratch* & 3 \\
\hline S2 & TX endometri* N3 biops* & 230 \\
\hline S1 & TX endometri* N3 injury & 9 \\
\hline
\end{tabular}

\section{Appendix 8. LILACS - search strategy}

(tw:(endometri* injury )) OR (tw:(endometri* scratch*)) limited by controlled clinical trial

\section{Appendix 9. Risk of bias tool}

The Cochrane Collaboration tool for assessing risk of bias (version 5.1)

\begin{tabular}{|c|c|c|}
\hline Domain & Support for judgement & Review authors' judgement \\
\hline \multicolumn{3}{|l|}{ Selection bias. } \\
\hline Random sequence generation & $\begin{array}{l}\text { Describe in sufficient detail the method } \\
\text { used to generate the allocation sequence to } \\
\text { allow an assessment of whether it should } \\
\text { produce comparable groups }\end{array}$ & $\begin{array}{l}\text { Selection bias (biased allocation to inter- } \\
\text { ventions) due to inadequate generation of } \\
\text { a randomised sequence }\end{array}$ \\
\hline Allocation concealment & $\begin{array}{l}\text { Describe in sufficient detail the method } \\
\text { used to conceal the allocation sequence to } \\
\text { allow determination of whether interven- }\end{array}$ & $\begin{array}{l}\text { Selection bias (biased allocation to inter- } \\
\text { ventions) due to inadequate concealment } \\
\text { of allocations before assignment }\end{array}$ \\
\hline
\end{tabular}


tion allocations could have been foreseen

in advance of, or during, enrolment

Performance bias

Blinding of participants and personnel Assessments should be made for each main outcome (or class of outcomes)
Describe all measures used, if any, to blind study participants and personnel from knowledge of which intervention a participant received. Provide any information related to whether the intended blinding was effective

\section{Detection bias}

Blinding of outcome assessment Assessments should be made for each main outcome (or class of outcomes)
Describe all measures used, if any, to Detection bias due to knowledge of the alblind outcome assessors from knowledge of located interventions by outcome assessors which intervention a participant received. Provide any information related to whether the intended blinding was effective

\section{Attrition bias}

Incomplete outcome data

Assessments should be made for each main outcome (or class of outcomes)
Describe the completeness of outcome data for each main outcome, including attrition and exclusions from the analysis. State whether attrition and exclusions were reported, the numbers in each intervention group (compared with total randomly assigned participants), reasons for attrition/ exclusions when reported and any re-inclusions in analyses performed by the review authors
Performance bias due to knowledge of the allocated interventions by participants and personnel during the study
Attrition bias due to quantity, nature or handling of incomplete outcome data
State how the possibility of selective outcome reporting was examined by the review authors, and what was found
Reporting bias due to selective outcome reporting

\section{Selective reporting}

Other bias
State any important concerns about bias not addressed in the other domains in the tool. If particular questions/entries were prespecified in the review's protocol, responses should be provided for each question/entry
Bias due to problems not covered elsewhere in the table 


\section{RANDOM SEQUENCE GENERATION}

Selection bias (biased allocation to interventions) due to inadequate generation of a randomised sequence

Criteria for a judgement of

'Low risk' of bias
Investigators describe a random component in the sequence generation process such as:

Referring to a random number table;

Using a computer random number generator;

Tossing a coin;

Shuffling cards or envelopes;

Throwing dice;

Drawing lots;

Performing minimisation*

*Minimisation may be implemented without a random element, and this is considered to be equivalent to being random

Criteria for the judgement of

'High risk' of bias

Investigators describe a non-random component in the sequence generation process. Usually, the description would involve some systematic, non-random approach, for example:

Sequence generated by odd or even date of birth;

Sequence generated by some rule based on date (or day) of admission;

Sequence generated by some rule based on hospital or clinic record number

Other non-random approaches happen much less frequently than the systematic approaches mentioned above and tend to be obvious. They usually involve judgement or some method of nonrandom categorisation of participants, for example:

Allocation by judgement of the clinician;

Allocation by preference of the participant;

Allocation based on the results of a laboratory test or series of tests;

Allocation by availability of the intervention

Criteria for the judgement of

Insufficient information about the sequence generation process to permit judgement of 'Low risk' or 'High risk'

\section{ALLOCATION CONCEALMENT}

Selection bias (biased allocation to interventions) due to inadequate concealment of allocations before assignment

Criteria for the judgement of 'Low risk' of bias

Participants and investigators enrolling participants could not foresee assignment because one of the following, or an equivalent method, was used to conceal allocation:

Central allocation (including telephone, web-based and phar-

Endometrial injury in women undergoing assisted reproductive techniques (Review)

Copyright @ 2015 The Cochrane Collaboration. Published by John Wiley \& Sons, Ltd. 
macy-controlled randomisation);

Sequentially numbered drug containers of identical appearance; Sequentially numbered, opaque, sealed envelopes

Criteria for the judgement of

'High risk' of bias
Participants or investigators enrolling participants could possibly foresee assignments and thus introduce selection bias, such as allocation based on:

Using an open random allocation schedule (e.g. a list of random numbers);

Using assignment envelopes without appropriate safeguards (e.g. if envelopes were unsealed or non-opaque or were not sequentially numbered);

Alternation or rotation;

Date of birth;

Case record number;

Any other explicitly unconcealed procedure

Criteria for the judgement of

'Unclear risk' of bias

Insufficient information to permit judgement of 'Low risk' or 'High risk'. This is usually the case if the method of concealment is not described or is not described in sufficient detail to allow a definitive judgement - for example, if use of assignment envelopes is described, but it remains unclear whether envelopes were sequentially numbered, opaque and sealed

\section{BLINDING OF PARTICIPANTS AND PERSONNEL}

Performance bias due to knowledge of allocated interventions by participants and personnel during the study

Criteria for the judgement of
'Low risk' of bias

Any one of the following:

No blinding or incomplete blinding, but the review authors judge that the outcome is not likely to be influenced by lack of blinding;

Blinding of participants and key study personnel ensured, and unlikely that blinding could have been broken

Criteria for the judgement of

'High risk' of bias
Any 1 of the following:

No blinding or incomplete blinding, and the outcome is likely to be influenced by lack of blinding;

Blinding of key study participants and personnel attempted, but likely that blinding could have been broken, and the outcome is likely to be influenced by lack of blinding
Criteria for the judgement of

'Unclear risk' of bias
Any 1 of the following:

Insufficient information to permit judgement of 'Low risk' or 'High risk'. The study did not address this outcome

\section{BLINDING OF OUTCOME ASSESSMENT}


(Continued)

Detection bias due to knowledge of allocated interventions by outcome assessors

Criteria for the judgement of

'Low risk' of bias
Any 1 of the following:

No blinding of outcome assessment, but the review authors judge that the outcome measurement is not likely to be influenced by lack of blinding;

Blinding of outcome assessment ensured, and unlikely that blinding could have been broken
Criteria for the judgement of

'High risk' of bias
Any 1 of the following:

No blinding of outcome assessment, and outcome measurement is likely to be influenced by lack of blinding;

Blinding of outcome assessment, but likely that blinding could have been broken, and outcome measurement is likely to be influenced by lack of blinding
Criteria for the judgement of

'Unclear risk' of bias
Any 1 of the following:

Insufficient information to permit judgement of 'Low risk' or 'High risk'. The study did not address this outcome

\section{INCOMPLETE OUTCOME DATA}

\section{Attrition bias due to quantity, nature or handling of incomplete outcome data}

Criteria for the judgement of 'Low risk' of bias
Any 1 of the following:

No missing outcome data;

Reasons for missing outcome data unlikely to be related to true outcome (for survival data, censoring unlikely to be introducing bias);

Missing outcome data balanced in numbers across intervention groups, with similar reasons for missing data across groups;

For dichotomous outcome data, the proportion of missing outcomes compared with observed event risk not enough to have a clinically relevant impact on the intervention effect estimate;

For continuous outcome data, plausible effect size (difference in means or standardised difference in means) among missing outcomes not enough to have a clinically relevant impact on observed effect size;

Missing data have been imputed using appropriate methods

Criteria for the judgement of

'High risk' of bias
Any 1 of the following:

Reason for missing outcome data likely to be related to true outcome, with either imbalance in numbers or reasons for missing data across intervention groups;

For dichotomous outcome data, the proportion of missing outcomes compared with observed event risk enough to induce clinically relevant bias in intervention effect estimate;

For continuous outcome data, plausible effect size (difference in means or stan- 
dardised difference in means) among missing outcomes enough to induce clinically relevant bias in observed effect size;

'As-treated' analysis done with substantial departure of the intervention received from that assigned at randomisation;

Potentially inappropriate application of simple imputation

Criteria for the judgement of

'Unclear risk' of bias
Any 1 of the following:

Insufficient reporting of attrition/exclusions to permit judgement of 'Low risk' or 'High risk' (e.g. number randomly assigned not stated, no reasons for missing data provided)

The study did not address this outcome

\section{SELECTIVE REPORTING}

\section{Reporting bias due to selective outcome reporting}

Criteria for the judgement of

'Low risk' of bias
Any 1 of the following:

Study protocol is available and all of the study's prespecified (primary and secondary) outcomes that are of interest in the review have been reported in the prespecified way;

Study protocol is not available, but it is clear that published reports include all expected outcomes, including those that were prespecified (convincing text of this nature may be uncommon)
Criteria for the judgement of

'High risk' of bias
Any 1 of the following:

Not all of the study's prespecified primary outcomes have been reported;

1 or more primary outcomes are reported using measurements, analysis methods or subsets of the data (e.g. subscales) that were not prespecified;

1 or more reported primary outcomes were not prespecified (unless clear justification for their reporting is provided, such as an unexpected adverse effect);

1 or more outcomes of interest in the review are reported incompletely, so they cannot be entered in a meta-analysis;

Study report fails to include results for a key outcome that would be expected to have been reported for such a study

Criteria for the judgement of 'Unclear risk' of bias

Insufficient information to permit judgement of 'Low risk' or 'High risk'. It is likely that most studies will fall into this category

\section{OTHER BIAS}

Bias due to problems not covered elsewhere in the table 
(Continued)

Criteria for the judgement of

'Low risk' of bias

Criteria for the judgement of

'High risk' of bias
Study appears to be free of other sources of bias

At least 1 important risk of bias is present. For example, the study:

Had a potential source of bias related to the specific study design used; or Has been claimed to have been fraudulent; or

Had some other problem

Criteria for the judgement of

Risk of bias may be present, but there is either:

'Unclear risk' of bias Insufficient rationale or evidence that an identified problem will introduce bias

\section{WHAT'S NEW}

Last assessed as up-to-date: 19 January 2015.

\begin{tabular}{l|l|l}
\hline Date & Event & Description \\
\hline 21 January 2015 & New search has been performed & $\begin{array}{l}9 \text { new studies have been included (Aleyamma 2013; } \\
\text { Baum 2012; Gibreel 2015; Guven 2014; Karim Zadeh } \\
\text { 2008; Polanski 2014; Safdarian 2011; Shohayeb 2012; } \\
\text { Yeung 2014), along with full published versions of 2 stud- } \\
\text { ies (Inal 2012; Nastri 2013). We updated the search in } \\
\text { January 2015 and categorised 1 study as awaiting classi- } \\
\text { fication (Hur 2012) }\end{array}$ \\
\hline 21 January 2015 & New citation required and conclusions have changed & $\begin{array}{l}\text { Comparisons have been restructured and conclusions } \\
\text { have changed }\end{array}$ \\
\hline
\end{tabular}

\section{CONTRIBUTIONSOFAUTHORS}

Updated methods: Carolina O Nastri, Sarah F Lensen, Ahmed Gibreel, Nick Raine-Fenning, Rui A Ferriani, Siladitya Bhattacharya, Wellington P Martins

Developed a search strategy: Wellington P Martins, Carolina O Nastri, Ahmed Gibreel

Searched for trials (usually 2 people): Wellington P Martins, Ahmed Gibreel

Selected which trials to include ( $2+1$ arbiter): Sarah F Lensen, Ahmed Gibreel, Carolina O Nastri

Extracted data from trials (2+1 arbiter): Sarah F Lensen, Ahmed Gibreel, Carolina O Nastri

Entered data into RevMan: Carolina O Nastri, Wellington P Martins

Carried out the analysis: Carolina O Nastri, Wellington P Martins

Endometrial injury in women undergoing assisted reproductive techniques (Review)

Copyright $\Subset 2015$ The Cochrane Collaboration. Published by John Wiley \& Sons, Ltd. 
Interpreted the analysis: Carolina O Nastri, Sarah F Lensen, Ahmed Gibreel, Nick Raine-Fenning, Rui A Ferriani, Siladitya Bhattacharya, Wellington P Martins

Drafted the final review: Carolina O Nastri, Sarah F Lensen, Wellington P Martins

Approved the final version: Carolina O Nastri, Sarah F Lensen, Ahmed Gibreel, Nick Raine-Fenning, Rui A Ferriani, Siladitya Bhattacharya, Wellington P Martins

Updated the review: Carolina O Nastri, Sarah F Lensen, Ahmed Gibreel, Nick Raine-Fenning, Rui A Ferriani, Siladitya Bhattacharya, Wellington P Martins

\section{DECLARATIONSOF INTEREST}

Three review authors (WPM, CON and AG) participated in two published studies included in this review, and two review authors (NRF, SFL) are participating in ongoing studies listed in this review.

\section{SOURCES OF SUPPORT}

\section{Internal sources}

- Coordenação de Aperfeiçoamento de Pessoal de Nível Superior, Brazil.

PhD scholarship

- Faculdade de Medicina de Riberião Preto da Universidade de São Paulo, Brazil.

Author salary

\section{External sources}

- None, Other.

\section{DIFFERENCES BETWEEN PROTOCOLANDREVIEW}

We have restructured the comparisons in the update of this review. We have included post hoc subgroup analyses as described. We have changed the method used for data synthesis: (1) We preferred to use risk ratio instead of odds ratio because it is easier to use and interpret; and (2) we used a random-effects model instead of a fixed-effect model because we believe the intervention used in all studies was not exactly the same.

\section{INDEX TERMS}

\section{Medical Subject Headings (MeSH)}

${ }^{*}$ Reproductive Techniques, Assisted; Abortion, Spontaneous [etiology]; Embryo Implantation [* physiology]; Endometrium [*injuries]; Live Birth; Odds Ratio; Oocyte Retrieval [methods]; Ovulation Induction [methods]; Pregnancy Rate; Pregnancy, Multiple; Randomized Controlled Trials as Topic 


\section{MeSH check words}

Female; Humans; Pregnancy 